\title{
Wissenssoziologische Organisationsforschung
}

Peter L. Berger und Thomas Luckmann haben mit ihrem gemeinsamen im Jahr 1966 erschienenen Werk Die gesellschaftliche Konstruktion der Wirklichkeit. Eine Theorie der Wissenssoziologie (1966/2009) Letztere als ein Teilgebiet oder eine Subdisziplin der Soziologie neu bestimmt. Als wesentliche Frage dieser neuen Wissenssoziologie gilt den beiden die folgende:

Wie ist es möglich, daß subjektiv gemeinter Sinn zu objektiver Faktizität wird? Oder, in der Terminologie Webers und Durkheims: Wie ist es möglich, daß menschliches Handeln (Weber) eine Welt von Sachen hervorbringt? So meinen wir denn, daß erst die Erforschung der gesellschaftlichen Konstruktion der Wirklichkeit - der „Realität sui generis“ - zu ihrem Verständnis führt. Das, glauben wir, ist die Aufgabe der Wissenssoziologie (Berger, \& Luckmann, 1966/2009, S. 20, Hervorheb. i. O.).

Damit rücken Berger und Luckmann (1966/2009) nicht nur die großen Ideologien und Weltanschauungen in den Fokus ihrer Wissenssoziologie, sondern allem voran eine Untersuchung der Alltagswelt und der Wahrnehmungsweisen der in ihr lebenden Individuen:

Es geht um eine systematische Beschreibung der intersubjektiven Prozesse, in denen die Menschen ihr Wissen um die Welt erwerben, es gesellschaftlich verfestigen, kontrollieren und weitergeben (Berger, \& Luckmann, 1966/2009, Klappentext).

In diese von Berger und Luckmann konzipierte Wissenssoziologie reiht sich auch die vorliegende Forschungsarbeit in ihrer theoretischen und empirischen 
Ausrichtung ein. ${ }^{1}$ Im Folgenden geht es zunächst um die Entwicklung dieses soziologischen Teilgebiets und dessen grundlegende Fragen. Mit anderen Worten: Wissenssoziologie wird als diejenige wissenschaftliche Disziplin thematisiert, der auch diese Arbeit mit ihrem Forschungsgegenstand, der organisationalen Wissensgenese und Wissensverwendung, angehört. Es handelt sich hier um eine empirische Studie, so dass die nun folgende Thematisierung von Wissen in der Wissenssoziologie als ein erster Schritt in Richtung ihrer theoretischen Verortung begriffen werden kann. Vollzogen wird dieser Schritt anhand der Darstellung eines, aus heutiger Perspektive, weiten, im Vergleich mit anderen Wissenschaften jedoch nur kurzen Weges aus der Vergangenheit in die Gegenwart.

Auf einen ersten in Richtung einer theoretischen Verortung dieser Forschungsarbeit zu gehenden Schritt folgt sodann ein zweiter; dieser führt zur Organisationsforschung oder auch Organisationssoziologie. Ein Theorierahmen, den diese Arbeit aufspannt, muss diese beiden Schritte beinhalten, wenn er für sich beansprucht, umfassend zu sein. ${ }^{2}$ Die zugrundliegende Fragestellung berührt nicht nur Wissen, sondern auch Organisationen. Realisiert wurde die empirische Untersuchung, auf der die vorliegende Arbeit gründet, innerhalb eines Unternehmens der deutschen Automobilindustrie. Dies bedeutet, dass die Ergebnisse der umgesetzten Studie in unmittelbarem Bezug zu dieser Organisation stehen; der deutsche Automobilhersteller ist das Fallbeispiel dieser Arbeit. Ein Einblick in die Organisationsforschung und Organisationssoziologie ist somit unabdingbar.

Karl E. Weick (1985/2015), den die Organisationssoziologie nicht außer Acht lassen sollte, hat folgendermaßen umschrieben, was auf der Suche nach einer Organisation gefunden werden kann:

\footnotetext{
${ }^{1}$ Im weiteren Verlauf dieser Arbeit werden daher die für sie bedeutsamen Aspekte der von Berger und Luckmann formulierten Theorie der Wissenssoziologie noch näher betrachtet. Mit Hauptaugenmerk auf die theoretische Bedeutung ihrer Wissenssoziologie geschieht dies im Rahmen des vorliegenden Kapitels; mit Fokus auf die empirische Relevanz in einem Exkurs über den Sozialkonstruktivismus (4.1) im Zuge der Darstellung des Untersuchungsmaterials und methodischen Vorgehens (Kapitel 4.).

${ }^{2}$ Wenn hier die Rede davon ist, dass diese Studie den „Anspruch auf einen umfassenden Theorierahmen“"erhebt, so ist damit kein Anspruch auf Vollständigkeit verbunden. Vielmehr wird versucht, möglichst alle für die empirische Untersuchung relevanten Aspekte vorab theoretisch zu betrachten.
} 
Die meisten „Dinge“ in Organisationen sind in Wirklichkeit Beziehungen, in systematischer Weise miteinander verbundene Variablen. Die Ereignisse hängen daher von der Stärke dieser Verbindungen, der Einflußrichtung und der Zeit ab, die Informationen in der Form von Unterschieden benötigen, um die Zyklen zu durchlaufen. Das Wort Organisation ist ein Substantiv, und es ist außerdem ein Mythos. Wenn Sie nach einer Organisation suchen, werden Sie sie nicht finden. Was Sie finden werden, ist, daß miteinander verbundene Ereignisse vorliegen, die durch Betonwände hindurchsickern; und diese Sequenzen, ihre Pfade und ihre zeitliche Ordnung sind die Formen, die wir fälschlich in Inhalte verwandeln, wenn wir von Organisationen reden (Weick, 1985/2015, S. 129, Hervorheb. i. O.).

In einer solchen Organisation, verkörpert durch einen deutschen Automobilhersteller, wurde der Wissensgenese und Wissensverwendung im Kontext der digitalen Methode der Social-Media-Analysen auf den Grund gegangen. Um einen Theorierahmen für die vorliegende Forschungsarbeit abzustecken, gilt es also sowohl die Wissenssoziologie als auch die Organisationsforschung zu betrachten. So richtet sich der Blick auf die wissenssoziologische Organisationsforschung. Damit ist auch die Richtung benannt, die die hier vorliegende empirische Studie über die organisationale Wissensgenese und Wissensverwendung eingeschlagen hat.

\subsection{Wissen in der Wissenssoziologie}

Berger und Luckmann haben mit ihrer Theorie der Wissenssoziologie die vorliegende Forschungsarbeit maßgeblich geprägt. Dies sei an dieser Stelle ebenso wiederholt wie das nun folgende Zitat, mit dem sie die Aufgabe dieser soziologischen Subdisziplin umreißen:

Wie ist es möglich, daß subjektiv gemeinter Sinn zu objektiver Faktizität wird? Oder, in der Terminologie Webers und Durkheims: Wie ist es möglich, daß menschliches Handeln (Weber) eine Welt von Sachen hervorbringt? So meinen wir denn, daß erst die Erforschung der gesellschaftlichen Konstruktion der Wirklichkeit - der „Realität sui generis“ - zu ihrem Verständnis führt. Das, glauben wir, ist die Aufgabe der Wissenssoziologie (Berger, \& Luckmann, 1966/2009, S. 20, Hervorheb. i. O.).

Obwohl Berger und Luckmann die Wissenssoziologie als Teilgebiet der Soziologie mit ,ihrem sozialkonstruktivistischen Ansatz' damals neu konzipiert haben, geht aus ihrer Zusammenfassung von deren Aufgabe doch die grundlegende Fragestellung hervor, der die Wissenssoziologie seit jeher nachgeht. Die Vorläufer der Wissenssoziologie haben sich wie auch die sogenannten „klassischen“ oder 
„modernen“ oder auch „deutschen“ Wissenssoziologen mit der Wissensgenese, also der Entstehung von Wissen beschäftigt; die sozialkonstruktivistische Wissenssoziologie tut dies bis heute. Daher und wegen der Relevanz dieser Thematik für die in dieser Studie durchgeführten empirischen Untersuchung und deren Ergebnisse steht im Folgenden die Auseinandersetzung der Wissenssoziologie mit ihrem Gegenstand, dem Wissen und der Wissensgenese oder laut Berger und Luckmann ihrer Aufgabe im Zentrum der Betrachtung. Dementsprechend wird die Entstehungsgeschichte der Wissenssoziologie nachgezeichnet. Dies geschieht durchweg in Orientierung an der Forschungsfrage dieser Arbeit sowie hinsichtlich der empirischen Untersuchung, mit der ihr nachgegangen wurde.

Zunächst richtet sich das Augenmerk auf zwei Varianten der Entstehung von Wissen, denen hier wesentliche Bedeutung zukommt: Einerseits auf die Wissensgenese durch Ideologien, andererseits auf die Wissensgenese durch Wissenschaft. Im Anschluss daran folgt eine Thematisierung der klassischen Wissenssoziologie der Moderne. ${ }^{3}$ Sodann rückt die sozialkonstruktivistische Wissenssoziologie bis in die Gegenwart in den Mittelpunkt. Die Ausführungen münden in einem Exkurs über Wissenskulturen. So wird ein Bild von Wissen in der Wissenssoziologie gezeichnet, wie es für die vorliegende Forschungsarbeit zur theoretischen Verortung beziehungsweise für die Interpretation und Deutung ihrer Ergebnisse erforderlich ist.

Wie bereits mehrfach angesprochen, reiht sich diese Arbeit in theoretischer, vor allem aber auch in empirischer Hinsicht in die von Berger und Luckmann neu begründete Wissenssoziologie ein. Daneben kommt der Wissenssoziologie von Karl Mannheim beziehungsweise dessen als Ideologiekritik formulierter Theorie, die ein Vorläufer der Konzeption von Berger und Luckmann ist, eine zentrale Stellung in dieser Studie zu, insbesondere im Zusammenhang mit der Interpretation und Deutung der aus der empirischen Untersuchung hervorgegangen Ergebnisse sowie deren Rückkoppelung an die wissenssoziologische Theorie. Mannheims Wissenssoziologie ist Thema im nun folgenden Abschnitt. Der von der Wissenssoziologie geleisteten Ideologiekritik kommt ein hoher Stellenwert zu. Daher wird die Entwicklung der Wissenssoziologie anhand von bedeutenden Theorien behandelt, die zum einen die Tradition der Ideologiekritik maßgeblich geprägt haben und zum anderen im Hinblick auf diese Arbeit von Relevanz sind. Dies geschieht antichronologisch wegen des Fokus auf Mannheim, der neben dem auf die erst am Ende der gesamten wissenssoziologischen Entwicklung und damit am Ende von

\footnotetext{
${ }^{3}$ In der Literatur wird begrifflich nicht trennscharf zwischen „klassischer“, „moderner“ und ,deutscher" Wissenssoziologie unterschieden. Daher ist in dieser Forschungsarbeit die Rede von der „klassischen Wissenssoziologie der Moderne“, worunter auch die deutsche Wissenssoziologie subsumiert wird.
} 
deren Darstellung in dieser Forschungsarbeit stehenden Theorie von Berger und Luckmann besteht. Im Anschluss an die Thematisierung von Mannheim lassen sich zwei Zeitsprünge nicht vermeiden; zu Theorien, die dessen Ideologiekritik vorangingen. Zum Zweck der Orientierung sei dies hier erwähnt und begründet. Jeder Zeitsprung wird an der entsprechenden Stelle im Verlauf dieser Arbeit nochmals gezeigt.

\subsubsection{Wissensgenese durch Ideologien: Karl Mannheim}

Eine Variante der Entstehung von Wissen, welche die Wissenssoziologie oder teilweise noch deren Vorläufer erkannt und zu ihrem zentralen Thema gemacht haben, besteht darin, dass Wissen aus Ideologien hervorgeht oder durch Ideologien generiert wird, dass also Denken im Rahmen von Ideologien sattfindet und somit eine ,Determination“ erfährt. Die Wissensgenese durch Ideologien ist ein wissenssoziologisches Kernthema. Sowohl ihre Vorläufer als auch die Wissenssoziologen haben sich damit beschäftigt. Zwei berühmte Namen sind in diesem Zusammenhang zu nennen: Mannheim und Karl Marx. Ersterer wird heute als ein Klassiker der Wissenssoziologie gelesen, Letzterer als einer ihrer Vorläufer; Ideologiekritik haben sie beide betrieben. Es ist die Theorie Mannheims, der im Kontext dieser Forschungsarbeit eine zentrale, noch näher zu zeigende Bedeutung zukommt. Mit seiner Ideologiekritik nimmt Mannheim unter anderem Bezug auf Marx, auch indem er sich von ihm abgrenzt, und gilt heute als einer der Begründer der Wissenssoziologie (Meja, \& Stehr, 1982a, S. 12 f.). Volker Meja und Nico Stehr (1982) beschreiben das Verhältnis von Wissenssoziologie zu Ideologiekritik und damit zugleich auch das von Mannheim zu Marx wie folgt: ${ }^{4}$

\footnotetext{
${ }^{4}$ Mit seinem Materialismus beziehungsweise der Annahme, dass das gesellschaftliche Sein der Menschen ihr Bewusstsein bestimmt, hat Karl Marx (1818-1883) einen maßgeblichen Beitrag zur Wissenssoziologie geleistet. Siehe hierzu zum Beispiel: Dahrendorf, 2006; Knoblauch, 2014, 42 ff.; Lachmann, 2001; Marx, \& Engels, 1845-1846/1958; Negt, 2007.
} 
Ideologiekritik und Wissenssoziologie unterscheiden sich also vor allem darin, daß der von beiden verwandte Ideologiebegriff eine völlig verschiedene Bedeutung annimmt. Die Fragestellung ist [. . . ] demgemäß eine grundsätzlich andere: „Sie lautete nicht: Durch welche Bindungen des erkennenden Subjektes an eine Ideologie und an hinter ihr stehende Interessen sind seine Aussagen nicht objektadäquat, also falsch, sondern: wann und wo ragen historisch-soziale Strukturen in die Art des Denkens hinein und in welchem Sinne können sie diese in concreto bestimmen. Der Begriff des ,falschen * Bewußteins, der in der Ideologienlehre so häufig gebraucht wird, wird daher in der Wissenssoziologie bewußt vermieden. Hier spricht man von sozialstandortgebundenen Bewußtseins- oder ,Aspektstrukturen ““. Die Abgrenzung von Ideologiekritik und Wissenssoziologie kann deshalb als ein Teil jenen Prozesses verstanden werden, der in eins mit der faktischen deutschen Gesellschaft auch die Wissenschaft dieser Gesellschaft in eine bürgerliche und eine marxistische Soziologie aufspaltete (Meja, \& Stehr, 1982a, S. 13).

Inhalt dieses Abschnitts ist es allerdings nicht, die Beeinflussung Mannheims durch Marx respektive die Intensität dessen Einfluss zu diskutieren. Damit setzen sich die Abhandlungen in dem Werk Der Streit um die Wissenssoziologie (Meja, $\&$ Stehr, 1982a, 1982b) bereits hinreichend auseinander. Thema hier ist einzig die Wissensgenese durch Ideologien: Karl Mannheim (1893-1947). Es geht also um seine Konzeption der Wissenssoziologie.

Es ist also Ideologiekritik, die Mannheim in zweiter oder gar dritter Instanz als klassische oder moderne oder auch deutsche Wissenssoziologie konzipiert hat. ${ }^{5}$ Mannheims Arbeit verlief vor dem Hintergrund der einander widersprechenden Ideologien seiner Zeit. Dies veranlasste ihn dazu, nach den sozialen Bedingungen bestimmter Weltanschauungen und dem Einfluss von sozialen Faktoren auf das gesellschaftliche Wissen zu fragen. Indem er die konventionelle Erkenntnistheorie radikal kritisierte, begründete Mannheim die Wissenssoziologie als unabhängige „kritische Theorie des Denkens, Erkennens und Wissens“ (Endreß, 2007a, S. 77; Knoblauch, 2014, S. 65 ff., S. 100; Maasen, 2012, S. 18 ff., S. 24; Mannheim, 1929/1995; Wirth, 1952/1995, S. IX, S. XXI).

\footnotetext{
${ }^{5}$ Mannheim selbst beschreibt die von ihm konzipierte Wissenssoziologie als in enger Beziehung mit der Ideologiekritik der Moderne stehend, den Ideologiebegriff versucht er wegen dessen starker Belastung im Sinne negativer Konnotation jedoch zu vermeiden. Stattdessen spricht er von einer „seinsverbundenen - oder standortgebundenen - Aspektstruktur“ des Denkens (Mannheim, 1931/1959, S. 659 f.).
} 
Sein berühmtes wissenssoziologisches Hauptwerk Ideologie und Utopie (1929/1995) hat Mannheim als Essaysammlung konzipiert und selbst als „Experiment" bezeichnet (Barboza, 2009, S. 29). Es nimmt eine besondere Stellung ein wegen Mannheims

[... ] Absicht, der Epochenkrise mit nichtrevolutionären Mitteln beizukommen. Noch heute beeindruckt sein Insistieren darauf, dass intellektuelle Probleme intellektuelle Lösungen und nicht das Opfer des Intellekts erfordern. Die Denkkrise erschien Mannheim nicht als Fragwürdigkeit einer Reihe von Ideologien, sondern als die einer Welt, in der die grundsätzliche Relativität aller [. . . ] Denkweisen von diesen selbst nicht durchdacht worden war (Kaube, 2015, S. IX).

Mannheim beabsichtigte den Ideologiebegriff und über diesen die Wissenssoziologie als solche zu einem analytischen Instrument, einem Werkzeug sozialwissenschaftlicher Reflexion und Forschung zu machen (Barboza, 2009, S. 11, S. 29 f., S. 89 f.; Kettler, \& Meja, 2007, 2006; Mannheim, 1929/1995, S. 47; Schofer, 2001): 6

Mannheim sieht die Wissenssoziologie als intellektuelles Werkzeug einer vom Stigma des „falschen Bewußtseins“ befreiten neuen Gestalt der Geistesgeschichte. Die Wissenssoziologie ist soziologische Diagnose und Therapie zugleich (Kettler, \& Meja, 2007, S. 261).

Seine Überlegungen gründen dabei in erster Linie im Positivismus nach Auguste Comte, in der Ideologiekritik von Marx, in der Soziologie von Max Weber sowie in der Wissenssoziologie von Max Scheler. Mannheims dynamische Wissenssoziologie, die auf einer dem historischen Wandel unterworfenen Wahrheit beruht, hat jedoch auch im Historismus einen ihrer zentralen Ausgangspunkte gefunden (Endreß, 2007a, S. 77 f.; Hillmann, 2007, S. 524; Kaube, 2015, S.VIII; Knoblauch, 2014, S. 100 f.; Mannheim, 1931/1959, S. 678, 1929/1995, S. 8 f.; Schofer, 2001).

Für Mannheim gilt es als eine Tatsache,

[... ] daß die gleiche Welt verschiedenen Beobachtern verschieden erscheinen kann (Mannheim, 1929/1995, S. 7).

\footnotetext{
${ }^{6}$ Eine ausführliche Diskussion der einzelnen Essays Mannheims, die gemeinsam sein Werk Ideologie und Utopie bilden, findet sich beispielsweise bei Barboza (2009) oder auch bei Kettler und Meja (2007).
} 
Entsprechend erkennt er in der Moderne eine infolge der Säkularisierung entstandene und zu seiner Zeit vorherrschende Vielfalt von Denkstilen. Diesen Zustand begreift er zwar als Krise, die er jedoch zum Anlass seiner Konzeption der Wissenssoziologie als Methode nimmt (Kaube, 2015, S. VII; Mannheim. 1931/1959, S. 659, 1929/1995, S. 3 ff.; Wirth, 1952/1995, S. X, S. XXIII):

Wird das Problem von diesem Gesichtspunkt aus angepackt, dann gibt gerade die Unsicherheit, die im öffentlichen Leben zu einem kaum mehr tragbaren Unbehagen geführt hat, den Boden ab, von dem aus die moderne Soziologie ganz neue Einsichten zu gewinnen vermag. Und zwar in dreifacher Hinsicht. Erstens handelt es sich um die Tendenz zur selbstkritischen Analyse kollektiv-unbewußter Motive, sofern diese das moderne soziale Denken bestimmen; zweitens um die Tendenz, Geistesgeschichte so zu treiben, daß die Wandlungen in den Begriffen auf gesellschaftlich-geschichtliche Veränderungen hin interpretiert werden können; und drittens die Tendenz, unsere Erkenntnistheorie, die bisher die gesellschaftliche Natur des Denkens nicht genügend berïcksichtigte, zu revidieren. Die Wissenssoziologie ist derart eine Systematisierung des Zweifels, der sich in der Gesellschaft als dumpfe Unsicherheit und Ungewißheit äußert (Mannheim, 1929/1995, S. 44 f.).

Mannheims Wissenssoziologie ist insbesondere dadurch gekennzeichnet, dass sie nicht nur soziale Strukturen in den Blick nimmt, sondern Sinn und damit geistige und soziale Gebilde in Gestalt verborgener Absichten oder soziohistorischer Interpretationen in den Mittelpunkt der Betrachtung rückt. ${ }^{7}$ Über lange Zeit hinweg waren Wissen und Denken als Forschungsgegenstände sowohl der Logik als auch der Psychologie vorbehalten und wurden nicht als soziale Prozesse begriffen. Den besonderen Beitrag von Mannheims Werk sieht Louis Wirth darin,

[... ] daß ausdrücklich anerkannt wird, daß das Denken nicht bloß ein Gegenstand der Logik und Psychologie ist, sondern nur dann voll verständlich ist, wenn es soziologisch gesehen wird. Dies schließt ein, daß die Grundlage gesellschaftlichen Urteilens bis in ihre spezifischen interessengebundenen Wurzeln in der Gesellschaft zurück verfolgt werden [... ] (Wirth, 1952/1995, S. XXIII f.).

Mannheim geht davon aus, dass sich im Wissen das soziale Sein widerspiegelt - eine Annahme, die letzten Endes auch seinen Ideologiebegriff bestimmt (Knoblauch, 2014, S. 101 ff.; Mannheim, 1929/1995, S. 26 ff.):

\footnotetext{
${ }^{7}$ Angelehnt an die Kultursoziologie von Alfred Weber, unterscheidet Mannheim verschiedene Sinntypen, wie „objektiven Sinn“, ,intendierten Ausdruckssinn“ und ,dokumentarische Interpretation". Thematisiert und einander gegenübergestellt werden diese von Knoblauch (2014, S. $101 \mathrm{ff}$.$) .$
} 
Der Begriff der Ideologie reflektierte [. . . ], daß herrschende Gruppen in ihrem Denken so intensiv mit ihren Interessen an eine Situation gebunden sein können, daß sie schließlich die Fähigkeit verlieren, bestimmte Tatsachen zu sehen, die sie in ihrem Herrschaftsbewusstsein stören könnten. In dem Wort „Ideologie“ ist implizit die Einsicht enthalten, daß in bestimmten Situationen das kollektive Unbewußte gewisser Gruppen sowohl diesen selbst wie anderen die wirkliche Lage der Gesellschaft verdunkelt und damit stabilisierend wirkt (Mannheim, 1929/1995, S. 36). ${ }^{8}$

Eine Ideologie beruht für Mannheim also auf einer „Situationsgebundenheit“ oder aber geht aus einer solchen hervor. Dies bedeutet zugleich, dass Ideen niemals ein eigener Sinn eignet, sondern dass Ideologien stets aus der Perspektive derjenigen gesehen werden müssen, die sie verwenden. Eine Ideologie ist bei Mannheim demnach ein soziales Produkt (Kaube, 2015, S. VII; Knoblauch, 2014, S. 103; Mannheim, 1929/1995, S. 27 ff.). ${ }^{9}$

Mannheim charakterisiert Ideologien zudem als ,seinstranszendent“, da sie soziale Gruppen gegen die Wahrnehmung von ,Wirklichkeit' gewissermaßen immunisieren und sogar dazu verleiten können, etwas wahrzunehmen, was den eigenen Interessen widerspricht. Die Aufgabe der Wissenssoziologie besteht nun darin, die Relation zwischen dem Sinn und dem Sein zu klären. Das Denken, auch bezeichnet als „Sinn“, hängt bei Mannheim von der sozialen Gruppe ab, die hinter dem steht, was er „Sein“ nannte; somit ist dem Denken eine „Seinsverbundenheit“" oder „Standortgebundenheit“" inhärent. Mannheim nennt diese Verankerung

${ }^{8}$ Ideologie kontrastiert Mannheim mit Utopie, welche er folgendermaßen charakterisiert: „Im Begriff des utopischen Denkens spiegelt sich die entgegengesetzte Entdeckung wider, [...] daß nämlich bestimmte unterdrückte Gruppen geistig so stark an der Zerstörung und Umformung einer gegebenen Gesellschaft interessiert sind, daß sie unwissentlich nur jene Elemente der Situation sehen, die diese zu negieren suchen. Ihr Denken ist nicht fähig, einen bestehenden Zustand der Gesellschaft korrekt zu erkennen; sie befassen sich keineswegs mit dem, was wirklich existiert, suchen vielmehr in ihrem Denken bereits die Veränderung des Bestehenden vorwegzunehmen. Ihr Denken zielt nie auf eine Situationsdiagnose ab; es kann nur als eine Anweisung zum Handeln benutzt werden. Im utopischen Bewußtsein verdeckt das von Wunschvorstellungen und dem Willen zum Handeln beherrschte kollektive Unbewußte bestimmte Aspekte der Realität. Es kehrt sich von allem ab, was den Glauben erschüttern oder den Wunsch nach einer Veränderung der Dinge lähmen würden“ (Mannheim, 1929/1995, S. $36 \mathrm{f}$.).

${ }^{9}$ Seine Wissenssoziologie hat Mannheim als eine Methode konzipiert und deren Anwendung mitunter über die „dokumentarische Interpretation“ vorgeschlagen. Im Rahmen Letzterer differenziert er zwischen „totalem Ideologiebegriff“" und ,partikularem Ideologiebegriff“. Beide Begriffe stellt diese Arbeit nicht näher vor. Details hierzu sind unter anderem zu finden in: Barboza, 2009, S. 43 ff., S. 93 f., S. 120 f.; Knoblauch, 2014, S. 103; Mannheim, 1931/1959, S. 227 ff., 1929/1995, S. 53 ff.. 
des Denkens im sozialen Raum oder aber dessen Verbindung mit einer sozialen Gruppe, deren kollektive Erfahrung das Denken bedingt, „Seinsverbundenheit des Denkens“ oder „Standortgebundenheit des Denkens“ (Endreß, 2007a, S. 81 f; Hillmann, 2007, S. 524; Kettler, \& Meja, 2007; Knoblauch, 2014, S. 103 f.; Mannheim, 1931/1959, S. 229 ff.; Maasen, 2012, S. 24; Schofer, 2001).

Zwar offenbart die „Seinsverbundenheit des Denkens“ noch nicht die Ideologie, welche die gesamte ,Realität' überdeckt, ermöglicht aber doch Ableitungen in Bezug auf die Perspektive, aus der sie wahrgenommen wird. Die „Seinsverbundenheit des Denkens" ist für Mannheim auch der Grund dafür, dass die Mehrheit des existierenden Wissens interessenbasiert ist, also von der Perspektive derjenigen abhängt, die es vertreten. Unterschiedliche „Seinsverbundenheiten“ bedingen verschiedenes „Weltwollen“ im Sinne divergierender wirtschaftlicher oder politischer Interessen sozialer Gruppen, was zu Auseinandersetzungen führen kann. Denkstile sozialer Gruppen beruhen demnach auf deren "Seinsverbundenheiten“. Um soziale Lagen und einen Denkstil miteinander zu verbinden, führt Mannheim die Begriffe ,geistige Schichten“ und „Denkstandorte“ ein (Endreß 2007a, S. 79 ff.; Kettler, \& Meja, 2007, 2006; Knoblauch, 2014, S. 104 f.; Mannheim, 1931/1959, S. 661; Schofer, 2001).

Wie Mannheim weiter zeigt, unterscheiden sich soziale Gruppen nicht nur in Bezug auf ihre Denkstile, sondern ebenso hinsichtlich ihrer Weltanschauungen, wobei doch jede soziale Gruppe um den Entwurf eines möglichst umfassenden Weltbildes bemüht ist. Gemeinsam formen diverse Weltanschauungen eine „epochenspezifische Totalität“. Mannheims Anliegen oder vielmehr das seiner dynamischen Wissenssoziologie bestand letztlich in der Rekonstruktion des Wandels eben dieser unterschiedlichen Weltbilder. Es ging ihm darum, in Abgrenzung zu einer ideologischen Betrachtung, die lediglich gewisse Ausschnitte wahrnehmen kann, die Totalität des historischen Prozesses zu erkennen, die Situation vereinheitlicht und integriert zu sehen. Gelingen konnte dieses ambitionierte Vorhaben der Überwindung von Relativismus nur durch Relationalismus (Barboza, 2009, S. 93 f., S. 125; Endreß, 2007a, S. 78 f.; Kettler, \& Meja, 2007, 2006; Knoblauch, 2014, S. 107 ff.; Maasen, 2012, S. 25): ${ }^{10}$

\footnotetext{
${ }^{10}$ Mannheim hat eine „Methode der Analyse von Denkstilen“ entwickelt und unter Anwendung auf die Politik, mit der er sich auch von Marx und dessen Reduzierung des Denkens auf ökonomische Interessen und zwei Klassen abgrenzt, in seiner Gegenwart fünf politische Weltanschauungen identifiziert. Details hierzu können aus in diese Arbeit nicht eingehen, finden sich aber beispielsweise in: Barboza, 2009, S. 72 ff., S. 94 ff., S. 123 f.; Endreß, 2007a, S. 80 ff.; Knoblauch, 2014, S. 105 ff..
} 
Wie bei der Betrachtung eines konkreten Gegenstandes [. . . ] können wir das Wissen, die Ideologie und Weltanschauung von verschiedenen Seiten betrachten. Wir wissen, dass jede Betrachtung einer besonderen Perspektive unterworfen ist, die nie umfassend sein kann [... ]. Wenn wir also den ,relationalen“ Charakter unseres Denkens anerkennen, dann vergrößern wir damit zugleich unser Wissen. Wenn wir in der relationalen Betrachtung auch andere Betrachtungsweisen einbeziehen, wird unser Bewusstsein immer komplexer und umfassender. [.. . ] Wie die Totalität sich historisch entwickelt, schreitet auch der Relationismus voran und ermöglicht so die Vorstellung einer Totalität, die das historisch Erkennbare ausmacht. Auf dieser Grundlage wird Objektivität möglich (Knoblauch, 2014, S. 108). ${ }^{11}$

Methodisch empfiehlt Mannheim, dem Prozess des eben beschriebenen Relationierens den des Distanzierens ebenso voranzustellen, wie der des Partikularisierens zu folgen habe (Mannheim, 1929/1995, S. 239 ff.). So werde Wissenssoziologie

[... ] eines dieser Mittel [... ], dessen Aufgabe es ist, die Seinsverbundenheit und somit die Partikularität der Denkstandpunkte aufzudecken, ihr Zustandekommen transparent zu machen und so die Voraussetzungen für ihre höhere Rationalität zu schaffen (Srubar, 1980, S. 348).

Es lässt sich festhalten, dass Mannheims wissenssoziologischer Ansatz auf drei Thesen beruht: (1) Die Grenze zwischen ideologischen und wissenschaftlichen Erklärungen gilt als porös und die Wissenssoziologie als ,Selbstreflexionstherapie“ in genau diesem Grenzbereich. (2) Ideologien werden als Erkenntnisstrukturen eingestuft:

Jede Ideologie ist auf eigene Weise unvollkommen, beschränkt, perspektivistisch einseitig und der Korrektur durch andere Perspektiven unterworfen, aber dennoch wissenserzeugend (Kettler, \& Meja, 2006, S. 301).

(3) Die Wissenssoziologie zählt wegen ihres Einwirkens auf grundlegende, von der Ideologie gezeigte Probleme als Orientierungsbeitrag (Kettler, \& Meja, 2006, S. 301 f.).

${ }^{11}$ Seine Überlegungen zur Überwindung des Relativismus durch den Relationismus eröffnen Mannheim noch eine weitere Möglichkeit: die „sozial frei schwebende Intelligenz“. Von deren Betrachtung sieht die vorliegende Arbeit ab. Eine solche findet sich zum Beispiel in: Barboza, 2009, S. 29, S. 94 ff.; Endreß, 2007a, S. 84 ff.; Kaube, 2015, S.XIVf.; Knoblauch, 2014, S. 109 f.; Maasen, 2012, S. 25 f.; Mannheim, 1929/1995, S. 134 ff.. 
Mit seinem Werk hat Mannheim eine philosophisch wie politisch motivierte Diskussion ausgelöst. Durch die Kritik daran, die die Abhandlungen in dem Werk Der Streit um die Wissenssoziologie (Meja, \& Stehr, 1982a, 1982b) abbilden, wurde eine der drei bedeutsamen Kontroversen der deutschen Sozialwissenschaften im letzten Jahrhundert entfacht. Die Leistung des Streits besteht darin, dass er die Wissenssoziologie über die Grenzen der eigenen Disziplin hinaus international publik gemacht hat; erst seitdem ist die Rede von „,der“ Wissenssoziologie. Es gilt hier festzuhalten, dass Mannheim die Wissenssoziologie als ,reflexive Soziologie" konzipiert hat (Barboza, 2009, S. 103 ff.; Endreß, 2007a, S. 86 ff.; Kaube, 2015, S.XIIf.; Kettler, \& Meja, 2007; Knoblauch, 2014, S. 110 f.; Meja, \& Stehr, 1982a, S. 11 ff.). Mit seiner dynamischen Wissenssoziologie verfolgte er

[. . . ] nicht nur das wissenschaftliche Ziel, das menschliche Denken jenseits philosophischer Idealisierungen zu erfassen, sondern auch die praktische Absicht, durch die Einsicht in die unbewussten Kräfte hinter dem Wissen eine rationale Kontrolle jener bislang verborgenen Determinanten des Wissens zu ermöglichen (Schofer, 2001, S. 443).

\subsubsection{Wissensgenese durch Wissenschaft}

Eine alternative Variante der Produktion von Wissen haben vor allem die Vorläufer der Wissenssoziologie thematisiert. Diese beschäftigten sich mit der Wissensgenese durch Wissenschaft. Wissen haben sie nicht auf Ideologien zurückgeführt, sondern als ein Erzeugnis von Wissenschaft betrachtet, insbesondere in Abgrenzung zu dem durch Ideologien hervorgebrachten Wissen. Dabei handelte es sich bereits um eine Form der Ideologiekritik.

Die ideologiekritischen Konzeptionen des Wissens lauten: Wissen als Täuschung, als falsches Bewusstsein, als theologisch-fiktiv oder metaphysisch-abstrakt. Auf diese Weise fasst die Ideologiekritik das Wissen stets ex negativo und ersinnt Verfahren (Aufklärung, Erziehung) und behauptet Entwicklungen, die zu seiner „Positivwerdung“ beitragen sollen oder aber gelehrt davon abraten (Gegenaufklärung). All diese Bemühungen gelten einem Gegenstand, dem die Ideologiekritik enorme Bedeutung für die gesellschaftliche Reproduktion zuspricht: dem Wissen. In seinen individuell und/oder gesellschaftlich bedingten und historisch spezifischen Verzerrungen stützt es in der Regel die Mächtigen, legitimiert aber auch die Leidenschaften und tröstet die Bedürftigen. [... ] Die kritische Haltung selbst, hier das Wissen der Aufklärer, Gegenaufklärer ebenso wie das der Positivisten, ist Resultat derselben gesellschaftlichen Verfassung (Maasen, 2012, S. 17 f., Hervorheb. i. O.). 
In erster Linie haben sich die Vorläufer der Wissenssoziologie mit der Entstehung von Wissen durch Wissenschaft auseinandergesetzt und diese als Form der Ideologiekritik konzipiert. Mannheim sollte diese erst später fortführen. Daher erfolgt hier nun der erste antichronologische Zeitsprung in Bezug auf die Entwicklung der Wissenssoziologie in eine Zeit weit vor Mannheim. Zunächst wird die Ideologiekritik der Aufklärung und danach der Positivismus nach Comte in den Fokus der Betrachtung gerückt, zwei Etappen der Entstehungsgeschichte der Wissenssoziologie, die sowohl die Variante der Wissensgenese durch Wissenschaft begründet als auch die wissenssoziologische Konzeption von Mannheim beeinflusst haben.

Da diese Forschungsarbeit relevante Aspekte der Entwicklung der Wissenssoziologie antichronologisch zeigt, seien hier einige grundlegende Hinweise zur Einordnung der einzelnen theoretischen Momente vorweggenommen. Zum einen sei bemerkt, dass Mannheim insbesondere in Abgrenzung zum Positivismus nach Comte, der selbst auf die Ideologiekritik der Aufklärung folgte, gesehen werden muss. Durch die Themen „Objektivität“ und „Rationalität“" werden beide jedoch wieder geeint. Zum anderen sei nochmals darauf hingewiesen, dass Mannheim, sowie auch Berger und Luckmann, für die hier vorliegende Arbeit einen zentralen Moment der theoretischen Entwicklung der Wissenssoziologie markiert. Aus diesem Grund ist die Darstellung anderer theoretischer Konzeptionen im Vergleich kurz gehalten und nach ihrer Relevanz für Mannheim ausgewählt. Eingang finden nur wesentliche Theorien der Entstehungsgeschichte der Wissenssoziologie und jene Aspekte von Mannheims Vorläufern, Zeitgenossen und Nachfolgern, die für das Verständnis von Mannheims Ideologiekritik erforderlich sind.

\subsubsection{Ideologiekritik der Aufklärung}

Im Hinblick auf die Wissensgenese beschreibt die Ideologiekritik der Aufklärung eine Ausdifferenzierung von Ideologien und Wissenschaft. Thematisiert werden Hindernisse, wie Ideologien, die ein ,wahres ' Wissen von Natur und Gesellschaft, erlangt durch Wissenschaft, beeinträchtigen. Letztlich zielt Ideologiekritik auf die Entstehung oder Produktion von Wissen, das nicht länger ausschließlich auf Ideologien beruht, sondern durch Wissenschaft hervorgebracht wird und damit auf eine Wissensgenese durch Wissenschaft. Ideologiekritik bedeutet dabei die Feststellung von und Kritik an der ,Interessenbedingtheit des Wissens“, auf die später dann auch Mannheim Bezug nahm (Fuchs-Heinritz, 2007, S. 13; Knoblauch, 2014, S. 18, S. 30; Maasen, 2012, S. 12; Mannheim, 1929/1995).

Die Idee der Wissensgenese durch Wissenschaft kann bereits auf die Idolenlehre von Francis Bacon zurückgeführt werden (Fuchs-Heinritz, 2007, S. 13 f.; 
Knoblauch, 2014, S. 23 ff.; Maasen, 2012, S. 12); doch erst die französischen Philosophen der Aufklärung übertrugen

[... ] den Anspruch auf Wissenschaftlichkeit und Vernünftigkeit über den Bereich der Natur auf den des Sozialen [. . . ]. Ihnen galten die überlieferten christlichen Glaubensvorstellungen (vor allem die der römisch-katholischen Kirche) als durch Vernunft nicht belegbar, als Vorurteile oder als Aberglaube, also als Behinderungen des wahren Denkens [... ] (Fuchs-Heinritz, 2007, S. 14).

Sowohl von Niccolò Machiavelli als auch Thomas Hobbes beeinflusst, entwickelten die französischen Aufklärungsphilosophen Claude Adrien Helvétius und Paul Henri Thiry d'Holbach, die als Materialisten oder Ideologen gelten, die Priesterbetrugstheorie (Fuchs-Heinritz, 2007, S. 14 f.; Knoblauch, 2014, S. 26 ff.):

Hinter den Anschauungen und Glaubensvorstellungen stehen die Machtinteressen besonderer sozialer Gruppen, die ihre Machtposition durch eben diese Vorstellungen und Weltanschauung verschleiern wollen. Wer also auf Ideen blickt, muss auch immer nach dem Cui bono fragen, also danach, für wen sie von Nutzen sind (Knoblauch, 2014, S. 28, Hervorheb. i. O.).

Mit dieser Priesterbetrugstheorie wurde kritisiert, dass eine wissende Elite durch die Instrumentalisierung von Religion die Masse zu ,falschem 'Wissen führt. Helvétius und d'Holbach betrachteten menschliches Denken und Wissen als mit sozialen Interessen, welche selbst wiederum auf sozialen Bedingungen beruhen, in engem Zusammenhang stehend, sie gingen von seiner sozialen Determination aus und verorteten es damit in einem gesellschaftlichen Herrschaftsverhältnis. Auf diese Weise formulierten sie eine Analogie von Weltbildern, Ideen und Wissensformen auf der einen, Berufsgruppen, Klassen, Ständen und sozialen Positionen auf der anderen Seite. Begreift man die Interessentheorie als Ausweitung der Priesterbetrugstheorie auf andere Kreise als Priester, so basiert auf dieser eine frühe Form von Ideologiekritik. Letztere bezieht sich nicht nur auf Religion, sondern setzt sich mit Ideen insgesamt auseinander. Dies ist der ,wissenspolitische Veränderungswille" der Philosophen der Aufklärung, deren Absicht darin bestand, eine „Wissenschaft der Ideen“ zu begründen und die Welt durch Bildung zu verändern; in ihrem Vorhaben stießen sie jedoch auf erheblichen Widerstand der Herrschenden. Doch die Bildung wurde säkularisiert und ging vom Klerus auf eine neue humanistische Gelehrtenschicht über. Dieser Konflikt ging mit der Emanzipation des europäischen Bürgertums, dem Zerfall der mittelalterlichen Ständegesellschaft, dem Austausch von Ideen und der Entwicklung der kapitalistischen Geldwirtschaft einher (Fuchs-Heinritz, 2007, S. 15; Knoblauch, 2014, S. 28 ff.). 
In erster Linie hat sich die aufklärerische Ideologiekritik des 17. und 18. Jahrhunderts auf das Bündnis von Klerus und Adel konzentriert; religiöse Dogmen, politische Doktrinen und individuelle Werte wurden als Wissen untersucht und als Interessen oder Täuschungen ausgemacht. Die Ideologiekritik der Aufklärung verfolgte die Absicht, den ,realen“ Missstand durch das Auflösen irrationaler Machtverhältnisse, welche als Vorbedingungen der Ideologien galten, zu beseitigen Parallel zu dieser Tradition, die nicht durchgängig progressiv ist, hat sich eine konservative etabliert. Letztere begreift nicht nur Denken und Wissen als historischen Prozess, sondern betrachtet das gesamte Verhältnis von Sozialem und Geistigem als geschichtlich variabel. Giambattista Vico (1668-1744) hat diese geschichtsphilosophische Tradition entscheidend geprägt; später findet sie sich im historischen Materialismus von Marx, in der evolutionistischen Theorie von Émile Durkheim und im Historismus von Weber wieder. Neben einer von britischen und französischen Aufklärern erkannten „Interessenbedingtheit des Wissens “wurde der Ideologiebegriff historisch konzipiert, so dass fortan die historisch-materialistische Perspektive vernünftiges und unvernünftiges oder auch , wahres ' und ideologisches Denken unterschied. Ideologiekritik kann also in zwei Spielarten zutage treten: einer radikal-aufklärerischen und einer konservativen. Der Befund der ideologischen Natur des gesellschaftlich kursierenden Wissens eint beide Konzeptionen. Systematisch wurde die Frage nach dem Wissen erst seit der zweiten Hälfte des 18. Jahrhunderts (Knoblauch, 2014, S. 18; Maasen, 2012, S. 13 ff.):

In konservativer Spielart fragt man nach seinen gesellschaftlichen Funktionen, in radikal-aufklärerischer Art darüber hinaus nach seinen historischen Bedingungen. In beiden Varianten jedoch stößt die Aufklärung mit dem Widerspruch von Kritik und Wahrheitsprätention an ihre Grenzen. Zwar kann sie mit funktionalen und historischen Argumentationsfiguren die ständisch-klerikale Gesellschaftsstruktur entlarven und kommentiert mit gegensätzlichen Empfehlungen deren Untergang. Sie kann jedoch keine Anwendung auf sich selbst zulassen [.. . ]: Gegenaufklärung und Revolution sind daher die vermeintlichen Auswege der funktionalistischen oder historischen Ideologiekritik [. . . ] (Maasen, 2012, S. 16). ${ }^{12} 1314$

\footnotetext{
${ }^{12}$ Einen zusätzlichen Ursprung von Ideologien erkannten die Vertreter der Aufklärung in menschlichen Affekten. In dieser Studie wird weder dieser Einfluss des Irrationalismus auf Wissen und Denken noch dessen Bedeutung für die Wissenssoziologie im Kontext der Wissensgenese beleuchtet. Siehe hierzu: Knoblauch, 2014, S. 55 ff.; Maasen, 2012, S. 13 f.. ${ }^{13}$ Eine Darstellung der für die Wissenssoziologie bedeutsamen Konzeptionen von Durkheim und Weber findet sich im weiteren Verlauf dieser Arbeit. Auf Vico wird nicht eingegangen; siehe hierzu: Fuchs-Heinritz, 2007, S. 20; Knoblauch, 2014, S. 31 ff..

${ }^{14}$ Die Beziehung von Geschichte und Wissen oder auch Denken behandelt diese Forschungsarbeit nicht. Siehe hierzu Knoblauch (2014, S. 34 ff.).
} 


\subsubsection{Positivismus nach Auguste Comte}

Im Zusammenhang mit der Wissensgenese durch Wissenschaft ist ferner dem aus der Ideologiekritik der Aufklärung entstandenen Positivismus nach Auguste Comte (1798-1857) Beachtung zu schenken. Comte war der Ansicht, dass die zerrissene Gesellschaft zur Ruhe gebracht und die „geistige Anarchie“ überwunden werden müsse:

$\mathrm{Zu}$ diesem Zweck transferiert Comte die naturwissenschaftliche Methode auf Geschichte, Gesellschaft und Politik, um auch in diesen, bisher der Theologie, Philosophie und Jurisprudenz überlassenen Bereichen verläßliches Wissen einzuführen (Bock, 2007, S. 75).

In seinem geschichtsphilosophischen Modell hat er das in der Gesellschaft vorhandene Wissen untersucht, wobei er von dessen historischer Weiterentwicklung ausging. Eine Realisierung dieser Idee des Fortschritts erfolgt gemäß Comte über drei Perioden hinweg; formuliert hat er diesen Befund in seinem „Dreistadiengesetz". Dieses Gesetz ordnet die Phasen der menschlichen Denkweisen und Wissensformen in Bezug auf die Natur und die Gesellschaft als insgesamt drei jeweils aufeinander folgende Stadien: Das theologische, das metaphysische und das positive Stadium (Bock, 2007; Bock, 2006; Endruweit, 2001; Fuchs-Heinritz, Klimke, Lautmann, Rammstedt, Stäheli, Weischer, \& Wienold, 2011, S. 516, S. 649; Fuchs-Heinritz, 2007: S. 16 f.; Knoblauch, 2014, S. 39):

Im ersten Stadium erklärt der Mensch die Erscheinungen, indem er sie Wesen und Kräften zuschreibt, die dem Menschen ähneln. Im zweiten Stadium beruft er sich auf abstrakte Wesenheiten, wie etwa die Natur. Und im dritten Stadium beschränkt sich der Mensch darauf, die Erscheinungen zu beobachten und die Regeln festzustellen, die zwischen ihnen bestehen. Hatte die Phantasie in der theologischen und metaphysischen Phase noch das Übergewicht, so ist es nun die empirische Beobachtung (Knoblauch, 2014, S. 39).

Positive Philosophie zeichnet sich für Comte durch eine Denkweise oder Wissensform aus, die nicht nach den letzten Ursachen der Dinge fragt, sondern die Beziehungen der Tatsachen feststellt, um deren Gesetze zu rekonstruieren. Sind diese in Bezug auf die Gesellschaft bekannt, ist der weitere soziale Fortschritt nach Einschätzung Comtes prognostizierbar. Comte ging davon aus, dass mit dem Positivismus dessen Denkweise bestimmend werde. In den unterschiedlichen Disziplinen erfolgte die wissenschaftliche Entwicklung zeitlich versetzt, wobei den Naturwissenschaften hier eine Vorreiterrolle zukam. Im Vergleich sei jedoch der Gegenstand der Soziologie, die Gesellschaft, am komplexesten. Die Disziplin 
zeichne sich durch die Breite ihrer Methoden aus. Im soziologischen Methodenrepertoire seien nicht nur Logik, Beobachtung, Experiment und Klassifikation enthalten, sondern zudem der historische Vergleich. Damit sei die Soziologie dazu imstande, Gegenstände, die lange Zeit der Theologie und Metaphysik vorbehalten waren, wie auch das Soziale, zum Gegenstand positiver Beobachtung und rationaler Planung zu machen. Comte hat also eine Konvergenz der Entwicklung von Erkenntnis und Gesellschaft erkannt und damit die Soziologie als positive Wissenschaft bestimmt. Naturwissenschaftliches Denken integriert er in die Sozialwissenschaften. Eine sozialstrukturelle Besonderheit des positiven Stadiums oder auch positivistischen Zeitalters ist weiterhin das Entstehen der durch wissenschaftliche Organisation der Arbeit gekennzeichneten Industriegesellschaft (Bock, 2007; Bock, 2006; Endruweit, 2001; Fuchs-Heinritz, 2007, S. 17; Knoblauch, 2014, S. 40 f.; Maasen, 2012, S. 17):

Die Gründung der Soziologie durch ihn, Auguste Comte, ist nicht irgendein zufälliger Einfall [. . . ], sie ist schlicht ,,an der Zeit“. Es handelt sich um eine Art wissenssoziologischer Selbstbegründung für den Anspruch, daß die Soziologie gerade hier und jetzt die Führungsrolle unter den Wissenschaften und bei der Reorganisation der Gesellschaft übernehmen muss (Bock, 2006, S. 46).

Die wissenssoziologische Bedeutung der Phasenbildung nach Comte zeigt sich in zwei Aspekten: Zum einen in der Einschätzung von Denkweisen als historisch variable Größen; zum anderen im Bezug ihrer Entwicklung auf soziale Kategorien. Die in der Historizität des Wissens vorausgesetzte Gesellschaftlichkeit ist grundlegend für die Wissenssoziologie. Für den Übergang in das positive Stadium erachtet Comte eine Synthese des, wahren' Wissens als erforderlich; eine intellektuelle Elite in Gestalt der positiven Philosophie würde diese erarbeiten. Damit ist der von Comte begründete Positivismus als zentrales Bindeglied zwischen Ideologiekritik der Aufklärung und klassischer Wissenssoziologie zu begreifen (Fuchs-Heinritz, 2007, S. 17; Knoblauch, 2014, S. 42; Maasen, 2012, S. 16):

Der Kern seiner Soziologie ist mithin ein wissenssoziologischer: Denn das Ziel Comte'scher Ideologiekritik ist, alle „Hindernisse für das Positivwerden von Sozialwissenschaften und Gesellschaft wegzuräumen“ [ . . ] (Maasen, 2012, S. 16).

Die vorklassische Wissenssoziologie hat also zwei Themen verfolgt: Einerseits eine Analyse des Wissens der Gesellschaft, andererseits die Unterbreitung eines Vorschlags, wie die Gesellschaft zu ,wahrem' Wissen kommen und wie dieses ,wahre' Wissen des Weiteren eine die Gesellschaft formende Kraft entfalten kann: 
Sie hatte jeweils in der Gesellschaft wirksame Ideen, Gedanken, Glaubensüberzeugungen vor Augen - die christliche Überlieferung, die Ideale der bürgerlichen Revolution, die grundlegenden Kategorien der kapitalistischen Gesellschaft-, die nicht als (wahres) Wissen gelten sollten. Die vorklassische Wissenssoziologie war Wissenspolitik auch in ihren drei unterschiedlichen ,Stufen ', zunächst in der Kritik des Aberglaubens und der christlichen Überlieferung in den Anfängen der bürgerlich-modernen Gesellschaft (von Bacon bis d'Holbach), dann im Entwurf einer durch positive Wissenschaft gestalteten Industriegesellschaft (Saint-Simon und Comte), schließlich in der Grundlagenkritik der verwirklichten kapitalistischen Gesellschaft und dem Entwurf ihrer praktischen Überwindung (Marx). Und sie war dies sowohl in ihrer, fortschrittlichen' (d'Holbach, Marx) wie in ihrer ,konservativen' (Comte) Ausrichtung (Fuchs-Heinritz, 2007, S. 21).

\subsubsection{Klassische Wissenssoziologie der Moderne: Max Weber}

Wissenssoziologie wird meist mit ihren klassischen Vertretern, Scheler und Mannheim, gleichgesetzt. Jedoch sind bereits Klassiker der Soziologie, wie Durkheim oder Weber, wissenssoziologischen Fragestellungen nachgegangen, die damals allerdings noch nicht als solche bezeichnet wurden; sie haben mitunter von einer ,Soziologie der Erkenntnis" gesprochen. Die Klassiker der Soziologie haben die Moderne aber nicht nur analysiert, sondern entscheidend geprägt; mit ihren Diagnosen haben sie zum Selbstverständnis ihrer Gesellschaft als einer modernen beigetragen. Die Entwicklung der Soziologie als Wissenschaft und die Ausbreitung der Moderne waren eng verwoben. Daher ist auch die Wissenssoziologie nicht ohne die Theorien soziologischer Klassiker zu begreifen. In ihrem weiteren Verlauf thematisiert diese Arbeit die klassische Wissenssoziologie der Moderne: Max Weber (1864-1920), indem eine für die Moderne ausschlaggebende Theorie Eingang findet, die ebenso einen wesentlichen theoretischen Moment für die gesamte Wissenssoziologie bedeutet (Kaesler, 2006e; Knoblauch, 2014, S. 65; Müller, 2006): ${ }^{15} 16$

15 Émile Durkheim (1858-1917) hat die französische Soziologie begründet sowie der soziologischen Wissenschaft ihren Namen gegeben. Als Klassiker der Soziologie beschäftigte er sich mit der Beziehung von Wissen und Sozialstruktur und hat so die Entwicklung der deutschen Wissenssoziologie maßgeblich beeinflusst. Durkheim gilt als Vertreter der soziologischen Erkenntnistheorie; Wissen begriff er nicht als Resultat psychischer, sondern als Ausdruck sozialer Vorgänge. Er reihte sich nicht in die verstehende Soziologie ein, sondern blieb der positivistischen Tradition verhaftet. Siehe zum Beispiel: Egger, 2007; Fuchs-Heinritz, 2008; Hofmann, 2001; Knoblauch, 2014, S. 65 ff.; Maasen, 2012, S. 19 f.; Müller, 2007a, 2007b, 2007c, 2006; Neu, 2001; Striebeck, 2001.

${ }^{16}$ Den expliziten wissenssoziologischen Anfang hat Max Scheler (1874-1928) gemacht; sein Beitrag hat Mannheim entscheidend beeinflusst. Gemeinsam gelten die beiden als Begründer der Wissenssoziologie und deren deutsche Klassiker. Mit Religion, Metaphysik und Wissenschaft unterschied auch Scheler, wie Comte, drei „Hauptformen des Wissens“, argumentierte 
In den ersten 30 Jahren des 20. Jahrhunderts formiert sich vor allem in Deutschland eine Wissenssoziologie aus der Erkenntnis, dass prinzipiell alles Wissen (das falsche und das wahre Bewusstsein) gesellschaftlich bedingt ist (Maasen, 2012, S. 18, Hervorheb. i. O.).

Im Folgenden wird ein Einblick in die Theorie Webers als bedeutendem Klassiker der Soziologie gewährt. Auch dies geschieht hinsichtlich der für diese Studie bedeutsamen Wissenssoziologie von Mannheim, indem vor allem jene theoretischen Elemente von Weber behandelt werden, die Mannheims Wissenssoziologie beeinflusst haben.

Weber gilt als einer der bedeutendsten Gründungsväter der Soziologie in Deutschland, zugleich als internationaler soziologischer Klassiker. Er hat einen erheblichen Beitrag zur Konzeption der Wissenssoziologie geleistet: durch seine religionssoziologische Forschung, mit seinen methodologischen Überlegungen und über die methodische Umsetzung seiner historisch-vergleichenden Analysen. Entsprechende Aspekte sind in Webers Arbeiten jedoch eher implizit vorhanden, weswegen seine wissenssoziologische Relevanz oft verborgen bleibt (Endreß, 2007b, S. 42 ff.; Kaesler, 2006a, 2006b, 2006c, 2006d; Knoblauch, 2014, S. 74; Oesterdiekhoff, 2001; Steiner, 2001):

\begin{abstract}
Webers Forschung steht vor dem Hintergrund eines Methodenstreits, der sich um die Wende zum 20. Jahrhundert insbesondere innerhalb der deutschen Soziologie abspielte und für die sich konstituierende Wissenssoziologie prägend werden sollte. Kontrahenten waren einerseits die Anhänger eines Positivismus im Gefolge Comtes auf der einen Seite und die Vertreter einer vom Historismus geprägten „,geisteswissenschaftlichen“ Position auf der anderen Seite. Waren die Positivisten [. . . ] der Meinung, die Wissenschaften sollten allesamt die Methoden der Naturwissenschaften anwenden [... ], war das zweite Lager gegensätzlicher Auffassung: Der Gegenstand der Sozial- und Geisteswissenschaften unterscheidet sich in ihren Augen grundlegend von dem der Naturwissenschaften. Deswegen bedürfen sie auch einer besonderen Methodologie. (Knoblauch, 2014, S. 74, Hervorheb. i. O.).
\end{abstract}

jedoch gegen den Positivismus. Er rückte den sozialen Charakter des Wissens oder vielmehr dessen ,soziale Konstitutionsbedingungen“ in den Fokus seiner Forschung. Für Scheler waren es ihre sozialen Träger, die gewisse Ideen zur Umsetzung bringen; er erkannte „,herrschende soziale Interessenperspektiven“ als Ursprung von Ideen. Die Wissenssoziologie begriff er als wichtiges politisches Instrument, das die Lösung ideologischer Konflikte durch Vermittlung und Zerstören falscher Vorurteile erlaubt. Siehe beispielsweise: Ernst, 2001, S. 593; Knoblauch, 2014, S. 90 ff.; Lichtblau, 2007, S. 364; Maasen, 2012, S. 21 ff.; Scheler, 1926; Schützeichel, 2007, S. 55 ff.. 
Die Erforschung sozialer Phänomene begriff die zweite, dem Historismus verpflichtete Perspektive zunächst als die ihre, eine geisteswissenschaftliche Aufgabe. Daher wird der Historismus auch als direkter Vorläufer der Wissenssoziologie betrachtet. Seine Prämisse lautete, dass die Gegenwart, also „das Gewordene“, in Verbindung mit der Vergangeheit und aus ihr heraus verstanden werden müsse. Geschichte begriff er nicht nur als einen Zusammenhang von Ideen. Dem Verständnis des Historismus nach trägt sie einen Sinn in sich. Daher müssten singuläre Ereignisse und nicht Gesetze der Gegenstand wissenschaftlicher Erkenntnis sein. Alle Tatsachen, auch wissenschaftliche, seien als historische Phänomene anzusehen. Da diese die Beteiligung der Handelnden beinhalteten, lieBen sie sich nur verstehen, nicht aber erklären (Berger, \& Luckmann, 1966/2009, S. 7; Knoblauch, 2014, S. 75).

Anhand dieses Einblicks in den Historismus wird deutlich, dass sich in diesem nicht nur die Wissenssoziologie abzeichnet, sondern damit einhergehend auch die Konzeption empirischer Sozialforschung in ihrer qualitativen Ausprägung in Abgrenzung zum Positivismus. Qualitative Sozialforschung verfolgt die Rekonstruktion von Sinn durch Deutung oder Interpretation und ermöglicht dadurch Verstehen; Letzteres kann jedoch nur durch Einbezug des gegebenen Kontexts gelingen. Zu Zeiten Webers wurde der Historismus zwar heftig kritisiert, war für ihn selbst aber dennoch oder auch gerade deswegen elementar, mitunter als Gegenposition zum Positivismus. Zwar hat er die Gesellschaft nie als „objektives System" begriffen, jedoch eingestanden, dass es nicht ausreiche, sie zu verstehen, sondern dass die Soziologie als Wissenschaft Gesellschaft auch erklären müsse (Kaesler, 2006d; Knoblauch, 2014, S. 79; Meurer, 2001):

Um das Handeln der Menschen erklären zu können, müssen wir verstehen, welchen geistigen Vorgaben sie folgen, also welchen Sinn sie verfolgen. Das ist das Grundprinzip seiner verstehenden Soziologie (Knoblauch, 2014, S. 80, Hervorheb. i. O.).

Webers verstehende Soziologie ist durch die von ihm konzipierten soziologischen Grundbegriffe ,soziales Handeln“ und ,subjektiv gemeinter Sinn“ bestimmt. Weber begreift soziales Handeln als den Objektbereich der Soziologie und subjektiv gemeinten Sinn als ihr Zentrum (Kaesler 2006a, 2006c; Meurer 2001; Steiner 2001):

„Soziales“ Handeln aber soll ein solches Handeln heißen, welches seinem von dem oder den Handelnden gemeinten Sinn nach auf das Verhalten anderer bezogen wird und daran in seinem Ablauf orientiert ist (Weber, 1921/1972, S. 1, Hervorheb. i. O.). 
Weiterhin prägt Weber die Soziologie maßgeblich als eine eigenständige Disziplin und beschreibt sein Konzept der ,verstehenden Soziologie“ in methodischer oder auch methodologischer Hinsicht:

Soziologie [. . . ] soll heißen: eine Wissenschaft, welche soziales Handeln deutend verstehen und dadurch in seinem Ablauf und seinen Wirkungen ursächlich erklären will (Weber, 1921/1972, S. 1).

Die verstehende Soziologie nach Weber ist also eine ,empirische Soziologie des Sinn-Verstehens“ von sozialem Handeln. Von einem ,kausalanalytischen Vorgehen“" ist diese jedoch nicht zu trennen:

„Sinn“ wird verstanden als bestimmender Faktor menschlichen Handelns. Daraus
ergibt sich als Folgerung für jede wissenschaftliche Analyse menschlichen Handelns,
diesen Sinn in dessen Erklärung miteinzubeziehen. Auch der (vermeintlich), ,subjek-
tive“ Sinn ist ein sozialer, d. h. ein gegenseitig und an Ordnungen orientierter und
vermittelter (Kaesler, 2006c, S. 457).

Weber betont ferner die ,Konstruiertheit' des durch die verstehende Soziologie aus dem sozialen Handeln anhand von Deutungen und Interpretationen abgeleiteten subjektiv gemeinten Sinns:

Stellt der Begriff des „Sinns“ die entscheidende inhaltliche Kategorie des Weberschen Handlungsbegriffs dar, so steht das Konzept des „Verstehens“ im Zentrum seiner Methodologie. Da der „gemeinte Sinn“ eines Handelns „verstanden“ werden soll, entspricht die Differenzierung des Verstehens der des Sinns. „Verstehen“ bedeutet demnach „deutende Erfassung“ (Kaesler, 2006a, S. 442).

Dieses elementare Prinzip seiner verstehenden Soziologie findet sich auch in Webers Handlungstheorie, die implizit wissenssoziologische Annahmen aufweist. Er benennt vier Handlungstypen: (1) ,zweckrationales Handeln“ oder ,zielgerichtetes Handeln“, (2) ,wertrationales Handeln“, (3) „traditionales Handeln“, (4) ,affektuelles Handeln“. Weber unterscheidet diese Handlungstypen nach Wissensarten, assoziiert also soziales Handeln mit Wissen, das die Voraussetzung für dieses Handeln ist. Sein Ansinnen war es mitunter zu zeigen, dass Wissen nicht nur von der Wirtschaft determiniert wird, also das Ideelle nicht bloß die materiellen Verhältnisse widerspiegelt. Er hatte erkannt, dass das Wissen selbst das wirtschaftliche Handeln beeinflusst. Zum einen passt die handlungstheoretische Vorgehensweise von Webers verstehender Soziologie nicht zum Idealismus einer 
reinen, ausschließlich auf Verstehen zielenden Geisteswissenschaft, zum anderen widerspricht sie einem materialistischen Gesellschaftsbild. Webers Ansatz zeichnet sich durch seine Annahme eines, ,wechselseitigen Wirkungszusammenhangs" von institutionellen Prozessen mit Deutungsprozessen aus (Endreß, 2007b, S. 42 f.; Kaesler, 2006a; Knoblauch, 2014, S. 80 f.; Steiner, 2001; Weber, 1921/1972):

Webers verstehender Soziologie geht es somit darum, die Wirkung institutioneller Prozesse auf menschliche Ideen, Werte und Glaubensüberzeugungen und umgekehrt $\mathrm{zu}$ untersuchen und entsprechende geschichtliche Umwandlungen als Vorbedingungen für die Entwicklung unterschiedlicher Typen moderner Gesellschaften zu begreifen (Endreß, 2007b, S. 42).

Er rekurriert durchweg auf Ideen, die dem Wissen der Handelnden angehören, also soziales Handeln von und zwischen Menschen pragmatisch beeinflussen. Ideen nimmt Weber als konstitutiv für die soziale ,Realität' an; Handlungsprozesse, Prozesse der Vergesellschaftung und historische Entwicklungsprozesse sind für ihn durch Ideen geprägt. Im Fokus seiner Untersuchungen steht daher der Zusammenhang von sozialer ,Wirklichkeit" und Wissen, wozu er deutendes Erkennen, Verstehen, Bewerten zählt. Indem Weber seine verstehende Soziologie methodisch so konzipiert hat, dass die Untersuchung von sozialer ,Wirklichkeit' stets in sozio-ökonomischer, -politischer und -kultureller Hinsicht geschehen muss, zeigt sich ihre wissenssoziologische Bedeutung. Soziale ,Realität' analysiert Weber auf Basis der Interdependenz von Kultur, Herrschaft und Wirtschaft (Endreß, 2007b, S. 43 ff.).

Mit der Beziehung von Ideen und ,Wirklichkeit' setzt Weber sich konkret am Beispiel der Religion auseinander. Seine Religionssoziologie ist für die Wissenssoziologie vor allem aufgrund der Frage nach dem Zusammenhang von „protestantischer Ethik“ mit dem „Geist des Kapitalismus“ relevant. Er hat die Wirtschaftsethik der Weltreligionen verglichen, um die Entwicklung des Westens hin zur rationalisierten Kultur, die er „Entzauberung“ nennt, zu erklären (Endreß, 2007b, S. 44 ff.; Kaesler, 2006b, 2006d; Knoblauch, 2014, S. 84 f.; Oesterdiekhoff, 2001): ${ }^{17}$

${ }^{17}$ In Bezug auf Webers Religionssoziologie siehe: Endreß, 2007b, S. 47 ff.; Kaesler, 2006b; Knoblauch, 2014, S. 81 ff.; Oesterdiekhoff, 2001; Weber, 1921/1972. 
Für Weber sind die Prozesse der Wirkung von Ideen auf das Handeln von Individuen und Gruppen nicht gesteuert von „Sachzwängen“ oder „historischen Gesetzen“, sondern immer sind es handelnde Menschen, die diese Prozesse in Gang setzen. Andererseits entstehen die subjektiven Sinndeutungen der Handelnden immer auf der Folie materieller Zusammenhänge. Soziale Wirklichkeit wird von Weber als eine von Handelnden beeinflußbare und konstruierte gesehen, sie tritt diesen gleichzeitig als Bedingung und Begrenzung ihrer Handlungsmöglichkeiten gegenüber (Kaesler, 2006b, S. 450).

Weber erkannte im Verhältnis von Ideen zu sozialen Trägern eine Korrelation; beide Aspekte verband er in der Lebensführung und im Handeln. Nach Weber beruht auch die Art der Tätigkeiten, die soziale Träger ausüben, auf deren sozialer Lage. Soziale Gruppierungen hätten bestimmte Vorstellungen im Sinne kultureller Deutungsmustern. Die Dynamik historischer Prozesse werde weniger durch Ideen als solche geprägt als von auf diesen beruhenden Weltbildern und der durch sie geprägten Interessendynamik sozialer Gruppen (Endreß, 2007b, S. 46).

Zusammengefasst besteht Webers Diagnose im Prozess der zunehmenden, universalen Rationalisierung moderner Gesellschaften. Darunter subsumiert er sowohl Prozesse der Bürokratisierung als auch der Spezialisierung und Strukturierung von Wissen. Immer mehr Lebensbereiche würden den metaphysischen und religiösen Deutungen entzogen und der Systematisierung, Beobachtung und Kontrolle unterworfen. So komme es zu einer steigenden zweckrationalen Kontrolle von Natur, Gesellschaft und Kultur. Die von ihm diagnostizierte Entwicklung bewertet Weber nicht nur als positiv. Zugleich fürchtet er das Entstehen einer Gesellschaft, die alle Aspekte des menschlichen Lebens nüchtern kontrolliert und nur noch aus Fachmenschen mit Sonderwissen ohne transzendente Tiefe bestehe. Doch auch wenn die Rationalisierung bedenklich sei, schaffe erst sie ein Wissen, das keinen Glauben mehr benötige (Kaesler, 2006b, 2006c, 2006d; Knoblauch, 2014, S. 89 f.; Meurer, 2001).

Wie nahezu jede Theorie enthält auch Webers Werk Leerstellen. Dennoch ist es ihm mit seinen religionssoziologischen Untersuchungen in methodischer und methodologischer Hinsicht gelungen, eine für die Wissenssoziologie ausschlaggebende Analyse sozialer Wissensgenese vorzulegen. Webers Soziologie zeichnet sich durch die „Vermittlung von Individuum und Gesellschaft“ aus (Endreß, 2007b, S. 52 f.; Kaesler, 2006d): 
Für Weber ist das eine ohne das andere nicht denkbar und erklärbar. Wir sehen im Werk Max Webers jene intermediäre und reflexive Vermittlung angelegt, die von einer gesellschaftlichen Konstruktion der Wirklichkeit ausgeht, in der das Individuum zum einen einer ihm gegenüberstehenden „objektiven“ Wirklichkeit begegnet, die es zum anderen ,subjektiv“ verändern und mitbestimmen kann. Die ,subjektive“ Sinngebung ist keine Residualgröße gesellschaftlicher Wirklichkeit, sondern konstitutives Element für deren Entstehung und Veränderung. Damit wird die Erfassung sowohl der „subjektiven“ Sinnsetzung als auch der „objektiven“ gesellschaftlichen Wirklichkeit zur eigentlichen Aufgabe einer Soziologie im Sinne Max Webers (Kaesler, 2006d, S. $210 \mathrm{f}$.).

Damit schließt diese Arbeit ihre Darstellung der klassischen Wissenssoziologie der Moderne. Würde deren Chronologie entsprochen werden, dürfte an dieser Stelle erst die wissenssoziologische Konzeption Mannheims folgen. Wegen deren Bedeutung für diese Forschungsarbeit ist diese jedoch bereits zuvor thematisiert worden. Mit dem nächsten Abschnitt erfolgt ein Übergang in eine weitere Phase der Wissenssoziologie und damit, von Mannheim aus betrachtet, zugleich ein großer Zeitsprung in die Zukunft. ${ }^{18}$

\subsubsection{Sozialkonstruktivistische Wissenssoziologie bis heute}

Bereits ab den 1940er und 1950er Jahren, mit Nachdruck aber vor allem in den 1960er Jahren erlebte die Wissenssoziologie mehrere Differenzierungen und Schulenbildungen:

Zum einen dringt die Wissenssoziologie in immer weitere Spezialsoziologien und in die allgemeine soziologische Theorie ein, zum anderen wird sie von einer konstruktivistischen Wende ergriffen. Interpretative, poststrukturalistische, netzwerk- und systemtheoretische Ansätze beobachten mit verschiedenen Konzepten „die gesellschaftliche Konstruktion von Wissen" - und dies schließt nun auch die Konstruktion wissenschaftlichen Wissens ein. Ein weiteres Merkmal ist: Insgesamt werden die Ansätze empirischer und legen zunehmend spezialisierte Methoden vor (Maasen, 2012, S. 31).

${ }^{18}$ Etliche weitere theoretische Überlegungen, wie die Kritische Theorie, hätten in diese Forschungsarbeit aufgenommen werden können. Sie vermag jedoch bloß, die für ihre eigene theoretische und empirische Konzeption sowie die Interpretation ihrer Ergebnisse relevanten wissenssoziologischen Abhandlungen vorzustellen. Doch sei noch erwähnt, dass die europäische Wissenssoziologie mit der Emigration vieler Wissenschaftler zwischenzeitlich ihren Weg in die USA nahm, dem dort vorherrschenden Pragmatismus begegnete, entsprechend geprägt wurde und sich als Chicago School of Sociology und Symbolischer Interaktionismus ausdifferenzierte. 
Von der Vielzahl der so entstandenen wissenssoziologischen Konzeptionen ist für diese Forschungsarbeit insbesondere die phänomenologisch orientierte Wissenssoziologie in ihrer sozialkonstruktivistischen Ausprägung relevant. Daher wird die Wissenssoziologie der Gegenwart über die Theorien von zunächst Alfred Schütz sowie daran anschließend von Berger und Luckmann vorgestellt, die allesamt noch immer in die heutige Zeit hineinwirken und die aktuelle Forschung nach wie vor maßgeblich prägen. Ihren Endpunkt, zumindest im theoretischen Kontext dieser Forschungsarbeit, findet die Sozialkonstruktivistische Wissenssoziologie bis heute in der von Oliver Dimbath und Reiner Keller (2017) in einem gemeinsamen Aufsatz behandelten Frage nach der Wissenssoziologie der Gegenwart.

Wie es in dieser Arbeit zuvor bereits mit anderen Theorien geschehen ist, werden auch die wissenssoziologischen Konzeptionen von Schütz sowie Berger und Luckmann nur in ihrer relevanten Quintessenz betrachtet. Es wurde schon mehrfach angemerkt, dass neben der Wissenssoziologie Mannheims insbesondere dem Ansatz von Berger und Luckmann herausragende Bedeutung zukommt. Die Theorie Mannheims ist vorrangig im Hinblick auf die Interpretation und Deutung der gewonnen Forschungsergebnisse relevant, die von Berger und Luckmann vor allem als wissenssoziologische Theorie, die die empirische Umsetzung des Forschungsprojekts rahmt. Die sozialkonstruktivistische Wissenssoziologie wird daher aufgrund ihrer theoretischen Relevanz für die empirische Umsetzung des in dieser Arbeit dargelegten Forschungsprojekts, jedoch auch wegen ihrer Bedeutsamkeit in der wissenssoziologischen Entwicklung bis in die Gegenwart thematisiert. Allerdings wird damit an dieser Stelle nicht bereits ausgeschlossen, dass in den phänomenologisch orientierten Wissenssoziologien in sozialkonstruktivistischer Ausprägung auch Aspekte enthalten sind, die der Auslegung der Forschungsergebnisse zuträglich sein können. ${ }^{19}$

Bevor nun auf die wissenssoziologischen Konzeptionen von Schütz sowie Berger und Luckmann eingegangen wird, sei noch erwähnt, dass die phänomenologisch orientierte Wissenssoziologie ihren Ausgang in der von Edmund Husserl (1859-1938) begründeten phänomenologischen Philosophie genommen hat:

${ }^{19}$ Helmuth Plessner (1966/2009) behandelt in seinem Vorwort zu Bergers und Luckmanns Werk Die gesellschaftliche Konstruktion der Wirklichkeit. Eine Theorie der Wissenssoziologie (1966/2009), den wesentlichen Unterschied zu der wissenssoziologischen Konzeption Mannheims. So sei die mitunter von Mannheim begründete Wissenssoziologie der 1920er und 1930er Jahre eine „,Theorie des schlechten Gewissens gegenüber Marx“ und dessen „,radikalen Ideologieverdachts“; diese habe den Vorwurf der „Interessengebundenheit des Wissens“ und dessen darauf beruhende ,genuin ideologische Verfälschung“ thematisiert. Im Gegensatz zu der „Immunisierung gegen Marx“, die Mannheim anvisiert, zielen Berger und Luckmann darauf, die Wissenssoziologie für die Untersuchung aller potentieller Betrachtungsweisen der Welt zu befähigen (Plessner, 1966/2009, S. XI ff.). 
Im Unterschied zum verbreiteten Begriff der Phänomenologie, der häufig die Einteilung von Phänomenen aufgrund ihrer oberflächlichen Erscheinung bezeichnet, hat Husserl eine strenge Methode im Sinne, mit der die Voraussetzungen für Erfahrungen, die in Erfahrung gemachten Phänomene und das damit verbundene Wissen erforscht werden sollen. Im Vordergrund stehen dabei die willkürlichen und vor allem die unwillkürlichen Bewusstseinsaktivitäten und ihr Beitrag zu dem, was wir als erfahrbar, wirklich und seiend betrachten. Husserls Phänomenologie war wie ein Paukenschlag, der die moderne Philosophie [. . . ] entscheidend prägte und noch immer nachhallt (Knoblauch, 2014, S. 141).

\subsubsection{Alfred Schütz}

Alfred Schütz (1899-1959) hat die phänomenologische, auf der Philosophie Husserls beruhende Methode in die Soziologie eingeführt, mit wesentlichen Elementen der US-amerikanischen pragmatischen Wissenssoziologie verknüpft und somit letztlich deren sozialphänomenologische Grundlegung geschaffen. Indem Schütz Sinn und Handeln verband, hat er eine ,,integrative“ Wissenssoziologie verfolgt. Diese hat er vor allem in zahlreichen Aufsätzen, beispielsweise in Gesammelte Aufsätze I. Das Problem der sozialen Wirklichkeit (1971), aber auch in zwei Hauptwerken entfaltet: Zum einen in seiner Monographie Der sinnhafte Aufbau der sozialen Welt. Eine Einleitung in die verstehende Soziologie (1974/2016); zum anderen in seiner Arbeit Strukturen der Lebenswelt (1979\&1984/2003), die allerdings erst Luckmann postum anhand von Manuskripten, die Schütz hinterlassen hatte, ausgearbeitet und publiziert hat (Endreß, 2006a, 2006b; Keller, 2012, S. 175 ff.; Knoblauch, 2014, S. 141 f., 2007, S. 118; Schnettler, 2007, S. 102 f.; Schütz, 1974/2016, 1971; Schütz, \& Luckmann, 1979\&1984/2003; Schwab-Trapp, 2001; Soeffner, 2006):

[. . . ] Schütz und der phänomenologisch orientierten Wissenssoziologie geht es um die grundlegende Verknüpfung von Wissen und Handeln. Sinn und Handeln bilden für Schütz eine untrennbare Einheit, die der Wirklichkeit zugrunde liegt und Ausgangspunkt für den ,sinnhaften Aufbau der sozialen Welt“ ist [. . . ]: Sinn ist, was Handeln leitet, orientiert und ein Verhalten erst als Handeln auszeichnet. Wissen ist also nichts der Handlung Äußerliches, sondern konstitutiv für Handeln (Knoblauch, 2014, S. 142).

Den wesentlichen Brückenschlag zur Soziologie vollzieht Schütz mit Webers Definition des sozialen Handelns. Über eine Beantwortung der Frage, was ,typologisch geordneter Sinn" bedeutet, beabsichtigt Schütz Webers verstehende Soziologie sozialtheoretisch zu fundieren (Endreß, 2006a, 2006b; Keller, 2012, S. 179; Knoblauch, 2014, S. 142 f.; Knoblauch, 2007, S. 119; Schnettler, 2007, S. 103 f.; Schwab-Trapp, 2001): 
Wie ist es überhaupt im Alltag möglich, den Sinn, den andere mit ihrem Handeln verbinden, zu verstehen? Und wie kann das „Verstehen“ gleichzeitig zu einer wissenschaftlichen Methode werden? Der Schlüssel zur Beantwortung dieser Frage liegt für Schütz in der Erklärung der Art und Weise, wie im Einzelbewusstsein so etwas wie „Sinn“ aufgebaut (konstituiert) wird und wie schon der Alltagsmensch von da aus darauf schließen kann, dass es neben ihm andere menschliche Wesen gibt, die in vergleichbarer Weise „Sinn“ verwenden (Keller, 2012, S. 179, Hervorheb. i. O.).

Entsprechend konzipiert Schütz eine Theorie über das sinnhafte „Funktionieren“ des sozialisierten Bewusstseins. Zum einen soll aufgedeckt werden, wie die Konstitution der Intentionalität menschlichen Verhaltens über individuelles Bewusstsein vonstattengeht; zum anderen geht es darum, in welcher Beziehung sich „Selbstverstehen“ und „Fremdverstehen“ befinden beziehungsweise worin „Intersubjektivität“ gründet. Schütz geht mitunter von der Annahme aus, dass subjektives Bewusstsein seit jeher in sozialen, intersubjektiven Zusammenhängen, einer „Lebenswelt“ existiert. Von herausragender Bedeutung in Schütz' Theorie ist der Begriff „Sinn“. Da sich das Bewusstsein stets auf etwas bezieht, gilt Schütz die Intentionalität als dessen Konstitutionsmerkmal. Er erkennt die grundlegende Struktur von Sinn als eine Relation zu etwas und führt auf diese Weise Bewusstseinsinhalte auf einen sozialen Ursprung zurück (Endreß, 2006a, 2006b; Keller, 2012, S. 180 ff.; Schnettler, 2007, S. 104 ff.):

Deswegen wird Sinn Schütz zufolge zwar im Einzelbewusstsein aufgebaut [... ], aber er ist seinem Wesen nach immer sozialer Sinn [. . . ]. Sinn macht unspezifische Erlebnisse zu spezifischen, aber sinnhaften Erfahrungen, die sich im Bewusstsein ablagern. [. . . ] Das „Ich“ greift im Rahmen seiner „,natürlichen Weltanschauung“ auf individuelles und kollektives Wissen und Vorwissen zurück, um solchermaßen sein Erleben in sinnhafte Erfahrung und sinnhaftes Handeln zu verwandeln (Keller, 2012, S. 185, Hervorheb. i. O.).

Sinn wird, so Schütz' Erkenntnis, im subjektiven Bewusstsein unter Rückgriff auf Deutungsschemata konstituiert (Keller, 2012, S. 195); diese erzeugen eine Ordnung:

Dem natürlichen Menschen sind nun seine Erfahrungen [. . . ] ,geordnet “ vorgegeben, wie ihm die ganze gegenständliche Welt geordnet vorgegeben ist [. . . ]. Wir wollen die Ordnungen, in welche sich der jeweilige Erfahrungszusammenhang gliedert [... ], Schemata unserer Erfahrung nennen und diesen Begriff wie folgt definieren: Ein Schema unserer Erfahrung ist ein Sinnzusammenhang unserer erfahrenen Erlebnisse [. . . ] (Schütz, 1974/2016, S. 108 f., Hervorheb. i. O.). 
Der Prozess der Einordnung von Erlebnissen unter Schemata der Erfahrung vollzieht sich, so Schütz weiter, durch die Interpretation oder Deutung dieser Erlebnisse:

Deutung ist dann nichts anderes als Rückführung von Unbekanntem auf Bekanntes, von in Zuwendungen Erfaßtem auf Schemata der Erfahrung. Diesen kommt also beim Prozeß des Deutens der eigenen Erlebnisse eine besondere Funktion zu. Sie sind die fertigen in der Weise des Wissens (Vorwissens) jeweils vorrätigen Sinnzusammenhänge zwischen kategorial vorgeformten Material, auf welches das zu deutende Erlebnis in einem neuen synthetischen Akt rückgeführt wird. Insoferne sind die Schemata der Erfahrung Deutungsschemata [. . . ] (Schütz, 1974/2016, S. 112, Hervorheb. i. O.).

Deutungsschemata selbst bestehen laut Schütz vor allem aus Sprache, so dass ihr eine zentrale Rolle zukommt. Schütz interessiert insbesondere die durch Intersubjektivität, Interaktion und Zeichenhaftigkeit realisierte Wissensvermittlung; er macht Sprache als deren zentrales Medium sowie als wichtigstes Zeichensystem von Gesellschaften aus. Ferner erkennt er, dass Subjekte durch das Vergleichen von Objekten in Bezug auf deren Ähnlichkeiten und Unterschiede durchweg Typisierungen vornehmen. Auch die Deutungsschemata, mit denen Erlebnisse belegt und zu Erfahrungen gemacht werden, sind als Typisierungen anzusehen (Endreß, 2006a, 2006b; Keller, 2012, S. 186, S. 195; Knoblauch, 2014, S. 143 f.; Knoblauch, 2007; S. 120 f.; Maasen, 2012, S. 32 f.):

Typisierungen von Erfahrungen sind [. . . ] so etwas wie Elementarformen des Wissens [. . . ]. Typisierungen sind nicht bewusste Klassifikationen. Ihr wesentlicher Kern besteht darin, dass sie Aspekte aktueller Erfahrungen mit Aspekten vergangener Erfahrungen so in Beziehung setzen, dass Ähnlichkeiten hervorgehoben werden - ein Vorgang, den das Bewusstsein großteils automatisch vollzieht. [. . . ] Typisierungen und Relevanzen bilden die Vorstufen des Wissens (Knoblauch, 2014, S. 143 f.).

Die „Lebenswelt“ setzt sich aus den Erfahrungsräumen des subjektiven Bewusstseins zusammen. Es handelt sich um eine Welt subjektiven Erfahrens, die neben eigenen Erfahrungen auch immer vermittelte Erfahrungen anderer umfasst. Schon die subjektive "Lebenswelt" eines singulären Bewusstseins besteht aus verschiedenen Erfahrungen. Diese durchlebbaren Erfahrungswelten nennt Schütz „mannigfaltige Wirklichkeiten“. Jedoch erklärt er, dass, obwohl nicht alle Erfahrungen eigene „Wirklichkeiten“ sind, auch darin sinnhafte Erfahrungen gemacht werden und damit Wissen erworben wird. Den verschiedenen „Wirklichkeiten“ komme auch eine unterschiedliche Bedeutung zu (Endreß, 2006a, 2006b; Knoblauch, 2014, S. 149; Knoblauch, 2007, S. 120 f.; Maasen, 2012, S. 32 f.; Schnettler, 2007, S. 106 ff.): 
Denn in unserem Bewusstsein ragt eine Wirklichkeit heraus, die man als Alltag genauer: Lebenswelt des Alltags bezeichnet. In ihr befinden wird uns, wenn wir uns handelnd und vor allem wirkend zur Welt verhalten. [. . . ] Die Lebenswelt des Alltags ist deswegen die Welt, in der wir mit anderen verkehren, also sozial handeln und kommunizieren. [. . . ] Der Umstand, dass unsere Lebenswelt nicht nur pragmatisch ist, sondern kommunikativ und sozial, hat tief greifende Auswirkungen auf unser Wissen: Denn wenn Wissen auch immer von einem Bewusstsein konstituiert werden muss, so muss es sich nicht um das eigene Bewusstsein handeln. Wissen kann indirekt von anderen erworben werden. In der Tat ist das meiste Wissen, über das wir empirisch verfügen, ,,sozial abgeleitet“: Vieles, von dem, was wir wissen, haben wir nicht selbst erfahren (Knoblauch, 2014, S. 149 f.).

Schütz hat mit seiner „Theorie der Lebenswelt“ nicht nur das theoretische, sondern auch das methodologische Verständnis der Sozialwissenschaften nachhaltig verändert. Sie gilt als Grundlegung der ,handlungsanalytischen, sinnrekonstruktiven Soziologie" und orientiert hermeneutisch-interpretative Verfahren der Sozialforschung in erheblichem Ausmaß noch bis heute. In methodologischer Hinsicht geht es ihm um die Fundierung Webers verstehender Soziologie; darauf zielt seine Erforschung der „Sinnkonstitution im Einzelbewusstsein“. Schütz führt dies in seiner „Theorie des Fremdverstehens als Projektion des Selbstverstehens“ aus. Beständige Prozesse des „Sinnverstehens“ sind für ihn das Merkmal der intersubjektiven „Lebenswelt“ des Alltags. Alltagsweltliches und sozialwissenschaftliches „Sinnverstehen“ beruhen letzten Endes auf den gleichen Prinzipien; jedoch interessiert Schütz sich nicht nur für deren Ähnlichkeit, sondern fragt ebenso nach den Unterschieden dieser beiden Prozesse (Endreß, 2006a; Keller, 2012, S. 182, S. 201; Schnettler, 2007, S. 109 f.):

Das sozialwissenschaftliche Verstehen unterscheidet sich nämlich durch die ,wissenschaftliche Einstellung “von den Verstehensprozessen des Alltags. Vereinfacht gesagt, besteht es in einem systematischen Erkunden von Sinnzuschreibungen. Es greift dabei auf unterschiedliche Mittel zurück, die wir im Alltag zumindest in systematisierter Form nicht einsetzen. [. . . ] Schütz insistiert darauf, dass sozialwissenschaftliche Erklärungen „Konstruktionen zweiter Ordnung“ sind, die auf den alltagsweltlichen „Konstruktionen der ersten Ordnung“ aufbauen (müssen). Die Soziologie müsse hier im Wesentlichen auf Typkonstruktionen zielen [. . . ] (Keller, 2012, S. 201 f.). ${ }^{20}$

\footnotetext{
${ }^{20}$ Besondere Bedeutung für die phänomenologische Wissenssoziologie kommt Schütz' Aufsatz Der gut informierte Bürger (1972) zu, in dem er die gesellschaftliche Strukturierung des Wissens oder auch das Verhältnis von Interesse und Wissensverteilung beleuchtet. Eine Auseinandersetzung damit findet sich in: Maasen, 2012, S. 33 f.; Schnettler, 2007, S. 110 ff..
} 
Es bleibt festzuhalten, dass Schütz für die sozialphänomenologische Grundlegung der Wissenssoziologie einen wegweisenden Beitrag geleistet hat. Sein Einfluss offenbart sich vor allem in der von seinen Schülern Berger und Luckmann formulierten neuen Wissenssoziologie. Mit dieser haben sie die phänomenologische Sozialtheorie ihres Lehrers Schütz fortgeschrieben und zugleich einen entscheidenden Wendepunkt in der gesamten wissenssoziologischen Theorieentwicklung markiert (Endreß, 2006a, 2006b; Knoblauch, 2007, S. 118; Schnettler, 2007, S. 113; Schwab-Trapp, 2001).

\subsubsection{Peter L. Berger und Thomas Luckmann}

Eine, wenn nicht gar die bedeutsamste Folge der von Schütz hergestellten Verbindung von phänomenologischer Methode mit pragmatischer Wissenssoziologie besteht in der Etablierung der neoklassischen Wissenssoziologie durch Peter L. Berger und Thomas Luckmann (1929-2017 und 1927-2016) sowie der darauf beruhenden Perspektive des Sozialkonstruktivismus. Mit ihrem Werk Die gesellschaftliche Konstruktion der Wirklichkeit. Eine Theorie der Wissenssoziologie (1966/2009), das als Schlüsselwerk der weiteren wissenssoziologischen Entwicklung und inzwischen auch längst der allgemeinen Soziologie gilt, haben sie zwar unmittelbar an Schütz' Theorie angeschlossen, zugleich aber einen zentralen Meilenstein in der wissenssoziologischen Entwicklung geschaffen (Keller, 2012, S. 203, S. 228 f.; Knoblauch, 2014, S. 141 f., S. 153; Maasen, 2012, S. 34): ${ }^{21}$

Grundthema von Bergers und Luckmanns Werk ist die Frage, wie sich Typisierungen, also die die Sinnkonstitution im subjektiven Bewusstsein prägenden Deutungsschemata, in historisch gewachsenen Gesellschaften zu der sprachlichen Form eines komplexen, sozial geteilten und damit kollektiven Wissensvorrats verfestigen können; und ferner, wie Individuen sich diesen Wissensvorrat in Sozialisationsprozessen aneignen. Berger und Luckmann fragen danach, wie Menschen „objektive Wirklichkeit“ konstruieren und warum sie sich an dieser weitgehend fraglos orientieren (Keller, 2012, S. 203 ff.):

\footnotetext{
${ }^{21}$ In diesem Kapitel geht es um Bergers und Luckmanns Konzeption der Wissenssoziologie, insbesondere in Bezug auf die Entwicklung dieses soziologischen Teilgebiets. Bergers und Luckmanns Werk war vor allem für die empirische Untersuchung im Rahmen dieser Forschungsarbeit bedeutsam und wurde als deren wissenssoziologischer Theorierahmen herangezogen. Daher schließt auch an das hier vorliegende Kapitel ein Exkurs in den Sozialkonstruktivismus (4.1) an, um relevante Aspekte zu vertiefen. Bei dem Exkurs handelt es sich um eine Brücke von der Theorie zur Empirie bevor das Untersuchungsmaterial und das methodische Vorgehen (4) thematisiert werden.
} 
Die Sinnkonstitution im Bewusstsein und die Wissenskonstruktion in der intersubjektiven Lebenswelt des Alltags sind gewissermaßen zwei Seiten einer Medaille [. . . ]. Aber die letztere stellt den eigentlichen Gegenstand einer sozialphänomenologisch fundierten sozialkonstruktivistischen Wissenssoziologie dar (Keller, 2012, S. 203, Hervorheb. i. O.).

In ihrem „theorieintegrativen“ Werk haben Berger und Luckmann bereits etliche Jahre vor den heute in der Soziologie geführten Diskussionen betont, dass Gesellschaften mitsamt ihren „folgenreichen Wirklichkeitssichten“ in einem kontinuierlichen Prozess ,konstruiert' werden. Um den Ansatz von anderen wissenssoziologischen Konzeptionen abzugrenzen, hat sich die Bezeichnung „sozialkonstruktivistische Wissenssoziologie“ etabliert; mitunter wird dieser allerdings auch als ,,sozialphänomenologischorientierte Wissenssoziologie“ oder ,,neue Wissenssoziologie" bezeichnet (Keller, 2012, S. 203 f.).

\begin{abstract}
Berger und Luckmann verstehen [. . . ] ihre Theorie als strikt realistischen Ansatz, der [.... ] erklärt, wie die Prozesse verlaufen, durch die das, was wir als wirklich wahrnehmen, historisch vorgebracht werden. Die entsprechenden Konstruktionsprozesse sind nicht so zu verstehen, als handele es sich dabei um kurzfristige, dezionistische, kontrollierte oder gar konsensuell abgestimmte Akte oder „Setzungen“ dessen, das von nun an als ,wirklich“ zu gelten habe. Solchen Vorstellungen mögen fiktionale Literaturen oder diktatorische Regime vielleicht nahekommen. Der Begriff der Konstruktion weist vielmehr auf längerfristige geschichtliche Prozesse hin, in denen Menschen in ihrem Zusammenhang und in Auseinandersetzung mit Vorgefundenem die Sinnordnungen hervorbringen, die ihr Handeln orientieren. Das schließt natürlich unweigerlich auch die Ebene der materialen Wirklichkeit ein, ob diese nun als Natur, Ressource oder menschlich erzeugte Infrastruktur in Erscheinung tritt (Keller, 2012, S. 204 f.).
\end{abstract}

„Gesellschaftliche Konstruktion" beschreibt so zunächst nur die Annahme von durch die Menschen erzeugten „Wissenskonstruktionen“; für Berger und Luckmann ist aber auch Gesellschaftsordnung eine permanente menschliche Produktionsleistung. Daher gilt ihnen Gesellschaft als ,objektive und subjektive Wirklichkeit zugleich“. Jedoch ist ,Wirklichkeit", auch wenn sie den menschlichen Konstruktionsprozessen unterliegt und selbst ,konstruiert ' ist, nicht beliebig. Sie ist eine Konstruktion der Handelnden und als solche sowohl an die Möglichkeiten des Handelns als auch an die der Handelnden gebunden. Die Konstruktion ist also durch eine anthropologische Dimension gerahmt. Die Möglichkeiten des Handelns hatte Schütz in dessen Sinnhaftigkeit erkannt. Dies bedeutet, dass Handeln immer in einer „Welt des Sinns“ stattfindet; dieser Sinn gilt als „Produkt des Bewusstseins“ und nicht als ,Merkmal einer Wirklichkeit“ (Keller, 2012, S. 204 f., S. 211; Knoblauch, 2014, S. 154):22

${ }^{22}$ Ein Verständnis der Gesellschaft als ,objektive und subjektive Wirklichkeit zugleich“, wie Berger und Luckmann es vertreten, kann diese Arbeit nicht behandeln. Siehe hierzu: Keller, 2012, S. 212 ff.. 
Die Wirklichkeit der Menschen ist immer eine Sinnwelt - eine vom Bewusstsein erfüllte Welt. Sinn wiederum ist die subjektive Grundstufe des Wissens, das sozial vermittelt wird und Sinn damit gleichsam sozialisiert. Damit ist auch die zentrale Bedeutung des Wissens schon erkannt (Knoblauch, 2014, S. 154).

Berger und Luckmann haben Wissen als den Gegenstand der Wissenssoziologie wie folgt bestimmt:

„Wissen“ definieren wir als die Gewißheit, daß Phänomene wirklich sind und bestimmbare Eigenschaften haben (Berger, \& Luckmann, 1966/2009, S. 1).

Hubert Knoblauch (2014) hat die von Berger und Luckmann vorgelegte Definition von Wissen an die Theorie von Schütz rückgekoppelt und folgendermaßen konkretisiert:

[. . . ] Wissen als den gesellschaftlich relevanten, gesellschaftlich objektivierten und gesellschaftlich vermittelten Sinn [... ] (Knoblauch, 2014, S. 155).

Letztlich ist die von Berger und Luckmann festgesetzte Aufgabe der Wissenssoziologie aber empirischer Natur:

Wissenssoziologie darf ihr Interesse nicht nur auf die empirische Vielfalt von „Wissen“ in den menschlichen Gesellschaften richten, sondern sie muß auch untersuchen, auf Grund welcher Vorgänge ein bestimmter Vorrat von „Wissen“ gesellschaftlich etablierte „Wirklichkeit“" werden konnte. Wir behaupten also, daß die Wissenssoziologie sich mit allem zu beschäftigen habe, was in einer Gesellschaft als „Wissen“ gilt, ohne Ansehen seiner absoluten Gültigkeit oder Ungültigkeit. Insofern nämlich alles menschliche „Wissen“ schließlich in gesellschaftlichen Situationen entwickelt, vermittelt und bewahrt wird, muß die Wissenssoziologie zu ergründen versuchen, wie es vor sich geht, daß gesellschaftlich entwickeltes, vermitteltes und bewahrtes Wissen für den Mann auf der Straße zu außer Frage stehender ,Wirklichkeit“ gerinnt. Mit anderen Worten behaupten wir: Die Wissenssoziologie hat die Aufgabe, die gesellschaftliche Konstruktion der Wirklichkeit zu analysieren (Berger, \& Luckmann, 1966/2009, S. 3, Hervorheb. i. O.).

Der Begriff „Wissen“ wird von Berger und Luckmann in Anführungszeichen gesetzt, um zu betonen, dass es sich dabei um eine Alltagskategorie handelt; als Wissen gilt, was Handelnde für , wirklich“ und damit für Wissen halten (Keller, 2012, S. 211; Knoblauch, 2014, S. 155): 
Wenn wir von Wissen reden, haben wir es mit sozial konstruiertem Sinn zu tun. Zwar ist Wissen natürlich Sinn, Sinn aber ist nicht unbedingt Wissen. Wissen ist derjenige Sinn, der objektiviert, vermittelt und dann internalisiert werden kann. [. . . ] Diese Differenz zwischen Sinn und Wissen hat wesentlich mit der Rolle des Sozialen zu tun (Knoblauch, 2014, S. 155).

Berger und Luckmann haben die ,Konstruktion' jedoch nicht auf die gesellschaftliche ,Wirklichkeit' beschränkt. Es ist die gesamte ,Wirklichkeit', welche gesellschaftlich ,konstruiert' wird. Diese Definition nimmt dann Gestalt an im Wissen beziehungsweise in dem, was als Wissen gilt (Knoblauch, 2014, S. 156).

Letztlich sind es die den Rahmen der ,Konstruktion' formenden Prozesse, die Wissen generieren. Knoblauch bezeichnet diese als die

[... ] Trias der Externalisierung, Objektivierung und Internalisierung, die als Dialektik den Zusammenhalt von subjektiver und objektiver Wirklichkeit garantieren (Knoblauch, 2014, S. 156).

Somit beruht auch die ,gesellschaftliche Wirklichkeit“ auf der „,dialektischen Trias“ von Externalisierung, Objektivierung und Internalisierung; näher erklärt haben Berger und Luckmann dieses Kernelement ihrer wissenssoziologischen Konzeption anhand der Prozesse der Typisierung, Institutionalisierung, Legitimation und Sozialisation. Indem sie auch hier auf die Prozesse der Externalisierung, Objektivierung und Internalisierung rekurrieren, beschreiben Berger und Luckmann die Interdependenz zwischen einem oder auch mehreren Menschen und der Gesellschaft wie folgt (Keller, 2012, S. 203, S. 214 ff.; Knoblauch, 2014, S. 156 ff.; Maasen, 2012, S. 34 f.): ${ }^{23}$

Gesellschaft ist ein menschliches Produkt. Gesellschaft ist eine objektive Wirklichkeit. Der Mensch ist ein gesellschaftliches Produkt (Berger, \& Luckmann, 1966/2009, S. 65).

Wie andere Theorien wurde auch die Konzeption der Wissenssoziologie von Berger und Luckmann heftig kritisiert; die Kritik setzte mitunter an den Begriffen „Konstruktion“ und „Wissen“ an. In Bezug auf die wissenssoziologische Entwicklung sind jedoch eher die Stärken des Ansatzes hervorzuheben, die in seiner Betrachtung der Theorie von Berger und Luckmann auch Keller (2012) betont hat (Keller, 2012, S. 228 ff.):

\footnotetext{
${ }^{23}$ Für Berger und Luckmann findet die grundlegende gesellschaftliche Wissenskonstruktion im Rahmen der Prozesse von Externalisierung, Objektivierung und Internalisierung statt; deren Dialektik bestimmen sie näher anhand der Prozesse der Typisierung Institutionalisierung, Legitimation und Sozialisation. Diese Arbeit kann darauf nicht eingehen. Siehe hierzu: Keller, 2012, S. 214 ff.; Knoblauch, 2014, S. 156 ff.; Maasen, 2012, S. 34 f..
} 
Die wesentlichen Vorzüge dieses wissenssoziologischen Programms liegen darin, dass beide Ebenen gesellschaftlicher Wissensverhältnisse - kollektive und individuelle Wissensvorräte - in ihren wechselseitigen Konstitutionsverhältnissen und als permanenter Herstellungsprozess im Blick gehalten werden. Zugleich gelingt Berger und Luckmann damit eine Integration unterschiedlicher klassischer Traditionen der Soziologie (Marx, Durkheim, Weber) mit philosophisch-anthropologischen Grundannahmen und nicht zuletzt auch eine Verbindung der sozialphänomenologischen Überlegungen mit wichtigen Argumenten des Symbolischen Interaktionismus. Mit der Betonung der Interaktionsprozesse bei der Wissensgenerierung und Objektivierung insistieren sie auf der Bedeutung von Handlungen bzw. Praktiken für den gesellschaftlichen Wirklichkeitsaufbau als andauernde gesellschaftliche Produktion. Die Verweise auf den Zusammenhang von Institutionalisierungsprozessen, Legitimationsformen, Verdinglichungen und subjektiven Aneignungen bieten einen systematischen und umfassenden Entwurf der soziologischen Wissenstheorie als Sozialtheorie (Keller, 2012, S. 228, Hervorheb. i. O.).

Die Abhandlung Die gesellschaftliche Konstruktion der Wirklichkeit. Eine Theorie der Wissenssoziologie (1966/2009) von Berger und Luckmann gilt heute längst als eines der Standardwerke soziologischer Literatur; etliche theoretische sowie empirische Arbeiten aus den Reihen der Soziologie knüpfen explizit oder implizit an Berger und Luckmann an (Keller, 2012, S. 230; Maasen, 2012, S. 34).

\subsubsection{Wissenssoziologie der Gegenwart}

Um Orientierung in einem unübersichtlichen Forschungsgebiet zu bieten, sind im Jahr 2017 Oliver Dimbath und Reiner Keller in einem gemeinsamen Aufsatz der Frage nachgegangen, was Wissenssoziologie ist. Unternommen haben sie diesen Versuch im Rahmen der heutigen Wissenssoziologie, konkret deren phänomenologisch orientierter oder vielmehr noch sozialkonstruktivistischer Ausprägung. Daher ist ihr Aufsatz Was ist Wissenssoziologie? Zur Orientierung in einem unübersichtlichen Forschungsgebiet (Dimbath, \& Keller 2017) auch prädestiniert, um zum einen die Wissenssoziologie der Gegenwart beispielhaft innerhalb des theoretischen Teils dieser Forschungsarbeit zu thematisieren und zum anderen eine für den weiteren Verlauf dieser Studie geltende Wissensdefinition festzusetzen. Der zentrale Befund von Dimbath und Keller lautet:

Nur durch Wissen wirken wir (Dimbath, \& Keller, 2017, S. 1).

Um zu dieser die Wissenssoziologie der Gegenwart zusammenfassenden Erkenntnis zu gelangen beziehungsweise diesen Befund zu belegen, diskutieren Dimbath und Keller zunächst den hinter der Wissenssoziologie stehenden ,Sinn “. Anhand einiger Beispiele machen sie deutlich, dass sich selbst die Soziologie über die Bedeutung des 
Wortes „Wissen“ bislang nicht einig geworden ist; es liegen heterogene Definitionen vor, die mitunter in sehr unterschiedliche Richtungen gehen. Dimbath und Keller halten das Folgende als grundlegende wissenssoziologische Intention fest:

\begin{abstract}
Aus soziologischer Sicht möchte man herausfinden, welches Wissen unter welchen Umständen entsteht oder wie es interaktiv und kollektiv verfestigt wird, indem es etwa zu Institutionen und sozialen Rollen gerinnt. Außerdem ist zu ergründen, ob es eine Hierarchie des Wissens gibt - ob manches Wissen also in spezifischen Situationen, bei bestimmten Gruppen oder Kulturen relevanter ist als anderes Wissen. Nicht nur muss erforscht werden, auf welche Weise Wissen in sozialen Beziehungen angewandt und weitergegeben wird, sondern auch, wie spezifische ,Wissensordnungen " der Welt zum Gegenstand von Konflikten, kleineren Veränderungen und größeren Wandlungen werden. Im Blickpunkt soziologischer Ansätze steht dabei in erster Linie die soziale Beziehung, innerhalb derer Wissen erzeugt, weiterbenutzt, dargeboten, vermittelt und angewendet wird. Dabei sind sowohl die Art des Wissens als auch der jeweiligen Beziehung zu berücksichtigen. Hinzu kommt, dass Wissen mit Sinn beziehungsweise Bedeutung zu tun hat: Wissen erschließt uns die Welt in dieser oder jener Weise als mehr oder weniger geordnete Wirklichkeit, auf andere Weise hingegen nicht - was Vorzüge und Probleme mit sich bringt (Dimbath, \& Keller, 2017, S. 2 f.).
\end{abstract}

In groben Zügen skizzieren Dimbath und Keller einen Überblick über die Entwicklung der Wissenssoziologie. Dabei kommen sie neben den im Kontext dieser Arbeit bereits näher vorgestellten wissenssoziologischen Konzeptionen von Karl Mannheim, Auguste Comte, Max Weber, Alfred Schütz sowie Peter L. Berger und Thomas Luckmann sowie den nur am Rande erwähnten von Karl Marx, Émile Durkheim und Max Scheler auf einige weitere zu sprechen. So fallen mitunter auch Namen wie Giambattista Vico oder Francis Bacon; die Frankfurter Schule nach Theodor W. Adorno und Max Horkheimer wird ebenso genannt wie in aller Kürze auf die Überlegungen von Friedrich Nietzsche, Edmund Husserl, Ludwig Fleck, Norbert Elias, Harold Garfinkel und Hans-Georg Soeffner eingegangen wird. Zudem werden diverse Perspektiven, die als Ausbau bestehender Ansätze oder als deren Variationen zu verstehen sind, angesprochen und Namen der Soziologen angeführt, die diese geprägt haben. Hierbei handelt es sich um Niklas Luhmann, Robert K. Merton, die Ethnomethodologie, den Symbolischen Interaktionismus und Thomas S. Kuhn sowie um Michel Foucault und Pierre Bourdieu. Diese verschiedenen Schwerpunktsetzungen der Wissenssoziologie ordnen Dimbath und Keller unterschiedlichen "turns“ oder auch Wendungen zu, welche die jüngeren Sozial- und Geisteswissenschaften international beeinflusst haben. Es ist die Rede von „linguistic turn“, ,practical turn“, ,iconic oder visual turn“ und „material turn“. Eine Differenzierung der Wissenssoziologie bezüglich ihrer theoretischen Fundierung sowie im Hinblick auf ihre empirische Forschung sei das Ergebnis dieser Entwicklung und schreite weiter fort (Dimbath, \& Keller, 2017, S. 3 ff.). 
Abschließend beantworten Dimbath und Keller die von ihnen aufgeworfene Frage nach dem ,Sinn der Wissenssoziologie“ wie folgt:

Wissenssoziologie zu treiben bedeutet in erster Linie, Herkunft und Wirkung unseres Wissens zu hinterfragen. Insofern jede Form des Wissens als irgendwie, gewachsen 'oder, gesellschaftlich konstruiert' angesehen wird, muss jede Behauptung, letzter Wahrheiten " unter Generalverdacht gestellt werden. Wissenssoziologie ist Ideologiekritik, weil sie weiß, dass Wissen nur eine zwischenmenschliche Kategorie und jede Form von Wahrheit stets nur ,kontingent" sein kann. Klar ist damit auch, dass der Anspruch auf Wahrheit immer auch mit dem der Macht verbunden ist, die Geltung dieses Anspruches einfordern zu können. Die Analyse von Formen und Herkünften des Wissens ist unter diesem Aspekt so etwas wie ein ,Machtsichtgerät', das Licht in das Zwielicht des künstlich Verdunkelten fallen lässt (Dimbath, \& Keller, 2017, S. 5 f.).

Durch den Aufsatz von Dimbath und Keller lassen sich mehrere für den weiteren Verlauf der vorliegenden Forschungsarbeit sowie deren eigener Verortung wesentliche, in engem Zusammenhang miteinander stehende Punkte klären. Zum einen haben Dimbath und Keller eine Definition von Wissen vorgelegt; in der sie Wissen als eine „,vergangenheitsbezogene Orientierung für Handeln“ oder ,auf Erfahrung beruhende Orientierung" charakterisieren:

\begin{abstract}
Wissen ist [. . ] konstitutiv [. . . ] für das Leben schlechthin. [. . . ] Wissen ist wohl bereits das, was uns erlaubt, eine Situation, in der wir uns gerade befinden, als Situation hier und jetzt, in dieser oder jener Weise zu erleben [... ]. Wissen ermöglicht und darüber hinaus die Definition der Situation und damit das Handeln. Gleichwohl ist nicht ausgeschlossen, dass wir uns ganz gewaltig irren können oder etwas ganz anders wahrnehmen als alle anderen. [. . . ] Da Wissen nicht etwas ist, was ein einzelnes Bewusstsein mit sich selbst ausmacht, sondern in den Beziehungen zwischen Individuen nach bestimmten Regeln entsteht, eignet es sich als Gegenstand soziologischen Nachdenkens (Dimbath, \& Keller, 2017, S. 1).
\end{abstract}

Es handelt sich hier um eine aktuelle Wissensdefinition, mit der die Wissenssoziologie der Gegenwart arbeitet. Der von Dimbath und Keller vorgeschlagenen Definition von Wissen schließt sich auch die vorliegende Forschungsarbeit an, indem sie auf diese zurückgreift. Zum anderen betrachten Dimbath und Keller, wie ihre Wissensdefinition verdeutlicht, die Wissenssoziologie der Gegenwart aus einer sozialkonstruktivistischen Perspektive. In ihren theoretischen Überlegungen haben sie Wissen im Kontext der Wissenssoziologie nicht nur definiert, sondern die Wissenssoziologie der Gegenwart zudem sozialkonstruktivistisch aufgestellt. Damit hält ihr Aufsatz eine theoretische Definition von Wissen bereit, die für den 
weiteren Verlauf dieser Studie gelten soll, und thematisiert außerdem die Wissenssoziologie der Gegenwart aus einer Perspektive, die insbesondere für deren empirische Umsetzung relevant ist. Dimbath und Keller haben in ihrem Aufsatz den ,Sinn der Wissenssoziologie', genauer den ihrer phänomenologisch orientierten beziehungsweise sozialkonstruktivistischer Ausprägung benannt; dies haben sie in der Gegenwart getan. Für diese Forschungsarbeit haben sie damit zentrale theoretische Fragen beantwortet, vor allem in Bezug auf die Umsetzung der empirischen Untersuchung sowie die Interpretation ihrer Ergebnisse. ${ }^{24}$

\subsubsection{Exkurs: Wissenskulturen}

Für Angelika Poferl und Reiner Keller (2017, 2016) ist der Begriff „Wissenskulturen“ eine Option, um Phänomene der Wissensgenese zu untersuchen oder auch analytisch zu erschließen. Kulturen definieren Poferl und Keller so:

Kulturen sind historisch und kontextuell hervorgebrachte, situierte Symbolisierungs-, Diskurs- und Praxisfelder, welche spezifische Muster des Deutens und Handelns ausbilden und vorübergehend stabilisieren, die wiederum zum Gegenstand der [. . . ] Analyse gemacht werden können (Poferl, \& Keller, 2017, S. 84).

Damit folgen sie einem ,wissenssoziologischen, bedeutungs- und situationsorientierten Verständnis“ von Wissenskulturen, das den Grundgedanken der sozialen ,Konstruktion“ der ,Wirklichkeit' beinhaltet (Berger, \& Luckmann, 1966/2009; Poferl, \& Keller, 2017). Wegen der Eignung des Konzepts für die Erforschung der Produktion von Wissen umfasst diese Studie, ehe sie die theoretische Betrachtung von Wissen in der Wissenssoziologie schließt, einen Exkurs: Wissenskulturen; dieser gibt zugleich einen Einblick in die Wissenschaftssoziologie als Gebiet wissenssoziologischer Forschung:

\footnotetext{
${ }^{24}$ Im Hinblick auf den ,Sinn der Wissenssoziologie' beziehungsweise eine gegenwärtige Definition von Wissen siehe auch Dimbath (2016a, 2016b). Im weiteren Verlauf dieser Forschungsarbeit wird diese im Rahmen der Darstellung der ,Konstruktion ‘ von Wissen in der Automobilindustrie (6.) vertieft.
} 
Es ist ein differenziertes Forschungsfeld, aber es bewahrt immer noch einen besonderen Fokus, der es von anderen wissenssoziologisch relevanten Gebieten trennt, insbesondere dem Gebiet des Wissensmanagements, der Informationssoziologie und der Transformationstheorien, die auf eine Wissensgesellschaft hinweisen. Die neue Wissenschafts- und Techniksoziologie betrachtet Wissen nicht nur äußerlich, sondern von innen heraus: nicht nur von außen in Bezug auf seine soziostrukturellen, berufsbezogenen und anderen Implikationen, sondern von innen durch den Rekurs auf Wissensinhalte, Wissensverfahren und epistemische Beziehungen (Knorr Cetina, 2007, S. 337).

So kann im Anschluss an die vorab behandelten theoretischen Konzeptionen der Wissenssoziologie exemplarisch gezeigt werden, wie diese in einer bestimmten Ausprägung empirisch betrieben wird. Zudem dient der Exkurs als Übergang in den nächsten theoretischen Block dieser Arbeit, der Wissen in der Organisationsforschung betrachtet, und hält für die Untersuchung der Entstehung von Wissen in der Praxis, unter Einnahme einer sozialkonstruktivistischen Perspektive, Einsichten bereit (Detel, 2007; Knoblauch, 2014, S. 233, S. 246; Knorr Cetina, 2007; Maasen, 2012, S. 58 f.; Poferl, \& Keller, 2017). ${ }^{25}$

Aus dem ,starken Programm der Wissenschaftssoziologie“, das der ,externalistischen Position“ der Wissenschaft angehört und damit der ,internalistischen Interpretation" gegenübersteht, hat sich der Ansatz der Laborstudien entwickelt; dieser untersucht die Praktiken der Wissenschaftserzeugung als spezifische Wissenskulturen (Knoblauch, 2014, S. 233 f.; Knorr Cetina, 2007; Maasen, 2012, S. 58 f.). ${ }^{26}$

Von „Wissenskulturen“ zu sprechen, betont die Bedeutung spezifischer Zusammenhänge von sozialen AkteurInnen, Praktiken, institutionellen Settings und auch Materialitäten im Prozess der Wissenserzeugung (Keller, \& Poferl, 2016, S. 7).

Urvater des Konzepts der Wissenskulturen ist gemäß Keller und Poferl Ludwig Fleck (1896-1961). Aus wissenssoziologischer Perspektive habe er sich mit Denkkollektiven und Denkstilen beschäftigt. Für den weiteren Verlauf dieser Forschungsarbeit sind diese von Fleck geprägten, aber auch schon von Mannheim

\footnotetext{
${ }^{25}$ Forschungsstrategische und -ökonomische Erwägungen bedingen es, dass diese Arbeit nicht weiter auf die Wissenschaftssoziologie eingeht. Ein Einstieg in dieses Themengebiet der Wissenssoziologie ist zum Beispiel möglich über: Knoblauch, 2014, S. 233 ff.; Weingart, 2013; Maasen, Kaiser, Reinhart, \& Sutter, 2012; Maasen, 2012, S. 58 ff.; Knorr Cetina, 2007. ${ }^{26}$ Die vorliegende Studie behandelt weder die ,,internalistische Interpretation“ und ,externalistische Position“ der Entwicklung von Wissenschaft noch das ,starke Programm der Wissenschaftssoziologie“. Betrachtet werden diese Aspekte zum Beispiel in: Knoblauch, 2014, S. 233 ff.; Knorr Cetina, 2007; Maasen, 2012, S. 59 f..
} 
verwendeten Begriffe durchaus relevant. Die Wissenschaftssoziologie und ihr Ansatz der Laborstudien, der vor allem mit dem Namen von Karin Knorr Cetina (2000) eng verwoben ist, beruhen auf einer sozialkonstruktivistischen Perspektive, aus der seit dem Ende der 1970er Jahre versucht wird, wissenschaftliches Wissen als soziales Produkt empirisch zu untersuchen. Die Laborstudien sprechen der Wissenschaft zum einen eine materiale Grundlage zu und vertreten zum anderen die Ansicht, dass auch Wissenschaft eine Form der Praxis darstellt (Detel, 2007; Keller, \& Poferl, 2016; Knoblauch, 2014, S. 246; Knorr Cetina, 2007; Maasen, 2012: S. 58 ff.; Poferl, \& Keller, 2017).

Die Laborstudien zeichnen sich darüber hinaus dadurch aus, dass sie sich als Feldforscher in die [... ] naturwissenschaftliche Forschung etwa der Biochemie oder der Hochenergiephysik begeben, um den Prozess der gesellschaftlichen Konstruktion wissenschaftlichen Wissens bzw. die „Fabrikation von Erkenntnis“ als eine „empirische Epistemologie“ zu beschreiben. [. . . ] In ihrer mikrosoziologischen Vorgehensweise geht Knorr Cetina von einem konstruktiven Wissensbegriff aus [... ]. Ein Mittel zur Erzeugung von Wissenschaftlichkeit ist etwa die ,Abkapselung" eines Labors. [... ] Darüber hinaus müssen in der Forschung fortwährend Selektionen getroffen werden [... ]. Diese Selektionen unterwerfen die Erkenntnis einer Entscheidungslogik, die sich im sozialen Umfeld des Labors entfaltet (Knoblauch, 2014, S. 246 f., Hervorheb. i. O.).

In den wissenssoziologischen Diskurs um Wissensgenese oder Wissensproduktion hat Knorr Cetina daher das Konzept der „Wissenskulturen“ oder auch „epistemischen Kulturen" eingebracht. Im Rückgriff darauf umschreibt Knoblauch diese als ,die Innenausstattungen von Wissensgesellschaften“ (Detel, 2007; Knoblauch, 2014, S. 247). Wissenskulturen sind nach Knorr Cetina

[. . . ] diejenigen Praktiken, Mechanismen und Prinzipien, die [. . ] in einem Wissensgebiet bestimmen, wie wir wissen, was wir wissen (Knorr Cetina, 2002, S. 11, Hervorheb. i. O.).

Das Adjektiv „epistemisch“ soll auf den Aspekt der Erkenntnis verweisen und wird von Knorr Cetina definiert als

[... ] diejenigen Strategien und Prinzipien die auf die Erzeugung von „Wahrheit“ oder äquivalente Erkenntnisziele gerichtet sind (Knorr Cetina, 2002, S. 11). 
Im Vergleich zu dem Begriff „Wissenskulturen“ ist der Ausdruck „epistemische Kulturen“ etwas enger gefasst. Letztere beschreibt Knorr Cetina als

[. . . ] Kulturen, der Erzeugung, der Durchsetzung, der „Validierung“ von Wissen (Knorr Cetina, 2000, S. 232)

und präzisiert, dass sich epistemische Kulturen im Kontext von Wissensprozessen herausbilden. Mit ihrer Untersuchung von Wissenskulturen beabsichtigt Knorr Cetina die Betonung zweier Aspekte:

Erstens die der Innenwelten von Wissen, über die nach wie vor wenig Informationen vorhanden seien und die betreffend ein Einblick in die zeitgenössischen Wissensmaschinerien, ihre Komplexität und insbesondere ihre Diversität fehle; zweitens die des gegenwärtigen Übergangs zu einer Wissensgesellschaft, für die Wissenskulturen ein Strukturmerkmal seien (Knorr Cetina, 2002, S. 11 f.).

Poferl und Keller merken in ihrer Diskussion soziologischer Wissenskulturen an, dass die konkrete Form der Wissensproduktion als „Ausdruck einer Vielzahl miteinander verflochtener Einflussfaktoren“ zu betrachten ist. Denkräume und Denkmöglichkeiten würden durch diese abgesteckt und es entstehe die von Mannheim diagnostizierte „Seinsverbundenheit des Wissens“ (Keller, \& Poferl 2016; Mannheim, 1929/1995; Poferl, \& Keller, 2017).

Epistemische Praktiken der Wissenserzeugung in Labors bezeichnet Knorr Cetina auch als „Ethnomethoden“; dabei lehnt sie sich an die auf das Werk von Schütz aufbauende, von Harold Garfinkel (1917-2011) begründete Richtung der Ethnomethodologie an. Den Begriff „Ethnomethoden“ nutzte Garfinkel selbst, um zu betonen,

[. . . ] dass soziale Wirklichkeit nicht als objektives Gebilde existiert, sondern eine fortwährende Konstruktion darstellt. Ethnomethoden sind die Arten und Weisen, in denen Handelnde das hervorbringen, was als existent angesehen wird. Wissen ist aus dieser Perspektive nichts, was existiert, sondern etwas, das auf bestimmte Weisen handelnd erzeugt wird - etwa in solchen Weisen, wie sie für die Wissenschaft von Knorr Cetina beschrieben worden sind (Knoblauch, 2014, S. 249).

Innerhalb der Wissenssoziologie kommt dem ethnomethodologischen Ansatz Relevanz zu, da er Wissen als Produkt des Handelns begreift. Für diese Forschungsarbeit sind insbesondere die mit der Ethnomethodologie verwobenen Aspekte „Reflexivität“ und „Kontext“" relevant. „Reflexivität“ nutzt die Ethnomethodologie begrifflich als Synonym für Handlungswissen und betont dadurch, dass Handelnde nicht nur vermitteln, dass sie handeln, sondern auch, wie sie verstanden werden möchten. Verstehen von Handlungen, so die ethnomethodologische Auffassung, ist möglich aufgrund von Hintergrundwissen, welches es erlaubt den 
Handlungen einen Sinn zuzusprechen. Oftmals ist die Rede von ,kontextspezifischem Wissen"; der Sinn wird also durch Einbezug des Kontexts einer Handlung erschlossen. Die zentrale Annahme der Ethnomethodologie besteht, so fasst Knoblauch zusammen, darin, dass das „Was“ vor allem durch das „Wie“ erzeugt wird. Heute kommt die Ethnomethodologie in der Wissenschaftssoziologie zum Tragen. Reflexivität beziehungsweise Selbstreflexion sowie der Einbezug von Kontext sind nicht nur für die Ethnomethodologie und über diese für die Laborstudien nach Knorr Cetina beziehungsweise deren Konzept der „Wissenskulturen“ von Bedeutung; auch im Zusammenhang der Forschungsergebnisse dieser Arbeit kommt diesen Aspekten eine noch zu zeigende Bedeutung zu (Knoblauch, 2014, S. 249 f.).

In seiner Betrachtung von Wissenskulturen streicht auch Wolfgang Detel (2007) unter Bezugnahme auf die Ethnomethodologie das Kontextualisieren von Wissen, als deren zentralen Aspekt heraus; zudem beschreibt er Wissenskulturen in drei Varianten:

Der Begriff der Wissenskultur wird theoriestrategisch eingesetzt, um die Idee auszubuchstabieren, dass Wissen und Wissensansprüche auf ihre jeweiligen Kontexte bezogen (,kontextualisiert') werden müssen. Diese Idee tritt vor allem in ökonomischen Diskussionen, in sozialkonstruktivistischen Analysen und in der wissenschaftshistorischen Forschung auf. Daher kommt der Begriff der Wissenskultur in einer ökonomischen, sozialkonstruktivistischen und wissenschaftshistorischen Variante vor. In der ökonomischen Variante sollen Wissen und Wissensansprüche auf den Kontext der Unternehmen bezogen werden, in der sozialkonstruktivistischen Variante auf den Kontext der Maschinerie der Wissensproduktion vor allem in den Laborwissenschaften, und in der wissenschaftshistorischen Forschung auf den Kontext der Hintergrundinformationen sowie des historischen und gesellschaftlichen Umfeldes (Detel, 2007, S. 670).

Insbesondere die von Detel benannte ökonomische Variante von Wissenskulturen ist für diese Forschungsarbeit von Interesse; sowohl in Bezug auf deren empirischen Teil als auch hinsichtlich des nun folgenden Abschnitts, welcher den Blick auf Wissen in der Organisationsforschung richtet. ${ }^{27}$

Darauf, welche Aspekte dieses Exkurses für die vorliegende Arbeit im Zusammenhang der Interpretation ihrer Forschungsergebnisse relevant sind, wurde bereits hingewiesen; die zentralen seien noch einmal wiederholt. Dies sind vor allem das Verständnis von Wissenskulturen als Denkkollektive oder Denkstile, die Reflexivität und Selbstreflexion, das Kontextualisieren sowie auch die ökonomische Variante von

\footnotetext{
${ }^{27}$ Näher betrachtet wird die von Garfinkel begründete Ethnomethodologie von Knoblauch (2014, S. 182, S. 249 ff.) sowie insbesondere von Keller (2012, S. 241 ff.).
} 
Wissenskulturen. Laborstudien gehen davon aus, dass in spezifischen Wissenskulturen auch bestimmte Denkkollektive oder Denkstile vorherrschen. Damit nehmen sie mitunter Bezug auf die wissenssoziologische Konzeption von Mannheim oder vielmehr die von ihm postulierte ,Seinsverbundenheit des Wissens“. Zwar hat Mannheim Wissenschaft, vor allem die Naturwissenschaften, aus seiner Theorie ausgeklammert, wohingegen die Laborstudien sich explizit damit auseinandersetzen, aber in ihrem Kern beschreiben Wissenskulturen, wie sie von den Laborstudien thematisiert werden, und Ideologien im Sinne Mannheims Ähnliches. Wissenskulturen charakterisieren die Art, wie Wissen generiert wird, und können daher mit Ideologien oder auch Denkkollektiven und Denkstilen gleichgesetzt werden; zumindest geschieht dies in dieser Forschungsarbeit. Eine Ähnlichkeit der Theorie Mannheims und der Laborstudien ist festzustellen:

Spezifische Kulturen entstehen, wenn Bereiche der sozialen Welt sich voneinander separieren und sich über längere Zeiträume vorwiegend auf sich selbst beziehen; anders ausgedrückt, sie gedeihen in selbstreferenziellen Systemen, deren Teilnehmer sich mehr aneinander und an früheren Systemzuständen als an der Umwelt orientieren. [. . . ] Indem man sich auf Wissenskulturen statt auf Disziplinen oder Spezialgebiete konzentriert, amplifiziert man die Wissenspraxis [. . . ], bis das gesamte Gewebe technischer, sozialer und symbolischer Elemente sichtbar wird, das diese Praxis ausmacht (Knorr Cetina, 2002, S. 12 f.).

Poferl und Keller stellen fest, dass das im Begriff „Wissenskulturen“ kondensierte analytische Interesse weit über die Beobachtung der wissenschaftlichen Erzeugung von Wissen, die die Laborstudien praktiziert haben, hinausreicht. Auch Knorr Cetina betont dies sowohl durch ihr Konzept der ,Maschinerien, durch die Erkenntnis konstruiert wird" als auch anhand ihrer Frage nach der ,Konstruktion“ dieser Maschinerien (Keller, \& Poferl, 2016; Knorr Cetina, 2002, S. 13; Poferl, \& Keller, 2017).

Der Begriff der Wissenskultur, verstanden nicht als Bezeichnung für vollständig unterschiedene Gesamtheiten, sondern als dynamische Verflechtung und Konzentration von spezifizierbaren Formen der Wissenserzeugung und Wissensbegründung, erfasst Pluralität und Heterogenität, erlaubt aber zugleich, typische Elemente und Muster zu rekonstruieren. Wissenskulturen stellen keine abgeschlossenen ,Container dar; vielmehr sind sie in empirisch bestimmbarer Weise durch Bezüge nach außen, Austausch- und Entgrenzungsprozesse (mit-)konstituiert - sie sind in ein relationales Feld eingebettet (Poferl, \& Keller, 2017, S. 91, Hervorheb. i. O.).

Wissenskulturen weisen eine Nähe zu Ideologien und damit Denkkollektiven oder auch Denkstilen auf; in diesem Sinne sind sie für die vorliegende Studie relevant. 


\subsection{Wissen in der Organisationsforschung}

Umgesetzt wurde die empirische Untersuchung der Wissensgenese und -verwendung im Zusammenhang mit der digitalen Methode der Social-MediaAnalysen in einem ganz bestimmten Forschungsfeld, konkret bei einem der deutschen Automobilindustrie angehörenden Großkonzern, einem Automobilhersteller. Aus soziologischer Perspektive wurde damit innerhalb einer Organisation geforscht, die auch als Fallbeispiel der vorliegenden Arbeit dient (Kühl 2015a, S. 75; Kühl, 2011, S. 50 ff., S. 130 f., S. 141 ff.; Kühl, \& Muster, 2016, S. 9; Preisendörfer, 2016, S. 16, S. 90).

Daher gilt es nun den Blick auf die Organisationsforschung zu lenken, dem zweiten Teilgebiet der Soziologie, an welches diese Arbeit mit ihrer Fragestellung und ihrem Gegenstand anschließt, und Wissen in deren Kontext zu verorten. Nach wie vor, darauf sei deutlich hingewiesen, handelt es sich um eine wissenssoziologische Untersuchung. In deren Rahmen wurde jedoch die Genese und Verwendung von Wissen in einer bestimmten Organisation betrachtet, auf die auch durchweg Bezug genommen wird. Aus diesem Grund ist ebenso die Organisationsforschung zu thematisieren und in Bezug auf ihre Auseinandersetzung mit Wissen darzulegen; dies geschieht überblicksartig wie zuletzt im Hinblick auf die Wissenssoziologie. Mit anderen Worten: Organisationales Wissen ist der wesentliche Forschungsgegenstand der vorliegenden Studie; untersucht wurden dessen Genese sowie seine Verwendung im Kontext der digitalen Methode der SocialMedia-Analysen. Die Organisationsforschung ist neben der Wissenssoziologie die diese Arbeit prägende Disziplin und wird nun beleuchtet.

Im Folgenden geht es um Wissen in der Organisationsforschung. In einem ersten Schritt wird herausgearbeitet, was die Soziologie unter Organisationen versteht. Daraufhin richtet sich das Augenmerk auf Wissen in Organisationen und damit zugleich auf deren sozialen Charakter und ihr Verständnis als Wissenssysteme. Im Anschluss daran rückt die organisationale Wissensgenese in den Fokus der Betrachtung; es werden sowohl eine praxistheoretische als auch eine kognitionstheoretisch-wissenssoziologische sowie eine systemtheoretischwissenssoziologische Auffassung von der organisationalen Wissensgenese dargelegt. Danach wird Wissen in der Automobilindustrie vorgestellt und das für Automobilhersteller bedeutsame Kundenwissen behandelt. Sodann geht es um die Frage, wie Wissen in der Automobilindustrie generiert wird, wobei vor allem deren Marktforschung im Mittelpunkt steht. Abschließend gewährt ein Exkurs einen Einblick in das organisationale Wissensmanagement. 


\subsubsection{Organisationen}

„Organisation“ ist laut dem Wörterbuch der Soziologie (2007) von Karl-Heinz Hillmann

[... ] die Bezeichnung für ein soziales System oder ein soziales Gebilde als Gesamtheit aller geplanten, ungeplanten und unvorhergesehenen sozialen Prozesse, die innerhalb des jeweiligen sozialen Systems oder in Beziehung zu anderen, umgebenden Systemen ablaufen. Der soziolog[ische] O[rganisation]sbegriff unterscheidet sich von dem betriebswirtschaftl[ich] normativ orientierten Ansatz, dem O[rganisation] als Verfahrenstechnik im Sinne einer auf ein gesetztes Soll hin integrativen Strukturtechnik erscheint. Der soziolog[ische] Begriff O[rganisation] erfasst folgende Eigenschaften des bezeichneten Gegenstandes: bestimmbare Anzahl der Mitglieder; markierbare Grenze zwischen binnen- und außenorientierten einerseits und „fremden“ sozialen Beziehungsstrukturen andererseits; interne arbeitsteilige Rollengliederung nach einer zielorientierten, rationalen Ordnung; prinzipielle (gedankliche) Abhebbarkeit und Unabhängigkeit der sozialen Verhaltensstrukturen von den konkreten Mitgliedern. Eine soziale O[rganisation] ist demnach ein System bewusst geplanter und koordinierter Handlungseinheiten, die auf Personen als Positionsinhaber zur Ausführung verteilt sind. Sowohl der betriebswirtschaftl[iche] Begriff von O[rganisation] als Instrument als auch der soziolog[ische] Begriff des Systems haben eine Begriffsfassung verschüttet, die O[rganisation] als Assoziation begreift, d. h. als Zusammenschluss von Menschen zur Erreichung gemeinsamer Ziele (Hillmann, 2007, S. 651).

Hillmann (2007) umreißt mit seiner Definition einer Organisation deren wesentliche Kennzeichen, auf die im Folgenden noch näher eingegangen wird, unterscheidet jedoch ein soziologisches von einem wirtschaftswissenschaftlichen Organisationsverständnis und baut seinen Artikel auf dieser Differenzierung auf. Mit Organisationen beschäftigt sich die Soziologie demnach nicht exklusiv; Organisationen sind ein interdisziplinäres Forschungsfeld, das ebenso mitunter von der Wirtschaftswissenschaft oder Psychologie mit je eigenen thematischen Schwerpunktsetzungen behandelt wird. Insgesamt gilt es zwar als eine Schwäche der Organisationsforschung, dass diese eher von Theorie als von Empirie bestimmt wird, doch die Methodenkompetenz und eine durch diese meist erzeugte empirische Überprüfbarkeit sind besondere Eigenschaften der soziologischen Beschäftigung mit Organisationen; sofern diese keinem Luhmann-Bias unterliegt und abstrakt systemtheoretisch vorgeht, wie dies allerdings, vor allem im internationalen Vergleich, in Bezug auf die deutschsprachige Organisationssoziologie nicht selten festzustellen ist. Da sich die vorliegende Forschungsarbeit der Soziologie anschließt, richtet sie ihr Hauptaugenmerk auf den soziologischen Organisationsbegriff. Das heißt jedoch keineswegs, dass sie nicht auch Erkenntnisse für die Wirtschaftswissenschaft und weitere Disziplinen bereithält. Es handelt sich 
um eine empirische Forschungsarbeit der deutschsprachigen Soziologie, die sich in theoretischer Hinsicht zwar nicht in die Systemtheorie von Niklas Luhmann (1927-1998) einreiht, sich dieser gegenüber aber auch nicht verschließt. Des Weiteren sei vorangestellt, dass für die Entwicklung der Organisationsforschung Webers ,Rationalitätsthese“ wegweisend war (Allmendinger, \& Hinz 2002, S. 11; Hillmann, 2007, S. 651 f.; Liebig, Matiaske, \& Rosenbohm, 2017, S. 4 f.; Maurer, 2015, S. 129 ff.; Preisendörfer, 2016, S. 1 f., S. 13 ff.; Preisendörfer, 2015, S. 143; Tacke, \& Drepper, 2018, S. 2 ff., S. 7 ff., S. 15 ff., S. 41 ff.). ${ }^{28} 293031$ Jutta Allmendinger und Thomas Hinz (2002) erklären, weshalb Organisationen als Forschungsgegenstand attraktiv sind; dabei heben sie die große Bedeutung von Organisationen für moderne Gesellschaften hervor:

${ }^{28}$ Eine Auseinandersetzung mit der wirtschaftswissenschaftlichen und psychologischen Ausprägung des Organisationsbegriffs und den Forschungsschwerpunkten dieser Disziplinen kann diese Arbeit nicht leisten. Einen Einblick gibt Preisendörfer (2016, S. 13 ff.). Im Handwörterbuch Unternehmensführung und Organisation werden Organisationen aus wirtschaftswissenschaftlicher Perspektive behandelt; siehe: Schreyögg, \& Werder, 2004. Ähnlich geschieht dies beispielsweise auch in Schreyögg und Geiger (2016) oder mit einem Fokus auf strategische Fragestellungen in Schreyögg und Conrad (2010). Interdisziplinäre wie internationale Arbeiten finden sich zudem in Allmendinger und Hinz (2002).

${ }^{29}$ Über die Fragestellung, ob die Organisationsforschung eines eigenen Methodenrepertoires bedarf oder ob die quantitativen und qualitativen Methoden der Sozialwissenschaften auch für die Untersuchung von Organisationen geeignet sind, herrscht Uneinigkeit. Das Handbuch Empirische Organisationsforschung gibt einen Überblick über die empirische Organisationsforschung und deren Herausforderungen; siehe: Liebig, Matiaske, \& Rosenbohm, 2017. Ein weiteres Handbuch Methoden der Organisationsforschung liegt von Kühl, Strodtholz und Taffertshofer (2009) vor. Ebenso haben Allmendinger und Hinz (2002, S. 23 ff.) die methodischen Herausforderungen der Organisationsforschung überblicksartig diskutiert.

${ }^{30}$ Im Kontext einer soziologischen Arbeit scheint es naheliegend auf die „Rationalitätsthese“ von Weber einzugehen und darzulegen, dass die Organisationsforschung darauf beruht; diese Studie sieht allerdings davon ab. Erwähnt wird dieser Ursprung von Organisationssoziologie wie Organisationsforschung häufig, weiter vertieft von Maurer (2015).

${ }^{31}$ Ortmann (2015) beschäftigt sich mit dem Verhältnis von Organisation, Wirtschaft und Gesellschaft; anhand von zehn Thesen arbeitet er dabei vor allem die Unterschiede eines wirtschaftswissenschaftlichen und eines soziologischen Verständnis von Organisationen heraus. 
Ein zentraler Grund ist darin zu suchen, dass Organisationen Kristallisationspunkte für viele, eine moderne Gesellschaft prägende soziale Prozesse darstellen. [ . . . ] Organisationen haben grundlegende gesellschaftliche Funktionen. Ihre Bedeutung liegt darin, dass sie es individuellen Akteuren erlauben, sich zu koordinieren, sie liegt in ihrer Kraft, die Gesellschafts- und Wirtschaftsstruktur zu prägen. Dabei sind Organisationen Einheiten mittlerer Ebene, verortet zwischen Mikro- und Makrosoziologie. Organisationen sind auch symbolische Orte. In Organisationen und durch sie lassen sich theoretisch und empirisch herausfordernde Fragestellungen nach Herrschaft, Wettbewerb oder Kooperation, sozialem Wandel und nach der Bedeutung von Institutionen präziser, anschaulicher und mit neuen Erkenntnismöglichkeiten formulieren und untersuchen (Allmendinger, \& Hinz, 2002, S. 10).

Heutzutage wird das Leben maßgeblich von Organisationen bestimmt; Organisationen, so stellt die Organisationssoziologie fest, dominieren die Moderne. Da in nahezu allen Lebensbereichen Organisationen mittlerweile eine herausragende Bedeutung zukommt, wird die moderne Gesellschaft auch „Organisationsgesellschaft" genannt. ${ }^{32}$ Es gilt als gesetzt, dass Organisationen „dynamische soziale Systeme“ darstellen; als solche sind sie mit Prozessen des gesellschaftlichen wie wirtschaftlichen Wandels eng verflochten. In der Alltagssprache allerdings umschreiben „Organisation“ und „Organisieren“ meist nur „eine auf einen Zweck ausgerichtete planmäßige Regelung von Vorgängen“ (Abraham, \& Büschges, 2009, S. 11 f., S. 19 f., S. 29 ff.; Allmendinger, \& Hinz, 2002, S. 9 ff., S. 20 f.; Jäger, \& Schimank, 2005; Kühl, 2011, S. 10 f.; Kühl, \& Muster, 2016, S. 7; Liebig et al., 2017, S. 7; Mayntz, 1963, S. 147; Preisendörfer, 2016, S. 5 f.; Schimank, 2005a). Demgegenüber bestimmt die Organisationsforschung, hier in den Worten von Karl Weick (1985/2015), die Tätigkeit des Organisierens und damit Organisationen

[... ] als durch Konsens gültig gemachte Grammatik für die Reduktion von Mehrdeutigkeit mittels bewußt ineinandergreifender Handlungen. Organisieren heißt, fortlaufende unabhängige Handlungen zu vernünftigen Folgen zusammenzufügen, so daß vernünftige Ergebnisse erzielt werden (Weick, 1985/2015, S. 11, Hervorheb. i. O.).

Stefan Kühl (2011) stellt fest, dass mit einem derart breiten Organisationsverständnis letztlich nur ,eine Ordnung, die dazu genutzt wird, um etwas zu erreichen“ bezeichnet wird; wegen seiner Breite erfasse der Begriff alles, „was irgendwie strukturartig, regelhaft oder zielgerichtet" sei. Daher konstatiert Kühl einen „inflationären“ Gebrauch des Organisationsbegriffs. Im Gegensatz dazu

\footnotetext{
${ }^{32}$ Kühl (2015a) diskutiert das Konzept „Organisationsgesellschaft“ kritisch und hält ihm eine alternative Perspektive entgegen, die die Organisationssoziologie einnehmen könnte.
} 
habe es sich in der Wissenschaft etabliert, mit dem Begriff ,,eine besondere Form von sozialem Gebilde" oder ein soziales System zu bezeichnen (Kühl, 2011, S. 13 f.; Kühl, \& Muster, 2016, S. 8).

Bis zur Entstehung der Moderne haben andere Varianten der Einbindung von Personen dominiert, wie beispielsweise Sklaverei, Frondienst oder Zünfte; die Mitgliedschaft hing nicht von der individuellen Entscheidung ab, sondern war durch die Geburt vorgegeben. Vormoderne Organisationsformen zeichnen sich durch die vollständige Inklusion von Personen aus. Organisationen, insbesondere Arbeitsorganisationen, sind ein Produkt der gesellschaftlichen Entwicklung; ihre Entfaltung und Ausbreitung ging einher mit dem nicht zuletzt durch die funktionale Differenzierung gekennzeichneten sozialen Wandel, den das Aufkommen des Kapitalismus und die Industrialisierung bedingten „Mitgliedschaft gegen Lohn“ gilt als Prinzip der Moderne beziehungsweise begann sie erst sich mit dieser durchzusetzen. Mitunter aus diesem Grund sprechen Martin Abraham und Günter Büschges (2009) von „Organisationen als Agenturen sozialen Wandels“. Als solche sind gemäß Allmendinger und Hinz Organisationen zwar dazu in der Lage Innovationen zu befördern, können diese jedoch ebenso verhindern (Abraham, \& Büschges, 2009, S. 32 ff., S. 51 f.; Allmendinger, \& Hinz, 2002, S. 20 ff., S. 25 f.; Kühl 2011, S. 15 f.; Preisendörfer, 2015, S. 143; Schimank, 2005a, S. 35 ff.). ${ }^{33}$

Unter Rückgriff auf Luhmann arbeitet Kühl drei Merkmale von Organisationen heraus: (1) Mitgliedschaft, (2) Zwecke, (3) Hierarchien. Anhand dieser werde zum einen die Besonderheit von Organisationen in der modernen Gesellschaft deutlich und es zum anderen möglich, sie von anderen sozialen Formationen zu unterscheiden. Ihre Autonomie ist dabei wesentlich (Kühl, 2011, S. 16 ff.; Kühl, \& Muster, 2016, S. 8 f.): $:^{34} 35$

\footnotetext{
${ }^{33}$ Einige Auseinandersetzungen, die sowohl aus internationaler als auch interdisziplinärer Sicht explizit auf Arbeitsorganisationen fokussieren, finden sich bei Allmendinger und Hinz (2002).

${ }^{34}$ Kühl (2011) betrachtet die drei von ihm benannten zentralen Merkmale von Organisationen umfassend. In dieser Arbeit kann dies nicht geschehen.

35 Ebenso haben Abraham und Büschges (2009, S. 21 ff.) insgesamt vier Merkmale von Organisationen herausgearbeitet, anhand derer sich die als solche bezeichnete Zusammenschlüsse von Personen gleichen: Organisationen seien erstens von Akteuren geschaffen, zweitens seien sie arbeitsteilig gegliedert, drittens seien Organisationen mit einer Leitungsinstanz ausgestattet und viertens würden sie über eine Verfassung verfügen.
} 
Von zentraler Bedeutung ist, dass Organisationen über ihre Zwecke, Hierarchien und Mitgliedschaften selbst entscheiden können. Von einer Organisation können wir erst dann reden, wenn ein Unternehmen [. . . ] selbst darüber verfügen kann, wer Mitglied wird oder wer nicht. [... ] Besonders deutlich wird die Entscheidungsautonomie bei Hierarchien. [. . . ] Ähnlich zentral ist auch die Autonomie bei der Bestimmung von Zwecken. [. . . ] Selbstverständlich sind die Organisationen in ihren Entscheidungen nie völlig frei - schließlich sind sie immer auch Teil der Gesellschaft mit ihren rechtlichen Normierungen, politischen Einschränkungen und wirtschaftlichen Begrenzungen. [. . . ] Zentral ist jedoch, dass Organisationen innerhalb der Beschränkungen durch geltendes Recht, politische Vorgaben oder wirtschaftliche Knappheiten über ihre Zwecke, Hierarchien und Mitgliedschaften selbst disponieren - selbst entscheiden - können (Kühl, 2011, S. 21 f., Hervorheb. i. O.).

Auch die Organisationssoziologie als Disziplin setzt Hillmann wieder in Bezug zur Wirtschaftswissenschaft und charakterisiert sie als

[. . . ] eine spezielle Soziologie, die unter Anwendung soziolog[ischer] Problemstellungen, Theorien und Methoden auf die empir[isch]-theoret[ische] Erforschung der Organisation als sozialem Gebilde und auch als sozialer Assoziation ausgerichtet ist. Die O[rganisationssoziologie] ist in ihrer Entstehung besonders eng mit der Industrie- und Betriebssoziologie verbunden. Mit ihrer nicht-normativen Orientierung unterscheidet sie sich von der betriebswirtschaftl[ichen] Organisationslehre, der es als Aufbau- und Verfahrenslehre um die Entwicklung von Regeln für das zweckmäßige und effiziente Organisieren geht. Die O[rganisationssoziologie] widmet sich der Analyse der durch soziale Beziehungen zwischen Menschen geprägten Struktur der Binnenverhältnisse und Außenverbindungen organisatorischer Gebilde. Wichtigste Grundorientierung der O[rganisationssoziologie] ist die Erkenntnis, dass jede Organisation sich nicht in ihren planmäßigen, formalen Aspekten erschöpft, sondern dass in ihr immer zugleich ungeplante, unvorhergesehene Prozesse ablaufen und sich informelle Beziehungen und Gruppen herausbilden, die wiederum durch organisatorische Planung und Gestaltung mitverursacht werden. Nach K. Türk sind Organisationen soziale Konstrukte und keine dinghaften Gebilde (Hillmann, 2007, S. 654). 
Mit seinem Verweis auf Klaus Türk (1995) findet sich bei Hillmann eine auch für diese Forschungsarbeit herzustellende Verbindung zwischen der Organisationssoziologie und der Wissenssoziologie oder genauer deren sozialkonstruktivistischer Konzeption. Mit Hillmann und Peter Preisendörfer (2016) ist die Organisationssoziologie als ,spezielle Soziologie“ oder „Bindestrich-Soziologie“ beschreibbar; ihre Aufgabe besteht in der Charakterisierung und Erklärung sowie Steuerung oder Gestaltung von Organisationen. Ferner arbeitet sie überaus interdisziplinär und ist stark in den internationalen Diskurs involviert; daher ist oft auch eher die Rede von „Organisationsforschung“ (Hillmann, 2007, S. 654; Maurer, 2015, S. 123, S. 134 ff.; Preisendörfer, 2016, S. 1 f.). ${ }^{36} 3738$

Die Organisationsforschung nun hat empirisch gänzlich unterschiedliche Aspekte ihres durch Heterogenität gekennzeichneten Forschungsgegenstands zu ergründen:

Im Rahmen der [. . . ] Aufgabe der Deskription bemüht sich die Organisationssoziologie u. a. um eine Aufdeckung von Regelhaftigkeiten im Ablauf organisationaler Prozesse und um ein Raster von Kategorien zur systematischen Erfassung der Struktur von Organisationen. [. . . ] Geht man den logisch nächsten Schritt und fragt nach den Gründen für beobachtete Unterschiede in der Ausgestaltung organisationaler Abläufe und Strukturen [... ], ist man bei der zweiten Aufgabe angelangt, bei der Erklärung des Geschehens in und im Umfeld von Organisationen. [. . . ] Die Beschreibung und Erklärung organisationaler Strukturen und Prozesse ist sehr oft kein Selbstzweck und bloßer Ausfluss wissenschaftlicher Neugierde oder Entdeckungsfreude, vielmehr steht hinter dem Ganzen nicht selten die Erwartung einer sozialtechnologischen Verwendung des Wissens (Preisendörfer, 2016, S. 2 f.).

\footnotetext{
${ }^{36}$ Für eine detailliertere Beschreibung der Entwicklung der Organisationssoziologie siehe: Abraham, \& Büschges, 2009, S. 74 ff..

${ }^{37}$ Ein sozialkonstruktivistisches Verständnis von Organisationen findet sich bei Abraham und Büschges (2009, S. 52 f.); auch wenn die Perspektive nicht explizit als eine sozialkonstruktivistische ausbuchstabiert wird, weist diese dennoch gewisse Anleihen einer solchen auf.

${ }^{38}$ Laut Apelt und Wilkesmann (2015) steht die deutsche Organisationssoziologie vor hochaktuellen Herausforderungen: ,,[Z]um einen ändern sich die Erscheinungsformen organisationalen Handelns massiv, so dass die Frage entsteht, ob Organisationen an gesellschaftlicher Relevanz verlieren, und wie darauf organisationstheoretisch und forschungspraktisch reagiert werden soll. Zum anderen wird die internationale Organisationsforschung durch an US-amerikanischen Business Schools geführte Organization studies dominiert; [...]“ (Apelt, \& Wilkesmann, 2015b, S. 9). Aus diesem Grund hat die deutsche Organisationssoziologie ein Zwischenfazit gezogen; dahinter steckt die Absicht, einen Beitrag zur eigenen Innovation und Zukunft zu leisten. Siehe hierzu: Apelt, \& Wilkesmann, 2015a.
} 
Eine erfolgreiche Gestaltung und Steuerung von Organisationen ist oft schwierig; dies liegt daran, dass Organisationen meist „Kollektivveranstaltungen mit eigeninteressierten individuellen Akteuren“ und keine „One-Man-Shows“ sind. Ihre Erforschung generiert „Wissen über das Funktionieren von Wirtschaft und Gesellschaft" (Preisendörfer, 2016, S. 3 f.; Schimank, 2005a, S. 24 ff.).

Auch Preisendörfer verweist auf die Bedeutung von Organisationen in der Moderne; er betont, dass die in der Moderne lebenden Individuen über ihr gesamtes Leben hinweg in zahlreiche Organisationen eingebunden sind, Organisationen ihr Dasein prägen und durchdringen. Wissen über die Gestaltungsoptionen von Organisationen und die damit einhergehenden Effekte bewertet er als für die Auseinandersetzung mit diesen sozialen Gebilden daher als überaus hilfreich. Brauchbares Wissen ist nach Preisendörfer daran zu erkennen, dass es zum Wohl, aber auch zum Schaden der Menschheit genutzt werden kann (Preisendörfer, 2016, S. 5 ff.).

Es bleibt festzuhalten, dass die Organisationsforschung national wie international zu den zentralen Forschungsfeldern der Soziologie gehört. Ihr wird ein erheblicher Beitrag an deren interdisziplinärer Anschlussfähigkeit zugesprochen (Maurer, 2015, S. 129). Im Lexikon zur Soziologie (2011) beschreiben Detlef Krause und Friedrich Blahusch „Organisationsforschung“ ähnlich wie dies Hillmann getan hat: ${ }^{39}$

Untersuchungen über Eigenschaften, Merkmale, Struktur, Funktionen, Arbeitsweise, Verfahren, soziale und andere Probleme von Organisationen zur Gewinnung grundlegender Erkenntnisse und/oder zur Prüfung organisationstheoretischer Aussagen. Die neuere Organisationsforschung legt das Schwergewicht auf die empirisch fundierte Erklärung von Organisationsstrukturen. Hiernach bestehen zwar in gewissen Grenzen gesicherte Zusammenhänge zwischen Zielen, Transformationstechniken, Organisationsideologien usw. und Strukturindikatoren, aber entzieht sich die tatsächliche Komplexität der vorgefundenen Strukturen allgemeinen und reduktionistischen Erklärungen (Krause, \& Blahusch 2011, S. 490).

\footnotetext{
${ }^{39}$ Verschiedene potentiell von der Organisationsforschung zu behandelnde Fragestellungen sowie diverse Ebenen und Elemente von Organisationsanalysen finden sich bei Abraham und Büschges (2009, S. 62 ff.).
} 
Damit ist ein Einblick in Organisationen als soziale Konstrukte sowie in die Soziologie und Forschung, die sich mit ihnen beschäftigt, gegeben. Es sollte ersichtlich geworden sein, dass es Wissen über Organisationen, welches in deren Transformationstechniken oder in Organisationsideologien bestehen kann, zu gewinnen gilt. Für den weiteren Verlauf dieser Forschungsarbeit kommt die nun folgende soziologische Definition von Organisationen zum Tragen; diese vereint deren wesentliche Merkmale: ${ }^{40}$

Von bestimmten Personen gegründetes, zur Verwirklichung spezifischer Zwecke planmäßig geschaffenes, hierarchisches [sic] verfasstes, mit Ressourcen ausgestattetes, relativ dauerhaftes und strukturiertes Aggregat (Kollektiv) arbeitsteilig interagierender Personen, das über wenigstens eine Entscheidungs- und Kontrollzentrum verfügt, welches die zur Erreichung des Organisationszweckes notwendige Kooperation zwischen den Akteuren steuert, und dem als Aggregat Aktivitäten oder wenigstens deren Resultate zugerechnet werden können (Abraham, \& Büschges, 2009, S. 58 f.).

Dieser Absatz konnte nur einen Einblick in Organisationen, in deren Erforschung und in die Soziologie, die sich mit diesen beschäftigt, geben. Veronika Tacke und Thomas Drepper (2018) sind der Frage nachgegangen, worin nun das genuin Spezifische der Soziologie der Organisationen besteht und kamen zu folgendem Schluss:

${ }^{40}$ Abraham und Büschges (2009, S. 100 ff.) schlagen weiterhin verschiedene Kriterien zur Klassifikation von Organisationen vor, thematisieren deren mögliche Ziele sowie Strukturen, betrachten Organisationen zum einen als Interaktionssysteme, zum anderen als Interaktionspartner und verorten diese im Kontext der Gesellschaft. Da sich diese Studie auf eine bestimmte Organisation bezieht und die entsprechenden Aspekte schon behandelt hat, lässt sie diese außer Acht. 
Das Markenzeichen organisationssoziologischer Analysen kann man in gesellschaftsbezogenen, deskriptiven Analysen von Organisationen als Sozialsystemen sehen. Die Organisationssoziologie analysiert Organisationen im Rahmen einer differenzierten Gesellschaft. Als ,Spezielle Soziologie ‘ analysiert sie dabei ihren Gegenstand zunächst einmal organisationsbezogen. Organisationen sind ihr Gegenstand. Der Gesellschaftsbezug der Organisationssoziologie entfällt dabei nicht. Direkt sichtbar und thematisch wird er dort, wo die ,Organisationsgesellschaft " im Sinne der Effekte und Folgen zum Thema wird, die die Durchdringung der Gesellschaft mit Organisationen mit sich bringt. Direkt sichtbar ist der Gesellschaftsbezug soziologischer Organisationsanalysen auch dort, wie die Auseinandersetzung von Organisationen mit differenzierten gesellschaftlichen Umwelten eigens zum Thema wird, wobei die Begriffe der Analyse allerdings nicht von vornherein durch eine einzelne und bestimmte gesellschaftliche Funktion [. . . ] so überformt ist, dass die Eigenständigkeit und Eigenwilligkeit des organisatorischen Geschehens ,übersehen“ werden. So paradox es anmutet: Die Organisationssoziologie ist als soziologische Teildisziplin speziell für organisationsbezogene Forschungen zuständig. Sie kann aber als Organisationssoziologie - also als eine soziologische Teildisziplin - zugleich nicht auf einen gesellschaftlichen Bezug verzichten. Sie muss in ihrer Perspektive auf den Gegenstand allerdings in Rechnung stellen, dass weder die Gesellschaft in ihren Organisationen aufgeht noch umgekehrt Organisationen die Gesellschaft sind. Eine gewisse Eigenständigkeit von Organisationen gegenüber der Gesellschaft vorausgesetzt, hat die Organisationssoziologie es mit dem Verhältnis von Organisationen und Gesellschaft zu tun (Tacke, \& Drepper, 2018, S. 14, Hervorheb. i. O.).

\subsubsection{Wissen in Organisationen}

Die Organisationsforschung scheint durch den Wissensbegriff für die Berücksichtigung des sozialen Charakters von Organisationen sensibilisiert worden zu sein. Im Rahmen entsprechender Ansätze werden Organisationen mitsamt ihren internen Prozessen der Sinnkonstruktion und ihren externen Beziehungen als soziale Systeme untersucht. Über den Wissensbegriff entdeckt und erfindet die Wissensgesellschaft gewissermaßen auch ihre Organisationen neu (Drepper, 2007, S. 588).

Wie überhaupt inzwischen der Wissensbegriff im Organisationskontext Hochkonjunktur hat, so hat auch diese Studie den Organisationsbegriff in ihre empirische Untersuchung von Wissen integriert; konkret ist dies über Festsetzung des organisationalen Wissens und dessen Genese wie Verwendung als zentralem Forschungsgegenstand geschehen. Daher gilt es nun, den theoretischen Blick auf Wissen in Organisationen zu richten. 
Wenn verstanden werden soll, wie bestimmte Organisationen operieren und strukturiert sind, muss deren Wissen analysiert werden. Konzepte wie „Wissensorganisation“ und „Wissensmanagement" oder „Knowledge Engineering“ und „Wissensarbeit" nehmen unmittelbar Bezug auf den Wissensbegriff, indem sie ihn in ihrem Titel führen. ${ }^{41}$ Aber auch andere Begriffe, die nicht direkt darauf rekurrieren, wie „Lernende Organisation“, „,Virtuelle Organisation“, „Kompetente Organisation“, „Organizational Intelligence“, „Intellectual Capital“ und „Intellectual Assets“ beschreiben

[. . . ] einen (scheinbar) paradigmatischen Wandel von klassischen Organisationsformen der industriellen Moderne zur postmodernen Organisationswirklichkeit [. . . ]. Bemerkenswert ist an diesen Konzepten besonders die Intensität, mit der Organisation auf den Konnex von Innovation und Wettbewerbsfähigkeit gerichtet wird, basierend auf der verbreiteten Einschätzung, dass tayloristisch orientierte Produktions- und Organisationsformen und Kontrolltechnologien den komplexen Governanceproblemen der Organisationen des 21. Jahrhunderts gegenüber immer ungeeigneter erscheinen. Daten, Informationen und Wissen werden zu den relevanten Ressourcen im ausgehenden 20. und beginnenden 21. Jahrhundert [. . . ] (Drepper, 2007, S. 589).

Die Bedeutung des Wissensbegriffs beruht auf der Beschreibung sowie Reflexion von Prozessen des gesellschaftlichen und organisationalen Wandels. Wissen ist nicht nur gesamtgesellschaftlich relevant, sondern für Organisationen auch als Produktionsfaktor. Wissen gilt als intellektuelles Kapital moderner Organisationen, Ressource der Zukunft, zentraler Wettbewerbsfaktor und Motor für Innovationen. Durch Wissen erfahren die klassischen Produktionsfaktoren, Kapital und Arbeit, eine Bedeutungsverschiebung; Wissen wird zum relevanten Kriterium für Organisationen und Wirtschaft (Drepper, 2007, S. 589; Gutounig, 2015, S. 42 ff.; Stewart, 2001, S. 18; Strulik, 2007, S. 714 f.; Wimmer, 2012, S. 215 ff.).

Es lässt sich vermuten, dass dies mit dem Wesen der Moderne selbst zu tun hat. Eine Zeit, deren Grundzug Veränderung und Beschleunigung ist, hat ihre Orientierung auf die Zukunft ausgerichtet. Statt nach dem Vorbild der Tradition auf das Immerwährende zu schauen, geht es um eine Erkundung, Erschließung und Verwertung von Möglichkeiten in der Zukunft (Strulik, 2007, S. 713).

${ }^{41}$ Bei „Wissensarbeit“ handelt es sich wie beim „Wissensmanagement“ um ein Konzept, welches im Rahmen der Diskussion des Wissensbegriffs im Organisationskontext überaus populär thematisiert wird. Forschungsökonomische sowie -strategische Gründe bedingen es, dass dieses keinen Eingang in die vorliegende Arbeit findet. Thematisiert wird Wissensarbeit mitunter von Jäger (2007b), Strulik (2007) und Willke (1998). Wissensmanagement behandelt im Folgenden ein weiterer Exkurs (2.2.6). 
Arnold Windeler (2015) geht noch einen Schritt weiter und thematisiert Organisationen und deren durch diverse Technologien unterstützte Fähigkeiten, Wissen zu generieren, zu speichern und auch zu manipulieren, im Kontext der ,radikalisierten Moderne“ nach Anthony Giddens. Die „Transformation von Bürokratien zu reflexiven Organisationen" gründet für ihn in genau zwei Veränderungen: Zum einen darin, welche Prinzipien und Gegenstände administrativ berücksichtig werden; zum anderen in der Frage, worin das Wissen besteht, auf dessen Grundlage Organisationen als solche handeln. Reflexive Organisationen würden zwar bürokratische Strukturmerkmale nutzen, sie aber ergänzen und so ihre Bedeutung verändern, etwa durch Social Media und Big Data:

\begin{abstract}
Reflexive Organisationen verschaffen sich [. . . ] das gegenüber Bürokratien tendenziell komplexer gewordene, zur Administration „benötigte“ Wissen über von ihnen im Organisationsfokus als relevant Angesehenes systematisch über Beobachtungen, Rationalisierungen und Motivationen von Geschehen in Organisationen wie in als relevant angesehenen Kontexten. Hierzu greifen sie nicht zuletzt auf Experten zurück, schaffen Einheiten wie Abteilungen, die spezielles Wissen generieren und verwenden als passend eingestufte Überwachungs- und Kontrolltechnologien. Und entscheidend ist: Sie verwenden das so generierte Wissen zur rekursiv-reflexiven Ausgestaltung von Bedingungen organisationalen Geschehens und des Handelns in und von Organisationen (Windeler, 2015, S. 181 f., Hervorheb. i. O.).
\end{abstract}

Eine von mehreren Herausforderungen radikal moderner Organisationen besteht in ,neuen Formen organisational vermittelter Ausdifferenzierung und Verbindung von Gesellschaftsbereichen“. Organisationen bieten diverse „Praktiken der Bearbeitung“ oder auch „Umgangsweisen mit Kontexten“ an (Windeler, 2015, S. 183 f.).

Das intellektuelle Kapital eines Unternehmen setzt sich nach Thomas A. Stewart (2001) aus mehreren Komponenten zusammen: (1) „Human Capital“, das Stewart mit „Talent“ gleichsetzt; (2) „Structural Capital“, das er als „Itellectual Property“, „Methodologies“, „Software“, „Documents“ und „Other Knowledge Artefacts“ präzisiert; (3) „Customer Capital“, das in "Client Relationships“ bestehe (Drepper, 2007, S. 589; Stewart, 2001, S. 11 ff.). Ähnlich beschreibt Rudolf Wimmer (2012) organisationales Wissen: 
Wissen hat offenbar sehr viel mit dem zu tun, was ein soziales System im Prozess seines Entstehens und seiner Geschichte an erfolgreichen Strategien zur Sicherung des eigenen Überlebens entwickelt hat. Es findet in den Produkten und Dienstleistungen, im gesamten Leistungsspektrum einer Organisation den äußerlich beobachtbaren, meist sinnlich nachvollziehbaren Ausdruck. Diese sind die nach außen sichtbaren Früchte, während das kollektiv erworbene Wissen die nicht leicht zugänglichen Wurzeln, die tiefer liegende Quelle der Leistungsfähigkeit einer Organisation, darstellt. Diese Quelle speist sich aus dem Erfahrungsschatz, der im Laufe der Zeit durch die erfolgreiche Bewältigung von Herausforderungen im Verhältnis zu spezifischen Umwelten, aber auch im Umgang mit den eigenen internen Entwicklungsproblemen aufgebaut worden ist. Ein solcher Erfahrungsschatz bündelt ganz unterschiedliche Wissenskomponenten (das Beherrschen bestimmter Technologien, unterschiedliches Prozesswissen, Kenntnisse der Bedürfnisse der Kunden und anderer externer Bezugsgruppen, das Wissen betreffend die Eigenheiten der eigenen Organisation, der handelnden Personen usw.). Erst das Zusammenwirken dieser Komponenten schafft die spezifische Know-howBasis einer Organisation, die die Einzigartigkeit ihres Problemlösungspotenzials im Vergleich zu anderen zu begründen vermag. Wissen ist eine Ressource, die sich durch ihren Einsatz nicht verbraucht, im Gegenteil. Gelingt es, die eigenen Operationen als erfolgreich zu qualifizieren, so bestätigt und festigt dies die in Anwendung befindlichen Wissensfelder, und dies wiederum schützt vor Verunsicherungen und Irritation (Wimmer, 2012, S. 220).

Entsprechend stellt auch Thomas Drepper (2007) eine ,semantische Neuerfindung der Organisation durch den Wissensbegriff“ fest und beleuchtet diese sowohl aus einer organisationstheoretischen als auch gesellschaftstheoretischen Perspektive. Ein erster Grund für diese „Redescription“ sei aus organisationstheoretischer Perspektive die Beratungskommunikation und die damit assoziierte Wissensindustrie mit ihrem Globalisierungs-, Wettbewerbs- und Innovationsvermögen. Ein zweiter Grund für die ,semantische Neuausrichtung der Organisation“ sei die organisationswissenschaftliche Ideenentwicklung. Fortwährend lote diese die Grenzen eines instrumentalistisch und zweckrationalistisch verkürzten Verständnisses von Organisationen aus und schlage Alternativen vor. Doch der Zweckrationalität von Organisationen stehe ihre Komplexität und Eigenlogik gegenüber. Drepper stellt fest, dass organisationale Strukturen und Prozesse im Zuge dieser „Redescription“ aus der Wissensperspektive betrachtet werden; Entscheidungsprämissen würden als bestimmte Wissensformen verstanden. Ferner merkt Drepper an, dass sich die ,semantische Neuausrichtung der Organisation“ durch die Wissensperspektive auch in der Rolle abzeichnet, welche Organisationen in gesellschaftlichen Prozessen besetzen. Allerdings werde hier die Wissenssemantik oft mit Semantiken der Wirtschaftskommunikation assoziiert. Der Auftritt und die Funktion von Organisationen als Wissenskonsumenten und Wissensproduzenten oder auch 
als Wissensdistributoren und Wissensselektoren würden in diesem wirtschaftlichen Kontext diskutiert. Drepper betrachtet außerdem die von ihm konstatierte „Redescription“ aus einer gesellschaftstheoretischen Perspektive. Wissen sei für Organisationen schon bedeutsam gewesen lange bevor von „Wissensgesellschaft“, „Informationsgesellschaft" oder auch „Mediengesellschaft" die Rede war (Drepper, 2007, S. 590 ff.).

Der Wandel, den die Neubeschreibung von Organisationen mit dem Wissensbegriff markiert, zeichne sich insbesondere in den neuen Konditionen ab, welche moderne Gesellschaften an Organisationen stellten. Drepper nimmt hier Bezug auf Haridimos Tsoukas (2005) und betont ,den Formalisierungsgrad, die Systematizität sowie die Expertenbasiertheit" von Wissen; das theoretische Wissen dominiere das empirische. Es herrsche ein erhöhter Anspruch an Verfahren und Prozeduren zur Objektivierung, Standardisierung, Dokumentierung und Evaluierbarkeit. Dieser Prozess werde zwar oftmals als „Verwissenschaftlichung“ deklariert, aber es gehe hier in erster Linie um den Methodenaspekt wissenschaftlichen Wissens, also um Komplexitätsreduktion und nicht um Theoriebezüge. Folglich diagnostiziert Drepper eine Differenzierung, Dezentralisierung sowie Dislozierung gesellschaftlich relevanten Wissens durch „Organisationsrationalitäten“ und durch Massenmedien (Drepper, 2007, S. 593). ${ }^{42}$ Mit Blick auf die „semantische Neuausrichtung der Organisation“ hält Drepper fest:

Die Ansprüche an die Spezialisierung, Systematisierung und Dokumentierung von Organisationspraktiken steigt. Der Bedarf an Expertenwissen ebenfalls. Dieses Wissen ist aber nicht mehr automatisch Professionswissen oder gar wissenschaftliches, an Wahrheitsfähigkeit orientiertes Wissen. Es geht um Problemlösungs- und Anwendungswissen, wobei die neuen Professionals und Experten Organisationsexperten oder aber Experten innerhalb medial vernetzter Themen- und Interessen-Communities sind, die, auf neue Informations- und Kommunikationstechniken gestützt, in dezentralen Netzwerken Themen produzieren und so mitunter auch neues Wissen kondensieren. [. . . ] In Organisationen sind es die sogenannten communities of practice, die ebenfalls, stark über neue Informations- und Kommunikationstechnologien getragen, themen-, problem- und projektbezogen interagieren und so bereichsspezifisches semantisches Material produzieren und kommunizieren [... ]. Der Management- und Organisationsimperativ erreicht nahezu alle gesellschaftlichen Bereiche und setzt diese unter Organisations- und Management- und damit unter verstärkten ökonomischen Rationalisierungs- und Effizienzdruck [. . . ] (Drepper, 2007, S. 594).

\footnotetext{
42 Der Rolle, die Massenmedien in diesem Zusammenhang einnehmen, kann innerhalb dieser Studie keine weitere Beachtung geschenkt werden. Siehe hierzu: Drepper, 2007, S. 593 f..
} 
Längst sind einige organisationstheoretische Ansätze zu verzeichnen, die sich um die Systematisierung der Beziehung von Organisationen und Wissen bemühen. Jedoch läuft ein Verständnis von Organisationen als Wissenssysteme oder wissensbasierte Systeme nach wie vor zahlreichen gängigen Perspektiven zuwider. In vielen Bereichen der Organisations- und Managementtheorie hat sich die Vorstellung von Organisationen als ,informationsverarbeitenden Systemen“ etabliert. Tsoukas und Nikolas Mylonopoulos (2004) sehen Organisationen nicht nur als solche oder als ,,informationsprozessierende Systeme“, sondern begreifen sie vor allem auch als Wissenssysteme (Drepper, 2007, S. 595; Tsoukas, \& Mylonopoulos, 2004, S. 7): ${ }^{43}$

\begin{abstract}
Viewing an organization, especially a firm, as a knowledge system focusses our attention not just on the kinds and amounts of information potentially stored in the formal organizational memory [... ] an on the consequent possibilities for searching for patterns in data warehouses [... ] but, more broadly and more subtly, on how organizational members' work-related experiences are turned into publicly accessible knowledge [... ] (Tsoukas, \& Mylonopoulos, 2004, S. 7).
\end{abstract}

\title{
2.2.3 Organisationale Wissensgenese
}

Nachdem zuletzt Wissen im Kontext von Organisationen thematisiert wurde, ist nun die organisationale Wissensgenese zu betrachten und der Frage nachzugehen, auf welche Weise Organisationen Wissen erzeugen. Mit anderen Worten: Es geht um die Relation von Organisationen und Wissen. Eine Beantwortung der Frage anhand entsprechender soziologischer Theorien ist für diese Studie bedeutsam, da organisationales Wissen, dessen Genese und Verwendung ihren wesentlichen Forschungsgegenstand darstellt. ${ }^{44}$

\footnotetext{
${ }^{43}$ Verstanden als Wissenssysteme werden Organisationen beispielsweise auch im Hinblick auf die ihnen inhärente Kultur und bezüglich ihrer institutionellen Logik analysiert. Ersteres geschieht mitunter dann, wenn „Knowledge as Culture“ betrachtet wird, wie bei McCarthy (1996); siehe hierzu auch: Maasen, 2012, S. 68 f.. Letzteres, also die Betrachtung von Organisationen in Bezug auf ihre institutionelle Logik ist ein Ansatz, der auch als NeoInstitutionalismus bekannt ist oder aber im Rahmen dessen aktueller Entwicklung geschieht. Zwar beinhaltet auch dieser aufschlussreiche Erkenntnisse, doch jede Studie bedarf Selektionen; daher wird der Neo-Institutionalismus nicht weiter thematisiert und verwiesen auf: Kirchner, Krüger, Meier, \& Meyer, 2015; Maurer, 2015; Senge, 2015; Preisendörfer, 2016, S. 166 ff.; Tacke, \& Drepper, 2018, S. 75 ff..

${ }^{44}$ Der Aspekt der Wissensverwendung wird jedoch nicht innerhalb des vorliegenden Abschnitts, sondern erst im weiteren Verlauf, im Rahmen der Ergebnisdarstellung der umgesetzten empirischen Untersuchung konkretisiert.
} 
Im Allgemeinen ist, unter Bezugnahme auf Mark Granovetter und dessen viel zitierten Aufsatz Economic Action and Social Structure: The Problem of Embeddedness (1985), auch von einer Social Embeddedness hinsichtlich der organisationalen Wissensgenese auszugehen; das meint institutionalisierte Vorstellungen darüber, ,wie etwas getan werden soll, wer etwas tun soll und mit welchem Ziel etwas getan werden soll“". ${ }^{45}$ Allmendinger und Hinz führen diese Annahme wie folgt aus:

Organisationen sind zweckgerichtet, aber sie sind dies - so eine zentrale Botschaft des Institutionalismus - immer bezogen auf größere soziale Kontexte. Darunter fallen Marktsegmente, Industriezweige, politische Systeme und Nationalstaaten. Diese embeddedness betrifft aber auch Arbeitsgruppen, die sich in Organisationen bilden oder von diesen gebildet werden. Sie betrifft letztlich auch den Erfolg von Führungsstilen in Organisationen. Die Frage nach dem Einfluss des Kontextes muss also breit und die Organisationsforschung übergreifend gestellt werden. Gleich welche spezifischen Kontexte man untersucht, immer haben sich diese durch in historischer Zeit ablaufende Prozess der Institutionalisierung von Vorstellungen darüber ausgebildet, wie etwas getan werden soll, wer etwas tun soll und mit welchem Ziel etwas getan werden soll. Man könnte sagen, es handle sich um allmählich sedimentierte, weithin geteilte Normen, welche durch Wiederholung und Verinnerlichung breite gesellschaftliche Wirkung entfalten. [ . . ] Institutionen verringern die unbegrenzte Zahl von Möglichkeiten auf ein feasible set, das sich durch geübte Praxis laufend selbst erneuert (Allmendinger, \& Hinz, 2002, S. 16, Hervorheb. i. O.).

Die Soziologie habe den Gedanken eines von Institutionen erzeugten „Feasible Sets" über eine lange Zeit hinweg als Widerspruch zur modernen gesellschaftlichen Dynamik und damit mitunter auch als Blockade sozialen Wandels verstanden. Dem stehe jedoch entgegen, dass den Institutionen selbst eine nicht zu unterschätzende Bedeutung für soziale Entwicklung zuzusprechen ist. Angehörigen eines gesellschaftlichen Systems geben Institutionen Sicherheit in Bezug auf ihr Handeln, Institutionen legitimieren eine Handlungspraxis; damit „organisieren“ sie soziale Vorgänge. Für Allmendinger und Hinz steht fest, dass ganze Organisationen sowie auch deren einzelne Einheiten stets in ein Umfeld eingebettet sind; Organisationssoziologie oder Organisationsforschung gelte es kontextbezogen zu betreiben. Sowohl der Kontext von Individuen in Organisationen als auch der von Organisationen selbst sei zu beachten; strukturelle Eingebundenheit sei für Individuen ebenso wie für Organisationen gegeben (Allmendinger, \& Hinz, 2002, S. 16 ff.).

\footnotetext{
${ }^{45}$ Auf die von Mark Granovetter begründete New Economic Sociology und dessen Konzept der ,Social Embeddedness“ kann diese Arbeit nicht näher eingehen. Siehe hierzu: Granovetter, 1985; Granovetter, \& Swedberg, 1992; Maurer, 2017a, 2017b, 2015, 2012.
} 
Ein Ansatz, welcher im weiteren Verlauf dieses Abschnitts im Hinblick auf die Relation von Wissen und Organisationen anhand der Überlegungen von Haridimos Tsoukas noch näher vorgestellt wird und seinen Fokus auf die von außen erkennbaren Praktiken in und von Organisationen legt, ist die praxistheoretische Perspektive. Mit dieser hat sich auch Sylvia Marlene Wilz (2015) auseinandergesetzt und kam dabei zu einem Schluss, der an die Ansichten von Allmendinger und Hinze anschließt, diese sogar vertieft:

Die Komplexität von Organisation ist [. . . ] am ehesten zu fassen, wenn bei aller Fokussierung auf die Fluidität von organisationalen Strukturen und Grenzen nicht verloren geht, dass Organisationen sehr wohl materiale und auf Dauer gestellte Entitäten sind, wenn bei aller Fokussierung auf das äußere Geschehen und die Bedeutung der Dinge nicht verloren geht, dass zum Handeln das Wahrnehmen, Deuten und gezielte Handeln gehört, das nur von menschlichen Subjekten geleistet werden kann, und wenn bei aller Fokussierung auf das sinnkonstituierende Zusammenwirken von Akteuren nicht verloren geht, dass Machtbeziehungen und Interessenverfolgung das organisationale Geschehen entscheidend mit prägen (Wilz, 2005, S. 264).

Zwar spricht Wilz von „Sinn“, Allmendinger und Hinz hingegen betonen „Kontext"; der vorliegenden Forschungsarbeit liegt jedoch die Annahme zugrunde, dass ein Sinn nicht ohne Einbezug des Kontexts erschlossen werden kann und somit beide Konzepte miteinander korrespondieren beziehungsweise zusammengehören.

Legt man eine solche praxistheoretische Perspektive zugrunde, sind Organisationen, so Wilz weiter,

[... ] also nicht als eine top-down-gesteuerte Entität anzusehen, sondern als Raum von Praktiken und als kommunikativer Prozess, an dem viele Akteure an verschiedenen Stellen beteiligt sind. In solchen Praktiken wird routinisiert und intentional gehandelt; Geschehen und Steuerung fließen als unterscheidbare, aber untrennbar miteinander verwobene Formen des Geschehens ineinander (Wilz, 2015, S. 265).

Organisationen als ,soziale Gebilde“ setzen sich gemäß Wilz aus einer Struktur, ihren Akteuren und deren Handeln zusammen. Sofern diese erforscht werden sollen, gelte es das Flechtwerk subjektiver Perspektiven, individueller ,Umgangsformen mit der Welt" und übergreifender Muster der Wahrnehmung, Deutung und Handlung einzubeziehen, denn diese Dimensionen bilden die Praxis von Organisationen. Letztere beinhalte auch bereits „Momente der Institutionalisierung“, wie Normen, Regeln und Standards. Bei Institutionen handle es sich um ,verallgemeinerbare Verfahren der Praxis“, die es zu wahren gelte. Basierend auf einer praxistheoretischen Perspektive ist also davon auszugehen, dass in Organisationen 
spezifische Praktiken der Wissenserzeugung institutionalisiert sind, die die organisationale Wissensgenese bestimmen. Dies entspricht dem, was Allmendinger und Hinz mit Granovetter „,soziale Eingebundenheit“ nennen (Allmendinger, \& Hinz, 2002, S. 16 ff.; Wilz, 2015; S. 265).

Im Folgenden werden nun unter Rückgriff auf Drepper die praxistheoretische sowie des Weiteren eine kognitionstheoretisch-wissenssoziologische und eine systemtheoretisch-wissenssoziologische Betrachtungsweise der Relation von Organisationen und Wissen beziehungsweise der Genese von Wissen in und durch Organisationen in groben Zügen nachgezeichnet. Was die drei Ansätze eint und auch deren Aufnahme in die vorliegende Arbeit rechtfertigt, soviel sei schon vorher gesagt, ist ihr Versuch, Wissen als soziales Phänomen begreifbar zu machen; dies tun sie im Hinblick auf Organisationen (Drepper, 2007, S. 608 f.). ${ }^{46}$

\subsubsection{Praxistheoretische Perspektive}

Die praxistheoretische Perspektive, mit der auf die Beziehung von Organisationen und Wissen geblickt wird, ist auch als „Practice Turn“ oder „Practical Turn" bekannt und wird in dieser Studie anhand von Haridimos Tsoukas' Arbeit Complex Knowledge. Studies in Organizational Epistemology (2005) vorgestellt. ${ }^{47}$ Tsoukas (2005) richtet seinen Blick auf die Moderne und bringt deren gesamtgesellschaftlichen Strukturwandel mit ihrem organisationalen in Verbindung. Er konstatiert eine Überbeanspruchung des Wissensbegriffs und fordert dessen Systematisierung (Drepper, 2007, S. 596). Für die Erklärung der Genese sowie Verwendung von organisationalem Wissen sind gemäß Tsoukas zwei theoretische Zugänge erforderlich:

$[\ldots]$ to understand the generation and utilization of knowledge we need a theory of knowledge, and to understand organizational knowledge we need a theory of organization (Tsoukas, 2005, S. 119).

\footnotetext{
${ }^{46}$ Eine der Darstellung von Drepper (2007) recht ähnliche, wenn auch deutlich weniger umfangreiche Thematisierung von Wissen und Organisationen, welche jedoch explizit mit Wirtschaftsorganisationen gleichgesetzt werden, findet sich bei Strulik (2007).

${ }^{47}$ Wilz (2015) hat eine Skizze der praxistheoretischen Debatte um Organisationen vorgelegt. Sie spricht ihr pragmatische, sozialkonstruktivistische und strukturationstheoretische Wurzeln zu und geht der Frage nach, wie praxistheoretische Überzeugungen in der Organisationsforschung angewendet werden können. Einige Gedanken Wilz' wurden in diesem Abschnitt schon angeführt.
} 
Der von Tsoukas vertretene praxistheoretische Wissensbegriff, der auch ein operativer ist, bindet Wissen an Handlungen sowie bestimmte soziale Praktiken. Für Tsoukas sind Wissen und Handeln untrennbar miteinander verwoben (Drepper, 2007, S. 596):

[. . .] knowledge begins with actions (Tsoukas, 2005, S. 96).

Drepper fasst Tsoukas' praxistheoretische Position insofern zusammen, dass Wissen die individuelle Fähigkeit sei, in Handlungskontexten Unterscheidungen zu treffen. Dabei sei der urteilende oder wertende Aspekt von Wissen maßgeblich. Tsoukas überträgt die Wissensperspektive der praxistheoretischen Position, welche das Verstehen und die Sinninterpretation von Individuen als soziale Praktiken begreift, auf Organisationen als Wissenssysteme (Drepper, 2007, S. 596 f.; Tsoukas, 2005, S. 121 ff.):

Organisationales Wissen ist dann die von Organisationsmitgliedern entwickelte Fähigkeit, in Organisationskontexten angemessene Unterscheidungen treffen zu können, die auf historisch entwickelte und kollektiv eingelebte Generalisierungen zurückgehen. Wissen wird organisational, insofern Individuen, indem sie in ihren Arbeitskontexten Unterscheidungen treffen, auf die Kontextualität ihrer Handlungen Bezug nehmen. D. h. sie agieren auf der Basis eines Korpus von Sinngeneralisierungen, die z. B. in Form typischer Regeln vorliegen (Drepper, 2007, S. 597).

In Bezug auf organisationales Wissen streicht Drepper vier Kernaussagen von Tsoukas als für dessen Bestimmung entscheidend heraus: (1) Dessen Träger sind sowohl die individuellen Mitglieder einer Organisation als auch die organisationalen Routinen. (2) Das organisationale Wissensproblem besteht in der Nutzbarmachung von Wissen. (3) Eine Organisation ist wegen ihrer internen Heterogenität als verteiltes Wissenssystem einzuordnen. (4) Organisationales Wissen ist aufgrund seines Ursprungs in weiteren, mit der Organisation verwobenen sozialen Kontexten verstreut (Drepper, 2007, S. 597). Damit liegt mit Tsoukas beziehungsweise seiner Interpretation durch Drepper eine für diese Forschungsarbeit relevante Bestimmung von organisationalem Wissen vor.

Ferner unterscheidet Tsoukas proportionales von narrativem Organisationswissen und thematisiert anhand dieser Unterscheidung die Herkunft organisationalen Wissens. Bei proportionalem Organisationswissen handle es sich um eines, das zu den institutionell ausdifferenzierten Organisationskontexten in unmittelbarem Bezug stehe; es entspreche ,geregelten, routinisierten und institutionalisierten sozialen Situationen“ und erzeuge durch seine Anwendung selbst wieder Regeln 
und Routinen für soziale Situationen. Jedoch gebe es Grenzen des proportionalen Wissens; dieses könne zwar Situationen und Erfahrungen der Vergangenheit generalisieren, aber kein Wissen zur Gestaltung von Regeln für die Zukunft liefern. Daher gründeten Organisationen nicht nur auf diesem, sondern ebenso auf narrativem Wissen, das auf soziale Praktiken verweise. Letztere bedürften wegen ihrer Unvollständigkeit oder auch Mehrdeutigkeit der Interpretation und Deutung. Die „Regelungslücke“ des propositionalen Wissens werde durch soziale Praktiken, also narratives Wissen geschlossen. Für diese Arbeit ist die von Tsoukas benannte und weiter von Drepper herausgearbeitete Differenzierung zwischen diesen beiden Wissensformen, soziale Praktiken einerseits, Regeln und Routinen andererseits, wesentlich. Erstere beschreiben, wie etwas in einer Organisation praktisch gemacht wird, letztere geben an, wie etwas darin gemacht werden soll oder sollte. Es handelt sich damit also um Wissen, das in Organisationen entweder aufgrund von Regeln und Routinen existiert oder auf sozialen Praktiken beruht. Dass zwischen diesen beiden Formen von Wissen unterschieden wird, bedeutet, dass das Sollen und das Tun nicht immer deckungsgleich sind und die Praktiken von den Vorgaben mitunter abweichen; es sind mehrere Gründe denkbar, weswegen dies der Fall sein könnte (Drepper, 2007, S. 597 f.; Tsoukas, 2005, S. $70 \mathrm{ff}$.).

Tsoukas streicht zwei strukturelle Merkmale von modernen Gesellschaften heraus, die das Wissensphänomen in Organisationen beeinflussen. Zum einen die „Paradoxien der Informationsgesellschaft“: (1) „More Information, Less Understanding“, (2) „More Information, Less Trust“, (3) „More Social Engineering, More Problems“. Zum anderen die aufgrund von modernen Informations- und Kommunikationsmedien ,hochgradig generalisierte Kommunikation“. Daten und Informationen würden aufgrund dieser mit Wissen assoziiert und als zentrale „Wirklichkeitselemente“ aufgefasst. Da die moderne Kommunikation die Selbstbeobachtung und auch -beschreibung der Gesellschaft enorm beeinflusse, erkennt Tsoukas eine ,informationszentrierte Wirklichkeitssicht" und damit einhergehend die Verbeitung eines Wissensbegriffs, der auf Informationen beruhe und diese mit Wissen gleichsetze. Informationen würde eine „objektive Qualität“ sowie Unabhängigkeit von Prozessen subjektiver Sinnstifung zugesprochen (Drepper, 2007, S. 599 f.; Tsoukas, 2005, S. 15 ff.):

Die Welt wird als rational steuer- und kontrollierbar vorgestellt, wenn und insofern im ausreichenden Maße Informationen erhoben, produziert, abgelegt und kontrolliert werden können [Tsoukas 2005: 20] (Drepper, 2007, S. 600). 


\title{
2.2.3.2 Kognitions- und wissenssoziologische Perspektive
}

Kognitionstheoretische Auseinandersetzungen mit Organisationen zeichnen sich durch eine für die vorliegende Forschungsarbeit bedeutsame Auffassung der organisationalen Wissensgenese aus. In deren Zentrum steht die Abhängigkeit sämtlichen Erkennens, Wahrnehmens, Denkens und Kommunizierens von Schemata, Beobachtungen und Unterscheidungen (Drepper, 2007, S. 601).

\begin{abstract}
Aus der kognitiven Forschungstradition entspringt [. . . ] der Ansatz der Organizational Sensemaking Studies, in dem die Herstellung und Aufrechterhaltung von Bedeutung in und durch Organisationen untersucht wird. Dabei stellt Sinn die Grundkategorie menschlichen Seins dar, d. h. Ursache und Wirkung allen menschlichen Denkens und Handelns. Indem Individuen und auch Kollektive ununterbrochen Sinn generieren und aufrechterhalten, bewahren sie die notwendige Übersicht und Handlungsfähigkeit in den komplexen Situationen, in denen sie sich ständig wiederfinden. Im Rahmen dieses Ansatzes wird Sinn auch als Metapher für die prinzipielle Konstruktion von Wirklichkeit herangezogen (Wetzel, 2005, S. 159 f., Hervorheb. i. O.).
\end{abstract}

Durch Karl E. Weicks Ansatz des Sensemaking oder auch seine „Epistemologie des Organisierens“" in Gestalt des Werks Der Prozeß des Organisierens (1985/2015) wird die kognitions- und wissenssoziologische Perspektive um Orientierung anhand von Sinn, Attribution und Bedeutung erweitert. Relevant ist dies vor allem für die qualitative Organisationsforschung (Drepper, 2007, S. 601; Hiller, 2005, S. 7 ff.). Im Folgenden wird diese Betrachtungsweise des Verhältnisses von Wissen und Organisationen anhand des Konzepts von Weick, vor allem über dessen Thematisierung von Drepper und Petra Hiller (2005) in den Blick genommen. ${ }^{48} 49$

Weick fasst die Rekursivität von Struktur und Handlung konsequent, indem er davon ausgeht, dass nicht nur Kognition Handlung bestimmt, sondern dass auch Handeln Erkenntnis produziert. Das drückt der enactment-Begriff im Weickschen Gestaltungsansatz aus. Enactment bzw. Gestaltung meint dabei den Akt der sinnhaften Setzung von Realitäten (Drepper, 2007, S. 601).

\footnotetext{
${ }^{48}$ Eine weitere detaillierte Auseinandersetzung mit der kognitiven Organisationsforschung findet sich in Wetzel (2005).

${ }^{49}$ Diese Arbeit kann nicht näher auf den von Weick herausgearbeiteten Organisationsprozess eingehen; eine Beschränkung auf das Verhältnis von Wissen und Organisationen, wie es von Weick beschrieben wird, muss erfolgen. Für eine tiefergehende Darstellung von Weicks Ansatz und Auseinandersetzung mit dessen Prozessmodell empfiehlt sich beispielsweise die Lektüre von Miebach (2009, S. 72 ff.), Rüegg-Stürm (2003, S. 136 ff.) und Wetzel (2005, S. 165 ff.).
} 
Mit ihrer Untersuchung von Organisationswissen hat Hiller eine wissenssoziologische Neubeschreibung von Organisation vorgelegt. Sensemaking übersetzt sie im Anschluss an Weick mit „Sinnerzeugung“; mithilfe von diesem Konzept beschreibe Weick

[. . . ] den Prozesscharakter der kontinuierlichen Hervorbringung von Realität [. . . ]. Sensemaking betont die aktive Generierung von Sinn, die nicht schon in den Gegenständen enthalten ist. [. . . ] Sinnerzeugung betont die der Interpretation vorgelagerten Konstruktionsprozesse (Hiller, 2005, S. 16).

Weick, so erklärt Hiller, habe sein, nicht als klassischen theoretischen Ansatz, sondern als Metaperspektive zu verstehendes Konzept der „Sinnerzeugung“ in Abgrenzung zum Interpretationsbegriff entwickelt. Letzterer suggeriere, dass es in der Welt bereits Interpretationsangebote gebe, die es zu entdecken gelte; im Gegensatz dazu beschreibe Sensemaking, dass Sinn erfunden und Realität beständig erzeugt werde. Organisationen charakterisiere Weick entsprechend auch als ,wissensgenerierende Sinnerzeugungs-, Interpretations- und Beobachtungssysteme“ (Hiller, 2005, S. 16 f.; Hiller, 2015).

Bei Johannes Rüegg-Stürm (2003) findet sich eine ausführlichere Erklärung:

Organisation versteht Weick deshalb als Organisieren, und Interpretation wiederum heisst für Weick in erster Linie Sensemaking. Sensemaking ist für Weick zugleich ein sozialer (kollektiver) und ein individueller, vergangenheitsorientierte Prozess, der dazu dient, vorerst ungeordnete mehrdeutige Ereignisse in einen sinnhaften Gesamtzusammenhang zu bringen, so dass koordiniertes Anschlusshandeln möglich wird. Dies ist für Weick auch Grund, die herkömmliche, rational geprägte betriebswirtschaftliche Logik sozusagen auf den Kopf zu drehen. Dies trifft vor allem das Primat des Handelns vor dem Denken, was die Erarbeitung von Zielen und die Bedeutung von Planung in neues Licht stellt. Weick vertritt den Standpunkt, dass Handlungen sehr oft Zieldefinitionen vorausgehen, d. h. dass Ziele erst im Nachhinein aufgrund erfolgter Handlungen formuliert werden, wie sich jeder Zielkonsens auf etwas Handfestes wie bereits erfolgte Ereignisse stützen muss (Rüegg-Stürm, 2003, S. 134, Hervorheb. i. O.).

Insbesondere in mehrdeutigen, unsicheren und unerwarteten Situationen, die dadurch gekennzeichnet sind, dass Routinen und Typisierungen in ihnen nicht greifen, werden Sinnerzeugungen unternommen. Es handelt sich bei diesen um einen „Mechanismus der Ordnungsgenese“; wesentlich dabei ist ein Selektionsprozess (Drepper, 2007, S. 601; Hiller, 2005, S. 18 f.; Miebach, 2009, S. 72 f., S. 76 f.; Rüegg-Stürm, 2003, S. 133 f.). 
Für Weick sind Organisationen keine Systeme, die nur auf ihre Umwelt reagieren, deren Informationen intern abbilden oder weiterverarbeiten. Weick begreift Organisationen als wissensgenerierende Systeme. Anhand selektiver Bedeutungszuschreibungen, die auf den persönlichen Relevanzen von Organisationen beruhen, würden sie ihre eigene Umwelt miterzeugen (Drepper, 2007, S. 601; Hiller, 2005, S. 18 ff.; Miebach, 2009, S. 78; Rüegg-Stürm, 2003, S. 133 f.):

Ein wesentliches Kennzeichen unseres Modells des Organisierens ist, daß die Umwelt eher als Output denn als Input angesehen wird. [... ] Wenn die gestaltete Umwelt einmal existiert, dient sie als glaubhafter Führer für zukünftige Handlungen und Interpretationen. Eine gestaltete Umwelt ist ein historisches Dokument, das im Retentionsprozeß gespeichert wird, gewöhnlich in der Form einer Ursachenkarte, welche künftigem Handeln übergelegt werden kann. In einem gewissen Sinn ist daher das Produkt einer Organisation, ihr Hauptergebnis, der „Grund“ für ihre Existenz oder ihr „Ziel“ die Schaffung von stabilen Interpretationen für mehrdeutige Vorlagen (Weick, 1985/2015, S. 326 f.).

Somit wird über Sinnerzeugungsprozesse in Organisationen die kognitive Ebene mit der Handlungsebene verknüpft; eine gestaltete Umwelt wiederum formiert den Kontext für Selektion und Interpretation. Weicks Ansatz gehört zur kognitiven Sozialpsychologie; diese beruht auf der Annahme, dass Wissensprozesse durch die soziale Einbettung der Handelnden bestimmt werden. Kognition ist keine Angelegenheit eines individuellen Bewusstseins, sondern Bestandteil eines sozialen Kontextes und kann auch nur aus diesem heraus verstanden werden. Die kognitionsorientierte Organisationstheorie geht also von einem sozialen Charakter des Wissens aus und richtet ihr Hauptaugenmerk auf die Bedeutungskonstruktion in Organisationen und damit auf die Interdependenz von individuellen und institutionellen Wissensstrukturen. Hiller betont die unverkennbare Nähe dieses Ansatzes zum interpretativen Paradigma. Organisationssoziologische Arbeiten, welche die Relation von Handeln und sozialer Kognition thematisieren, hätten ihren Ursprung insbesondere in der wissenssoziologischen Konzeption von Berger und Luckmann (1969/2009). Innerhalb der Organisationstheorie sei es dann allen voran Weick, der unter Rückgriff auf diese beziehungsweise die Überlegungen von Schütz die Relation von Handeln und sozialer Kognition in seinem Der Prozeß des Organisierens (1985/2015) behandle (Drepper, 2007, S. 601 f.; Hiller, 2005, S. 12 ff., S. 21).

Bernhard Miebach (2009) nennt Weicks Ansatz ,konstruktivistische Prozesstheorie" und charakterisiert deren Bedeutung für die Organisationstheorie so: ${ }^{.0}$

${ }^{50}$ Sehr ähnlich formuliert dies auch Rüegg-Stürm (2003, S. 132 f.). 
Das Buch Der Prozess des Organisierens von K. E. Weick (1985) stellt einen Meilenstein der Organisationstheorie dar. Mit diesem Buch wird die konstruktivistische Perspektive in der Tradition von Schütz der bis dahin vorherrschenden Definition von Organisation als zielgerichtetes rationales Handeln von Organisationsmitgliedern in einer vorgegebenen Organisationskultur entgegen gestellt (Miebach, 2009, S. 72, Hervorheb. i. O.).

Damit ist nun auch Weicks kognitionsorientierte Organisationstheorie eingereiht in die interpretative oder „kulturalistische“ Wende, die durch das Entfachen eines Interesses an Konzepten wie „Sinn“, „Deutung“ und „Bedeutung“ oder „Interpretation“ sowie an Begriffen wie „Mehrdeutigkeit“, „Attribution“, „Wahrnehmung“ und „Muster" geprägt war und heute als interpretatives Paradigma bekannt ist (Drepper, 2007, S. 602; Hiller, 2005, S. 14 f.; Miebach, 2009, S. 72 f.; Wetzel, 2005, S. 162 f.): $:^{51}$

In der Vorstellung einer Soziologie der Kognition in Organisationen geht es um soziale Kognitionen [. . . ]. Es geht um kognitive Schemata als Deutungssysteme, die Produktion und Reproduktion von Sinn, den Aufbau von Wissen sowie die Genese von Wissensprozessen und Sinnzuschreibungen als Erzeugungen organisationaler Wirklichkeiten (Drepper, 2007, S. 602).

Ein Zusammenhang von Kultur und Kognition wird angenommen; soziale Kognitionen werden auf ,generalisierte kulturelle Schemata“ beziehungsweise „kulturelle kognitive Schematisierungen“ zurückgeführt. Es geht also immer auch um die gesellschaftliche Einbettung von Organisationen. Organisationale Wissensprozesse sind auf gesamt- und suborganisationaler sowie auf gesellschaftlicher Ebene auszumachen. Es handelt sich um verschiedene „Dimensionen der kognitiven Struktur sozialer Organisationen" und damit unterschiedliche Formen der Wissensgenese. Generalisierte kulturelle Schemata sind in der sozialen Umwelt von Organisationen zu finden; diese können deren Wissensstrukturen widersprechen. Eine mitunter verschiedene Wahrnehmung dieser Umwelt bedingt das Entstehen spezifischer Denkstile, im Sinne ,gesellschaftlich institutionalisierter Klassifikationssysteme von Welt". Hiller führt hier das auch für diese Studie relevante Ingenieursdenken als Beispiel an (Drepper, 2007, S. 602; Hiller, 2005, S. 37 ff).

\footnotetext{
${ }^{51}$ Auf Weicks Anschluss an die wissenssoziologische Konzeption von Berger und Luckmann einerseits und Abgrenzung von dieser andererseits beziehungsweise deren Weiterentwicklung und Kritik kann im Rahmen dieser Arbeit nicht näher eingegangen werden; siehe hierzu: Hiller, 2005, S. 15 ff.. Die neue Wissenssoziologie von Berger und Luckmann wurde bereits thematisiert und wird im weiteren Verlauf dieser Forschungsarbeit ebenso wie das interpretative Paradigma noch näher beleuchtet.
} 
Für die Organisationsforschung schlägt Hiller unter Bezugnahme auf Luhmann, vor, kulturelle kognitive Schemata als analysierbare Entscheidungsprämissen zu begreifen. Organisationales Entscheiden sei kulturell verankert; Kultur gebe einen ,symbolisch appräsentierten Sinnhorizont“ des möglichen Erlebens und Handelns vor, der selektiv angepasst werde. Im Gegensatz zu formalen Strukturelementen von Organisationen, die als ,entscheidbare Entscheidungsprämissen“ gelten, seien kulturelle kognitive Schemata ,unentscheidbare Entscheidungsprämissen“. Letztere werden auch ,implizites Wissen“ genannt und haben die „kognitiv schematisierte Erzeugung sozialen Sinns“ zur Aufgabe. Ein organisationaler Wissenskomplex umfasst neben Entscheidungsprämissen eine „organisationale Identität“ oder ,organisationale Selbstbeschreibung“ (Drepper, 2007, S. 602 f.; Hiller, 2005, S. 30 f., S. 40 ff.): ${ }^{52}$

Organisationale Identitätsentwürfe sind kollektive Selbstbeschreibungen und als solche beobachtungsabhängige Konstruktionen [... ]. Als Vergleichsschemata begrenzen soziale Identitäten die Verhaltensmöglichkeiten von Organisationen [. . . ]. Identitätskonstruktionen können somit als hoch generalisierte Entscheidungsprämissen aufgefasst werden. [. . . ] Man kann auch anders sagen: Organisationale Selbstbeschreibungen strukturieren Sensemaking und damit die Generierung von Wissen in Organisationen (Hiller, 2005, S. 30ff., Hervorheb. i. O.).

\subsubsection{Systemtheoretische Perspektive}

Nicht selten weist die Organisationsforschung, vor allem im deutschsprachigen Raum, einen Luhmann-Bias auf. Weder unterliegt diese Arbeit einem solchen noch verschließt sie sich gegenüber der Konzeption von Luhmann. Um zum einen die ganze Bandbreite des Verhältnisses von Wissen und Organisationen anzudeuten und zum anderen keinen relevanten Aspekt dessen ungeachtet zu lassen, wird daher im Folgenden der Blick auf die systemtheoretische Perspektive gerichtet, aus der die Beziehung von Organisationen und Wissen beziehungsweise

\footnotetext{
52 Wie nahezu jede sozialwissenschaftliche Theorie sieht sich auch die von Weick einer Kritik ausgesetzt. Siehe hierzu: Hiller, 2005, 22 ff..
} 
die Wissensgenese im Zusammenhang mit Organisationen ebenso betrachtet werden kann. Zunächst ist zu klären, was diese Betrachtungsweise unter Wissen versteht. 5354

Ohne Angabe einer „Systemreferenz“ ist aus systemtheoretischer Perspektive Wissen im Sinne der "operativen Logik" der Wissensgenese überhaupt nicht möglich (Drepper, 2007, S. 603). Unter einer „Systemreferenz“ versteht Luhmann (1992/2015) das, was

[... ] ein Beobachter dem zugrunde legt, was wir mit aller Vorläufigkeit als „Wissen“ bezeichnen wollen (Luhmann, 1992/2015, S. 128).

Von einer systemtheoretischen Position aus gesehen, wird Wissen schließlich als eine bestimmte Kommunikationsstruktur begriffen. Luhmanns Ansatz gründet damit auf der operativen Trennung und zugleich strukturellen Verbindung von Kommunikation und Bewusstsein als ,eigenlogischer, selbstreferentiell operierender und strukturierter Sinnsysteme“ (Drepper, 2007, S. 603). Wissen begreift Luhmann damit als eine „soziale Tatsache“,

[. . . ] die sich in und nur in der sozialen Kommunikation aktualisiert und Bewußtsein allenfalls über strukturelle Kopplungen als unentbehrliche Umweltbedingung in Anspruch nimmt (Luhmann, 1992/2015, S. 68).

Für Luhmann ist Wissen eines der ,konstitutiven Merkmale des Gesellschaftssystems"; ohne unterstellbares Wissen wäre Kommunikation gar nicht möglich. Wissen entspricht damit zugleich einer Kommunikationsstruktur, die „Operationen“, wie beispielsweise auch Kommunikation, begünstigen, jedoch ebenso

\footnotetext{
${ }^{53}$ Diese geschieht in aller für diese Arbeit gebotenen Kürze, kann somit nicht weit in die Tiefe gehen, sondern muss oberflächlich bleiben und darf auch nur die Relation von Wissen und Organisationen behandeln. Die auf Luhmanns Systemtheorie beruhende Auffassung von „Organisation als soziales System“ stellen zum Beispiel Aderhold (2003) sowie Tacke und Drepper (2018, S. 41 ff.) näher dar.

${ }^{54}$ Mit Luhmanns systemtheoretischem Blick auf Organisationen und Wissen setzt sich auch Hiller (2005, S. 25 ff.) auseinander. Sie merkt an, dass es im Rahmen der kognitionstheoretischen Organisationstheorie nach Weick unberücksichtigt geblieben ist, dass Wahrnehmen zwar eine Bewusstseinsleistung darstellt, als solche aber keine „Organisationsqualität“ aufweist. Dieser Einsicht würde Luhmanns Ansatz gerecht werden, indem er davon ausgeht, dass sich die Autopoiese psychischer und sozialer Systeme unabhängig voneinander vollzieht.
} 
einschränken kann (Drepper, 2007, S. 603; Luhmann, 1992/2015, S. 122). Für Luhmann handelt es sich bei Wissen daher weiterhin

[. . . ] um eine Implikation des Kommunikationsvorgangs selbst, um eine mittransportierte Unterstellung, um ein Merkmal der sozialen Autopoiesis. Wissen muß, wie Sprachstrukturen, als Voraussetzung mitlaufen und kann thematisch nie voll in der Kommunikation expliziert werden (Luhmann, 1992/2015, S. 122).

Drepper bezeichnt Wissen in Anlehnung an Luhmann als

[. . . ] spezifisch typisierter, sedimentierter und stilisierter Sinn, der wiederum fundamentale Hintergrundserfüllung weiterer Kommunikation ist (Drepper, 2007, S. 604).

In den Worten von Luhmann:

Wissen ist demnach in einem extrem allgemeinen (und nicht kulturspezifischen) Sinne kondensiertes Beobachten und in einem spezielleren Sinne, der evoluiertes Unterscheidungsvermögen voraussetzt, eine als kognitives Erleben stilisierte Erwartungshaltung (Luhmann, 1992/2015, S. 145 f.).

Organisationen gelten innerhalb der systemtheoretischen Perspektive gemeinhin als „informationsverarbeitende Systeme“. Luhmann geht noch einen Schritt weiter und begreift diese gar als ,informationskonstruierende oder informationskonstituierende Systeme“. Mit den ihnen typischen Operationen, die Luhmann „Entscheidungen“ nennt, würden Organisationen Informationen nämlich nicht nur verarbeiten, sondern ebenso generieren. Dies nun ist die eigentliche Konsequenz seiner „Entscheidungstheorie der Organisation und Organisationstheorie der Entscheidung“. In Organisationen würden Entscheidungen in Entscheidungen und damit zugleich Informationen in Informationen umgewandelt werden:

In Luhmanns Verständnis hängen Unsicherheit, Unsicherheitsabsorption und Wissen miteinander zusammen. Der Schritt von Information zu Wissen läuft bei Luhmann darüber, dass Unsicherheitsabsorption Wissen als Kontext voraussetzt (Drepper, 2007, S. 605).

Dabei handelt es sich um Wissen, über das Organisationen selbst verfügen und das nicht von potentiellem Wissen einzelner Individuen abhängt. Vielmehr gilt dieses Wissen als Ergebnis von Lernprozessen innerhalb von Organisationen, ist in diesen gespeichert und kann bei Kommunikation vorausgesetzt werden (Drepper, 2007, S. 605).

In Organisationen, mit Luhmann als komplexe und differenzierte Systeme verstanden, kommt neben dem Wissen ebenso dem Nichtwissen eine wichtige und keinesfalls zu unterschätzende Funktion zu. Zum einen besteht diese in der 
„Kunst des Ignorierens“, zum anderen aber auch in der absichtlichen Generierung von Nichtwissen und seiner Erhaltung. Letztere in Organisationen praktizierte Strategie kann wiederum zwei Zielen zuträglich sein: einerseits der Absorption von Unsicherheit und andererseits, um in Kenntnis des Nichtwissens anderer die eigene Kommunikation durchzusetzen (Drepper, 2007, S. 605). ${ }^{55}$

In ihrer Untersuchung von Organisationswissen oder auch der wissenssoziologischen Neubeschreibung von Organisationen spannt Hiller einen Bogen zwischen der zuvor, anhand von Tsoukas dargelegten kognitionstheoretischen Sichtweise auf die Relation von Wissen und Organisationen und der hier unter Rückgriff auf Luhmann behandelten systemtheoretischen Perspektive. Für die vorliegende Studie ist dies relevant, da so das in und durch Organisationen generierte Wissen als soziales Phänomen begreifbar wird. Hillers Worte sollen daher die Betrachtung von Wissen in Organisationen beschließen:

Das systemtheoretische Instrumentarium liefert einen theoretischen Zugriff auf das Thema Wissensgenerierung in Organisationen [. . . ]. Im Kommunikationssystem der Organisation entscheidet sich, welche Wahrnehmungen aussortiert und welche als Wissen weiterbehandelt werden. Das Zusammenspiel von individuellen Bewusstseinsleistungen und organisationaler Kommunikation wird durch Mechanismen struktureller Kopplung möglich. Neben der Sprache sind es kulturelle kognitive Schemata, die diese Scharnierstelle der Regulierung von Außenkontakten besetzen und so zum zentralen Forschungsgegenstand einer Soziologie organisationalen Wissens werden müssen. Der Luhmannsche Begriff der strukturellen Kopplung vermag das, was Weick als lose Kopplung von Kognition und Handeln bezeichnet, erheblich präziser zu fassen. Er ermöglicht es, die Bedeutung kognitiver Schemata im Rahmen einer kognitionsorientierten Organisationssoziologie theoretisch zu beschreiben und ihrer Funktion nach zu bestimmen (Hiller, 2005, S. 29, Hervorheb. i. O.).

\subsubsection{Wissen in der Automobilindustrie: Kundenwissen}

Untersuchungsgegenstand der hier vorliegenden Forschungsarbeit ist das Wissen eines Automobilherstellers. Es setzt sich aus vielen verschiedenen Wissensformen zusammen. Für diese Studie ist vor allem das Kundenwissen bedeutsam, da sie die Praxis seiner organisationalen Genese und Verwendung im Zusammenhang mit der digitalen Methode der Social-Media-Analysen untersucht. Es gilt, Kundenwissen als eine Art von Wissen in den Blick zu nehmen. Im Folgenden

\footnotetext{
55 Nichtwissen betrachten außerdem auch Strulik (2007), Maasen (2012, S. 66 f., S. 84 f.) und Knoblauch (2014, S. 277 ff.).
} 
wird daher theoretisch abgesteckt, was Organisationen der deutschen Automobilindustrie, etwa Automobilhersteller, überhaupt als Kundenwissen einordnen und ferner welche Art von Kundenwissen für sie relevant ist. Es geht um Wissen in der Automobilindustrie: Kundenwissen. 565758

Diverse Ansätze der Unternehmensführung, die mit verschiedenen Methoden arbeiten, um am Markt Erfolg zu erzielen, sind seit Beginn der wirtschaftlichen Entwicklung in Deutschland zu verzeichnen. In den 1990er Jahren rückt der Kunde in den Mittelpunkt:

Es zeichnet sich eine Individualisierung der Produkte nach spezifischen Kundenwünschen und Erwartungen ab, weshalb die Unternehmen gezwungen sind, ihre Marketingaktivitäten in Form der Kundenorientierung an den Bedürfnissen des einzelnen Kunden auszurichten [. . . ] (Heiss, 2009, S. 22).

Dies gilt ebenso für die Automobilindustrie. Im Fokus von Automobilherstellern stehen deren Kunden. Kundenorientierung gilt ihnen als entscheidender Wettbewerbsfaktor. Um wettbewerbsfähig zu sein, müssen verschiedene Bedürfnisse der Kunden befriedigt und Anforderungen erfüllt werden. Neben Produktqualität gilt Kundenzufriedenheit als die wesentliche Zielgröße der Automobilhersteller. Die Kunden der Automobilindustrie sehen sich heute mit einer enormen Vielzahl ähnlicher Produkte konfrontiert; dies zwingt die Automobilhersteller dazu, sich von ihren Wettbewerbern weitestgehend abzuheben. Eine dabei entscheidende Komponente stellt Kundenwissen dar (Bruhn, 2011; Heiss, 2009; Hinterhuber, \&

\footnotetext{
${ }^{56}$ Andere in der Automobilindustrie relevante Wissensformen klammert die hier vorliegende Studie aus forschugsstrategischen wie -ökonomischen Gründen aus ihrer Betrachtung aus.

${ }^{57}$ Eine empirische Studie, die im Rahmen eines von einem deutschen Automobilkonzern geförderten Doktorandenprogramms entstanden ist und sich mit dieser Fragestellung bereits beschäftigt hat, stammt von Heiss (2009). Diese wird für die theoretische Betrachtung von Wissen in der Automobilindustrie als vorrangige Quelle herangezogen. Heiss hat die bei dem von ihr betrachteten Unternehmen existierenden Wissensquellen zu Kunden aus der Perspektive einer Forschungs- und Entwicklungsabteilung analysiert, strukturiert und schließlich unter Bezugnahme auf den deutschen Automobilhersteller ein Rahmenmodell für Kundenwissen entwickelt. Eine weitere Studie über die „Kultivierung von Kundenwissen“ hat Schaschke (2010) vorgelegt. Es handelt sich dabei um eine wirtschaftswissenschaftliche Arbeit mit einem entsprechenden Fokus. Da sie keine ergänzenden Aspekte enthält, wird von ihrer Betrachtung abgesehen. Die Arbeit von Heiss reiht sich in die Psychologie und Medienwissenschaften ein und ist damit der hier vorliegenden soziologischen Studie näher; ferner weist sie einen Bezug zur deutschen Automobilindustrie auf.

${ }^{58}$ Heiss' Ausführungen gründen auf dem „strukturgenetischen Wissensbegriff“ von Seiler und Reinmann (2004). In die vorliegende Studie geht er nicht ein. Siehe hierzu: Seiler, \& Reinmann, 2004; Reinmann, 2009, S. 26 ff., 2005, S. 7 ff.; Heiss, 2009, S. 12 ff., S. 21.
} 
Matzler, 2009; Gochermann, 2004; Riedel, \& Gresser, 2016; Spiegel, \& Chytka, 2007; Wildemann, 2004). ${ }^{59}$ Kundenorientierung, so betont Horst Wildemann (2004), fängt nicht erst beim fertigen Produkt an, sondern muss schon bei der Forschung zu neuen Produkten oder auch deren Entwicklung durch die frühzeitige Identifikation von Kundenanforderungen beginnen:

Dabei ist die zunehmende Bedeutung des Kunden bzw. die Kundeneinbindung in den Prozess der Produktentwicklung von ausschlaggebender Bedeutung und muss sich in einer entsprechenden Neuausrichtung der Organisation und des Entwicklungsprozesses widerspiegeln. Angesichts des erforderlichen Paradigmenwechsels im Kundenverständnis - weg vom bloßen Impulsgeber im Rahmen von den der Produktentwicklung vorgeschalteten Marktforschungen, hin zu einem Mitarbeiter im Entwicklungsprozess - steht das traditionelle Produktmanagement als Bindeglied zwischen Marketing und Entwicklung vor neuen Herausforderungen. Die frühzeitige Identifikation der Kundenanforderungen und des Erfahrungswissens der Abnehmer ist zum entscheidenden Erfolgsfaktor geworden (Wildemann, 2004, S. 383 f.).

Ebenso konstatiert Heiss, dass die Herausforderung, die die Automobilindustrie künftig meistern muss, in der Herstellung einer Verknüpfung von Kundenwissen und weiteren Einflussfaktoren, wie technologischen Entwicklungen der Unternehmen und auch deren Umwelt, besteht. Kundenwissen müsse direkt in die Forschung und Entwicklung neuer, innovativer, aber auch in die Optimierung bestehender Produkte einbezogen werden (Heiss, 2009, S. 1 f.; Pohl, 2003, S. 80 ff.; Roccasalvo, 2003, S. 42):

Entscheidend ist nicht der objektiv-technische Vorteil gegenüber der Konkurrenz, sondern ob er subjektiv vom Kunden als solcher festgestellt wird und Kaufentscheidungen getroffen werden. [. . . ] Ein genaues Verständnis der Kundenbedürfnisse, der Kundensegmente und gesellschaftlichen wie auch politischen Entwicklungen ist somit unumgänglich für den, der am Markt erfolgreich agieren will (Heiss, 2009, S. 1 f.).

Kundenorientierung, die letztlich auf einer Begeisterung der Kunden, einer Lösung von deren Problemen und einer künftigen Erfüllung ihrer Erwartungen beruht, korreliert mit Kundenzufriedenheit und ist daher für Automobilhersteller überaus bedeutsam. Doch für Kundenorientierung und Kundenzufriedenheit ist Kundenwissen im doppelten Sinne als Wissen von Kunden und als Wissen

${ }^{59}$ Zahlreiche Beiträge zu Kundenorientierung und Kundenzufriedenheit sowie dem damit verfolgten Ziel der Kundenbindung enthält der Sammelband von Hinterhuber und Matzler (2009); zudem haben sich Bruhn (2011) sowie Riedel und Gresser (2016) mit dem Konzept der „Kundenorientierung“ beschäftigt. 
über Kunden entscheidend: Wissenschaft wie Praxis haben dies längst erkannt (Gochermann, 2004; Heiss, 2009, S. 2 ff.). ${ }^{60}$

Über die Begriffe „Kundenorientierung“, „Kundenzufriedenheit“ und „Kundenwissen“ lässt sich das für diese Forschungsarbeit relevante Wissen in der Automobilindustrie konkretisieren. Manfred Bruhn (2011) nennt als Ziel von Kundenorientierung

[. . . ] die Erfüllung des individuellen Kundenwunsches bzw. der Erwartungen der Kunden und nicht die Schaffung eines allgemeinen Wettbewerbsvorteils (Bruhn, 2011, S. 45).

Daran anschließend definiert er Kundenorientierung als

[... ] die umfassende, kontinuierliche Ermittlung und Analyse der individuellen Kundenerwartungen sowie deren interne und externe Umsetzung in unternehmerische Leistungen sowie Interaktionen [. . . ] mit dem Ziel, langfristig stabile und ökonomisch vorteilhafte Kundenbeziehungen zu etablieren (Bruhn, 2011, S. 47).

Unter Rückgriff auf Hermann Simon und Georg Tacke (1994) merkt Heiss an, dass Kunden niemals Produkte an sich kaufen, sondern vielmehr Lösungen für ihre Probleme oder Befriedigungen ihrer Bedürfnisse. Wissen von und über Kunden sei die Grundlage für Produktverbesserungen und Innovationsentwicklungen. Kundenorientierung bedeute für ein Unternehmen, seine Kunden zu kennen. Allerdings, so erklärt Heiss weiter, können nicht alle Wünsche und Forderungen der Kunden in die Produktentwicklung eingehen; nur jene, die mit der Markenstrategie des Unternehmens in Einklang stünden, seien zu beachten. In Bezug auf den Wettbewerb gelte es, Alleinstellungsmerkmale festzusetzen. Bei Kundenorientierung handle es sich nicht um einen Zustand, sondern um einen Prozess. Dieser müsse „Mittel zum Zweck des ökonomischen Erfolgs“ bleiben (Heiss, 2009, S. 23 f.; Simon, \& Tacke, 1994, S. 171).

Die auf Kundenorientierung beruhende Kundenzufriedenheit erklärt Heiss anhand des „Kano-Modells“. ${ }^{61}$ Bezüglich dieser biete die Forschung verschiedene Ansätze, eine allgemein anerkannte Definition liege noch nicht vor. Oft findet laut

\footnotetext{
${ }^{60}$ Unter „Kunde“ fasst diese Arbeit, wie auch Heiss (2009, S. 9), den Endkunden oder Konsumenten. Wenn von „Kunde“ die Rede ist, so ist damit in der Regel die Beziehung „Business-to-Costumer“ (B2C) gemeint, also der Automobilhersteller gegenüber seinen Endkunden. Nicht gemeint sind damit hingegen Beziehungen der Art „Business-to-Business“ (B2B), wie Zulieferer gegenüber dem Automobilhersteller in der Kundenrolle.

${ }^{61}$ Bezüglich des von Heiss thematisierten, im Kontext der Analyse von Kundenwünschen durch Noriaki Kano entwickelten „Kano-Modells“ siehe: Heiss, 2009, S. 24 ff..
} 
Heiss ein „Soll-Ist-Vergleich“ statt. Die von Kunden wahrgenommenen Erfahrungen werden mit den Leistungen von Anbietern, dem Ist-Zustand, anhand der Erwartungen der Kunden, dem Soll-Zustand, bewertet. Kundenzufriedenheit sei dann das Resultat eines komplexen Informationsverarbeitungsprozesses (Heiss, 2009, S. 24).

Kundenwissen, das sowohl für Kundenorientierung als auch für Kundenzufriedenheit unerlässlich ist, macht laut Heiss einen bedeutenden Anteil an dem gesamten in einem Unternehmen vorhandenen Wissen aus. Unternehmen hätten jedoch noch längst nicht sämtliches Kundenwissen erschlossen. Organisationen stehe nur ein kleiner Teil dieses Wissens in expliziter Ausprägung als Kundenwissen zur Verfügung, der größte Teil sei implizit mit den Kunden verbunden. Allerdings können anhand von Kundenwissen, welches auf von Kunden gemachten Erfahrungen basiert, zentrale Erkenntnisse über die Wünsche und die Zufriedenheit der Kunden gewonnen werden (Gochermann, 2004; Heiss, 2009, S. 27).

Drei verschiedene Arten von Kundenwissen gilt es, so betont Heiss, zu unterscheiden: (1) Wissen über die Kunden, (2) Wissen der Kunden, (3) Wissen für die Kunden. Wie auch bei Heiss erfährt Wissen für die Kunden im Rahmen der vorliegenden Arbeit mangels Relevanz in Bezug auf die Fragestellung keine weitere Beachtung. Im Fokus steht stattdessen das Wissen der Kunden beziehungsweise von den Kunden sowie auch das Wissen über die Kunden. Das Wissen der Kunden beschreibt Heis wie folgt (Heiss, 2009, S. 27 f.):

Wissensträger ist der Kunde selbst. Er verfügt über wertvolles Wissen im Hinblick auf die Produkte des Unternehmens, Vor- und Nachteile dieser Produkte, Angebote der Konkurrenz, seine eigenen Ziele, Bedürfnisse und Erwartungen. Dieses Wissen muss das Unternehmen erst erschließen und ist vor allem für Innovationsprozesse und damit für die Produktentwicklung von Bedeutung (Heiss, 2009, S. 28).

Demgegenüber setzt sie das Wissen über die Kunden mit Kundeninformationen gleich:

Dieses kundenbezogene Wissen steht zum Großteil intern im Unternehmen zur Verfügung und beschreibt den externen Kunden. Es wird vor allem mit CRM-Methoden erfasst und analysiert, z. B. Verkaufszahlen. Wissensträger ist das Unternehmen bzw. die Mitarbeiter (Heiss, 2009, S. 28). 
Heiss zufolge stehen einem Unternehmen zwei Wege offen, um an Kundenwissen zu gelangen: Auf Kundenwissen ausgerichtete Aktionen von Unternehmensseite oder Reaktionen von Kundenseite auf Produkte und Dienstleistungen des Unternehmens. Da Unternehmen den Kunden als wesentliche externe Wissensquelle erkannt hätten, rücke dieser in den Mittelpunkt. Somit werde internes Wissen über Kunden um Wissen von Kunden und Wissen der Kunden ergänzt. Bedingt sei dies zum einen durch die erhöhte Wettbewerbssituation und zum anderen durch den Wandel von Märkten wie Kunden. Aufgrund technologischer Entwicklungen, wie Social Media und dem Web 2.0, seien Kunden immer besser informiert; demgegenüber nehme die Markentreue beständig ab (Heiss, 2009, S. 29 f.). ${ }^{62}$

Eine Erfassung und anschließende Verwertung von Kundenwissen ist also bezüglich der Steigerung des Unternehmenserfolgs unabdingbar, denn Kundenwissen ermöglicht die Minimierung des Risikos, Produkte und Dienstleistungen an den Erwartungen und Wünschen der Kunden vorbei zu entwickeln (Heiss, 2009, S. 3; Herstatt, 2006; Piller, 2006). Heiss betont die Leistung, die durch Gewinn und Nutzung von Kundenwissen, erbracht werden kann:

Eine intensive Interaktion mit dem Kunden kann zu einem besseren Verständnis der Kundenbedürfnisse führen, Trends werden früher erkannt, die Markentreue kann gestärkt werden und erfolgreiche Produktinnovationen umgesetzt werden [... ] (Heiss, 2009, S. 4).

Obwohl sich viele Unternehmen selbst als ,kundenorientiert“ oder ,,marktorientiert" bezeichneten, nutzten nur wenige neben ihrem Wissen über die Kunden auch das Wissen der Kunden (Heiss, 2009, S. 3 f.; Herstatt, 2006; Piller, 2006).

Von besonderer Bedeutung ist Kundenwissen, verstanden als das Wissen von und über Kunden, laut Heiss für die Unternehmensbereiche Strategie, Marketing und Vertrieb; jedoch sind ebenso die Forschung und Entwicklung (F\&E) der Automobilhersteller darauf angewiesen. Die Aufbereitung von Kundenwissen und dessen Weitergabe im Unternehmen über organisationale Grenzen hinweg, wie zum Beispiel Bereiche und Abteilungen, zählt Heiss zur Praxis von Wissensmanagement. In der Automobilindustrie sei diese nicht etabliert und daher auch nicht erfolgreich (Heiss, 2009, S. 6, S. 33 f.).

\footnotetext{
${ }^{62}$ Heiss (2009, S. 29 ff.) betrachtet in diesem Kontext die drei strategischen Managementansätze des Knowledge Management (KM), des Customer Relationship Management (CRM) und des Customer Knowledge Management (CKM). Im Rahmen dieser Studie kann dies gar nicht beziehungsweise nicht an dieser Stelle geschehen.
} 


\subsubsection{Wissensgenese in der Automobilindustrie: Marktforschung}

Für die Automobilindustrie ist Kundenwissen überaus relevant und Marktforschung beherrscht die angewandte Praxis organisationaler Wissensgenese. Daher gilt es nun, Letztere in den Blick zu nehmen und der Frage nachzugehen, wie Automobilhersteller derzeit Kundenwissen generieren. Im Mittelpunkt der weiteren Betrachtung steht die Wissensgenese in der Automobilindustrie: Marktforschung. ${ }^{63}$

Automobilhersteller, produzieren ' Kundenwissen in der Regel über Marktforschung. Für ihre Studien nutzen sie Methoden empirischer Sozialforschung in adaptierter Form. Zumeist bedienen sie sich quantitativer Ansätze, aber auch qualitative Verfahren und Methodenkombinationen kommen zur Anwendung. Kundenbefragungen, sowohl über Fragebogen als auch durch persönliche Interviews, sind die am häufigsten gewählten Methoden, wobei die Automobilmarktforschung weitere Verfahren zum Einsatz bringt. Exemplarisch seien angeführt: Beobachtungen, Trendanalysen und Milieustudien, Gruppendiskussionen mit Kundenfokusgruppen, Produktanalysen und Testkäufe, Konzept- oder Prototypen-Tests über Car Clinics, Lead User und Open Innovation Ansätze, Social-Media-Analysen. Jedoch werden die Erhebung und Auswertung der Daten in der Regel von externen Marktforschungsinstituten umgesetzt und nicht von den Automobilherstellern selbst beziehungsweise deren für Marktforschung zuständigen Organisationseinheiten (Heiss, 2009, S. 54 ff., S. 103; Kaiser, 2004, S. 2 ff.; Herstatt, Lüthje, \& Lettl 2007, S. 62 ff.; Herstatt, 2006; Piller, Möslein, Ihl, \& Reichwald, 2017; Reichwald, \& Piller, 2009, S. 115 ff.; Spiegel, \& Chytka, 2007, S. 575 ff.). ${ }^{64} 65$

\footnotetext{
${ }^{63}$ Für deren Darstellung wird neben anderen Quellen erneut auf Heiss (2009) zurückgegriffen.

${ }^{64}$ Einen vertieften Einblick in die Marktforschung geben Berekoven, Eckert und Ellenrieder (2006) oder auch Kuß, Wildner und Kreis (2018).

${ }^{65}$ Heiss hat sämtliche von der Automobilindustrie genutzte Verfahren zur Gewinnung von Kundenwissen detailliert beschrieben und die einzelnen Methoden, deren Inhalte und Zielsetzungen anhand von vier Kriterien strukturiert. Da im Fokus dieser Arbeit jedoch einzig Social-Media-Analysen in ihren diversen Ausprägungen als zur Anwendung gebrachte Methode stehen und auf diese noch gesondert eingegangen wird, wird davon abgesehen, die von der Automobilmarktforschung genutzten Methoden näher zu thematisieren; siehe dazu: Heiss, 2009, S. 54 ff., S. 104 ff.. Des Weiteren wird das Methodenportfolio der Automobilmarktforschung beispielsweise auch von Spiegel und Chytka (2007) oder aber mit dem Fokus auf Open Innovation von Reichwald und Piller (2009) behandelt. Zudem ist anzumerken, dass Heiss selbst nicht von „Social-Media-Analysen“ spricht, sondern Data Mining und Communities beschreibt; dies scheint der Zeit geschuldet, die zwischen der Veröffentlichung der Arbeit von Heiss und der hier nun vorliegenden Studie liegt.
} 
Aufgrund ihres Unvermögens, Innovationen hervorzubringen, ist die Marktforschung laut Heiss seit Längerem vehementer Kritik ausgesetzt. Mit ihren klassischen Methoden sei sie nicht in der Lage, radikale Innovationen zu erzeugen. Kunden würden als „repräsentative, statistische Durchschnittsgröße“ behandelt. Da nach den Erfahrungen, Einstellungen und Wünschen mit aktuellen Produkten gefragt wird, würden Kunden bei Erfahrungen in der Vergangenheit oder Gegenwart haften bleiben. Das Unvermögen der Marktforschung, Innovationen $\mathrm{zu}$ erzeugen, wird mitunter mit deren vorrangiger Nutzung quantitativer Methoden und der Vernachlässigung qualitativer Verfahren begründet. Im Gegensatz zu durch Offenheit gekennzeichneten qualitativen Interviews hätten Kunden im Rahmen von quantitativen Befragungen keine Möglichkeit eigene, gegebenenfalls innovative Ideen anzubringen. Trotz der Repräsentativität, die als das entscheidende Merkmal ihrer Studien gilt, wird den Marktforschungsergebnissen eine nur begrenzte Prognosekraft zugesprochen; obwohl die Erwartung ,der Marktforschung' gegenüber darin bestehen, dass sie Resultate bereitstellt, anhand derer abgesicherte Entscheidungen getroffen werden können. Die Automobilindustrie verkennt oftmals die Grenzen von Marktforschung und verlangt nicht selten Unmögliches von ihr. Wenn sich Automobilhersteller nur an Ergebnissen ihrer repräsentativen Marktforschungsstudien orientierten, liefen sie Gefahr, dass ihre Produkte und Dienstleistungen veralten und sie nicht wettbewerbsfähig bleiben (Heiss, 2009, S. 69; Herstatt, Lüthje, \& Lettl, 2007; Herstatt, 2006; Reichwald, \& Piller, 2009, S. 1 ff.).

Zusammenfassend bedeutet dies, dass zwei diametrale Anforderungen an die Marktforschung gestellt werden: (1) Sie soll auf statistischer Basis belastbare, sichere Ergebnisse liefern und (2) zugleich Innovationspotenziale aufzeigen. Beide Anforderungen scheinen mit den bisherigen (klassischen) Methoden der Marktforschung nicht realisierbar (Heiss, 2009, S. 69).

Innovationen untergliedert die Wirtschaft in ,inkrementelle“ und „radikale“‘.66

\footnotetext{
${ }^{66}$ Soziale Innovationen werden in wirtschafts- oder ingenieurwissenschaftlichen Betrachtungen meist ignoriert; zumindest bleiben diese in der entsprechenden Literatur oft unerwähnt. Diese soziologische Arbeit weist deutlich darauf hin, dass es ebenso diesen Innovationstyp zu bedenken gibt. Thematisiert werden soziale Innovationen beispielsweise in: Beck, \& Kropp, 2012; Howaldt, Kaletka, Schröder, \& Zirngiebl, 2018; Howaldt, Kopp, \& Schwarz, 2018, 2015; Howaldt, Kopp, Böschen, \& Krings, 2017; Howaldt, \& Jacobsen, 2010; Howaldt, \& Schwarz, 2010.
} 
Bei einer inkrementellen Innovation nutzt ein Unternehmen eine etablierte Technologie, um einen vorhandenen Markt mit einem bereits existierenden, aber aus Sicht der Nachfrager überlegenen Produkt zu bearbeiten. [.. . ] Nutzt ein Unternehmen eine neue Technologie um einen bestehenden Markt zu bedienen, liegt eine technische Innovation vor. [.. . ] Schließlich können neue Märkte durch neue Technologien erschlossen werden, die alte Lösungen verdrängen. In diesem Fall spricht man von einer radikalen oder disruptiven Innovation [. . . ] (Reichwald, \& Piller, 2009, S. 122).

Radikale Innovationen sind für die Automobilindustrie gemeinhin einfacher umzusetzen als disruptive. Aus diesem Grund leistet Marktforschung einen wesentlichen Beitrag im Hinblick auf die für die Umsetzung von Innovationen erforderliche Repräsentativität der Studienergebnisse, indem sie Kundenerwartungen und -zufriedenheit zu Beginn des Kaufs eines Produktes oder einer Dienstleistung sowie nach der Nutzung untersucht. Beispielsweise wird in einer späten Phase des Entwicklungsprozesses von automobilen Produkten im Rahmen von Car Clinics die Produktakzeptanz anhand von Prototypen überprüft. Eine häufig genutzte Methode zur Analyse von inkrementellen Innovationen, zum Beispiel Produktoptimierungen, sind Zufriedenheitsstudien wie Early Buyer Studies. Zur Erschließung radikaler Innovationen durch Kundenwissen sind jedoch statt diesen seit Langem etablierten Verfahren ebenso innovative Methoden vonnöten. Für die Automobilindustrie ist der Umgang mit den verschiedenen Ansprüchen hinsichtlich der Erschließung von Innovationen bei Kunden und gesicherter Ergebnisse in Bezug auf das Wissen von und über Kunden derzeit noch ungeklärt. Die Marktforschung tut sich nicht nur schwer damit, Innovationen hervorzubringen, sondern auch dabei, innovative Methoden statt der seit jeher genutzten Ansätze anzuwenden (Heiss, 2009, S. 69 f.; Piller, 2009, S. 119 ff.). ${ }^{67}$

Eva Balzer (2007) stellt eine ,Geschichtslosigkeit der deutschen Marktforschung" fest und macht diese für deren Schwierigkeiten im Hinblick auf die Entwicklung von innovativen Methoden und den Umgang mit ihnen verantwortlich. Geschichtslosigkeit beruhe stets auf einem unbewussten Umgang mit

\footnotetext{
${ }^{67}$ Heiss kontrastiert die Methoden empirischer Sozialforschung, wie sie die Wissenschaft nutzt, mit den von Seiten der Marktforschung zur Erfassung von Kundenwissen angewandten Verfahren. Hintergrund dieser Gegenüberstellung ist, dass Heiss in der Praxis eine Unsicherheit im Hinblick auf die Akzeptanz von einzelnen Methoden festgestellt hat. Zwar würde sich die Marktforschung des Repertoires der Wissenschaft bedienen, eine Reflexion in Bezug darauf welche Methoden sie bevorzugt und welche, mitunter wegen Vorurteilen, abgelehnt werden, stehe jedoch aus. Auf diese Kontrastierung wird hier nicht näher eingegangen; siehe hierzu: Heiss, 2009, S. 71 ff.. Diese Forschungsarbeit richtet ihren Fokus auf Methoden der Social-Media-Analyse im Kontext der Automobilmarktforschung. Kenntnisse in Bezug auf das Methodenrepertoire empirischer Sozialforschung und den entsprechenden Forschungsprozess werden vorausgesetzt.
} 
Gegenwart und Zukunft. Heute sei die Marktforschung sogar in zwei Spannungsverhältnisse eingebunden. Zum einen in das zwischen Wissenschaft und Wirtschaft, wobei Erstere durch Theorie gekennzeichnet sei und Letztere sich durch Praxis auszeichne. Bereits in dem Begriff „Marktforschung“ würden zwei Welten aufeinandertreffen; einerseits die Welt des Marktes, der Wirtschaft und der Praxis, andererseits die Welt der Wissenschaft, der Forschung und der Theorie. Zum anderen befinde sich die Marktforschung in einem Spannungsverhältnis zwischen quantitativen und qualitativen Methoden. Marktforscher in Deutschland hegten ein durchaus ambivalentes Verhältnis gegenüber der Theorie; ein ,akutes Theoriedefizit" sei zu erkennen, wobei dieses als das Ergebnis eines längeren Entwicklungsprozesses einzuordnen sei. Die wissenschaftliche Auseinandersetzung mit Märkten beginnt im universitären Umfeld bereits in den 1920er Jahren. Marktforscher sind zu Beginn oft „Intellektuelle und Praktiker in Personalunion“, arbeiten zugleich wissenschaftlich und theoretisch sowie praktisch; sie haben entschieden, ihr Wissen in der wirtschaftsnahen Praxis anzuwenden. Seit den 1970er Jahren gestaltet sich das bis dahin positive Verhältnis von Wissenschaft und Praxis immer schwieriger; die akademische Forschung und die Marktforschung entfremden sich zunehmend voneinander. Ein Theoriebezug hat in der praxisorientierten Marktforschung an Bedeutung verloren. Die Beschäftigung mit Theorie gilt als beschwerlich und unnötig, da sie keinen direkten ,Mehrwert“ für die Marktforschungspraxis in der schnelllebigen Wirtschaftswelt liefert. Seitdem stehen sich die Vorwürfe des Theoriedefizits und der fehlenden Praxisrelevanz gegenüber. In den 1960er Jahren, die durch den endenden Nachkriegsboom und die aufkommende Wirtschaftskrise geprägt sind, wird die Marktforschung noch stärker an die im Wandel befindlichen Unternehmen und deren Kulturen sowie Strategien angebunden. Die Marktforschung sieht sich mehr denn je mit der Erwartung konfrontiert, „direkte Marktvorteile“ und „unmittelbare Benefits“ zu generieren. Ein „,konkreter Praxisnutzen“ wird immer noch wichtiger und verstärkt die Widerstände gegen die theoretischen Auseinandersetzungen. Letzten Endes geht mit dem zurückgehenden Theoriebezug der Marktforschung zugleich ihr sinkender Gesellschaftsbezug einher. Deutlich wird dies auch anhand der Forderung nach einem direkten Nutzen von Marktforschungsstudien in Verbindung mit einer schwindenden Anzahl von Arbeiten, die Grundlagenforschung darstellen. Marktforschung ist inzwischen mit der Produktion kurzfristig umsetzbarer Ergebnisse für unmittelbare, spezifische Probleme des Marketings beauftragt (Balzer, 2007, S. 33 ff.; Heiss, 2009, S. 99 f.; Spiegel, \& Chytka, 2007, S. 571 ff.): 
Marktforschung verlor ihre ursprüngliche Funktion der langfristigen Strategieentwicklung zugunsten der Zulieferung von marketingrelevanten „Insights“ für die kurzfristige Produktplanung und Umsatzoptimierung. [. . . ] Die überaus paradoxe Entwicklung, dass die Marktforschung in dem Maße an Relevanz verliert, in dem sie sich an die Zielvorstellungen der sie beauftragenden Unternehmen anpasst und sich zur „Erfüllungsgehilfin des Marketing“ degradieren lässt, wurde kaum wahrgenommen, im Gegenteil: Die Annäherung an das Marketing gilt vielfach als Zukunftsweg der Marktforschung (Balzer, 2007, S. 39).

Mit der Fokussierung der Marktforschung auf einen unmittelbaren praktischen Nutzen und dem damit einhergehenden Verlust des Theoriebezugs verengte sich allerdings auch der Horizont der Marktforschung beständig. Theoriebezug bedeutet forschungspraktisch nämlich auch, dass die Erforschung des Marktes in einem gesellschaftlichen Kontext und nicht isoliert erfolgt. Die Entfremdung der Praxis von der Theorie geschah nicht einseitig; auch die Wissenschaft distanzierte sich von der Marktforschung (Balzer, 2007, S. 39 f.; Heiss, 2009, S. 100). Inzwischen sind gänzlich verschiedene Intentionen von Wissenschaft und Wirtschaft oder eben Sozialforschung und Marktforschung in der Auseinandersetzung mit der Gesellschaft der Gegenwart festzustellen:

Mit jeweils unterschiedlichem Vokabular und ebenso unterschiedlichen Nutzungsintentionen setzen sich (Sozial-)Wissenschaften und Unternehmen mit der Beschaffenheit der gegenwärtigen Gesellschaft auseinander. [. . . ] Den soziologischen Begriffen der „Gesellschaft“ und der „,sozialen Gruppen“, den „Milieus“, „Schichten“ und „Lebensstilen“ steht das Sprechen (und Denken) von der „Zielgruppe“ gegenüber. Diese Begrifflichkeit verweist schon darauf, dass es hier nicht um den Erkenntnisgewinn um seiner selbst willen geht, sondern um Absichten: Die Steigerung des unternehmerischen Erfolgs, dessen Voraussetzung es ist, die anvisierte Käuferschaft zu erreichen - das Ziel zu „treffen“ (Kritzmöller, 2004, S. 2).

Monika Kritzmöller (2004) konstatiert die „Notwendigkeit einer Kooperation zwischen Wirtschaft und Wissenschaft" mit ihren zahlreichen Chancen ebenso wie sie feststellt, dass eine sinnvolle Integration oft unterbleibt und dadurch die ,Versäulung zwischen Elfenbeinturm und schnödem Mammon“ aufrechterhalten wird. Anhand der Ähnlichkeit von Begriffen aus dem Marketing und der Soziologie hebt sie die Nähe der beiden Disziplinen hervor und betont die Notwendigkeit der Nutzung qualitativer Methoden: 
Mit dem „Segment of one“ wird eine (nicht unbedingt zutreffende) Konsequenz dessen nahe gelegt, was die Soziologie seit zwei Jahrzehnten als „Individualisierung“ diskutiert. [. . . ] Wenngleich auch in der Soziologie über das Ausmaß dieses Prozesses Uneinigkeit besteht, so wird doch deutlich, dass sich Marketing wie Sozialwissenschaften von einer hierarchisierenden und quantifizierenden Denkweise in Schichten und Klassen verabschieden müssen, selbst wenn derartige Bezeichnungen nicht nur in der Soziologie weiterleben, sondern auch etwas in der Kategorisierung von Automobilen in Mittel- oder Oberklasse. Gefragt ist eine differenzierte, (auch) am Einzelfall orientierte Betrachtung des Gegenstandes, wie sie die qualitative Sozialforschung zu leisten vermag. An Stelle (oder zusätzlich zu) einer quantitativen Kumulation von Massendaten ist es dringend erforderlich, nicht nur die Anhäufung, sondern auch die Qualität und das Zustandekommen eines Phänomens zu erörtern (Kritzmöller, 2004, S. 2).

Die für die Marktforschung und damit in der Regel auch für das Marketing relevanten Fragen sind, so Kritzmöller, zugleich immer auch gesellschaftliche Fragestellungen. In der Situation von stets komplexer werdenden Gesellschaftsstrukturen mit zugleich konkurrierenden Anbietern und gesättigten Märkten gelte es, sich um die Kunden zu bemühen. Hierfür seien Kooperationen zwischen Theorie und Praxis beziehungsweise Sozialwissenschaften und Wirtschaft ebenso erforderlich, wie es zahlreiche Optionen für die verstärkte Integration qualitativer Methoden in die Marktforschung gebe; trotz vermeintlich unüberbrückbarer Barrieren. Heiss sieht die größte Hürde jedoch in der Gestaltung der Forschung. Wissenschaftliche Untersuchungen hätten ganz andere Anforderungen an ihre Ergebnisse als Marktforschungsstudien. Unternehmen würden kurzfristig aussagekräftiger Ergebnisse bedürfen, um auf konkrete Problemstellungen zügig reagieren zu können; gefordert sei ein prägnanter Ergebnisbericht, der den Handlungsbedarf zeige, kein umfassender Forschungsbericht mit Theorie (Heiss, 2009, S. 100 f.; Kritzmöller, 2004). ${ }^{68}$

${ }^{68}$ Auf die teilweise unüberwindbar wirkenden Gegensätze, die zwischen den Sozialwissenschaften und der Wirtschaft zu bestehen scheinen, geht Kritzmöller (2004) näher ein und stellt ein Beispiel einer erfolgreichen Forschungskooperation mitsamt den dafür erforderlichen Voraussetzungen vor. Im Rahmen dieser Studie, die durch einen deutschen Automobilhersteller gefördert wurde und mitunter während der Teilnahme an dessen Doktorandenprogramm entstanden ist, könnten diese Differenzen, mit explizitem Bezug zur Automobilmarktforschung, auch detailliert thematisiert werden. Da dies jedoch nicht Inhalt der Forschungsfrage dieser Arbeit ist, sondern in deren Kontext ,nur ' ein Randphänomen markiert, wird hier davon abgesehen, jedoch nicht ausgeschlossen, dass dies noch an anderer Stelle geschehen wird. 
In Deutschland war die Marktforschung zunächst rein quantitativ ausgerichtet, bis in den 1950er Jahren die Motivforschung ihren Weg über die USA nach Deutschland nahm und letztlich in Gestalt der Psychologie in die Marktforschung einzog. Man hatte erkannt, dass menschliches Verhalten zu einem erheblichen Ausmaß von emotionalen, irrationalen und unbewussten Motiven geleitet wird - auch im Markt. Mithilfe von der Motivforschung sollten bislang unbeachtete Motive sichtbar und verständlich gemacht werden. Mit der Zeit avancierten auch qualitative Methoden zu einem festen Bestandteil im Methodenrepertoire der Marktforschung. Zurückzuführen ist diese Entwicklung auf den hohen, zunehmend auch anerkannten praktischen Nutzen, den qualitative Methoden der Marktforschung bringen können (Balzer, 2007, S. 43 ff.; Heiss, 2009, S. 102 f.; Kaiser, 2004, S. 4; Spiegel, \& Chytka, 2007, S. 574). Im Gegensatz zur quantitativen kann die qualitative Marktforschung nach Hartmut Holzmüller und Renate Buber (2009) ,blinde Flecken' erkunden:

Marketingforscher beschneiden [. . . ] ihre forscherische Kompetenz sehr oft durch Überbetonung der positivistischen Forschungstradition (Holzmüller, \& Buber, 2009, S. 6).

Trotzdem ist die Automobilmarktforschung noch immer eher quantitativ als qualitativ ausgerichtet (Balzer, 2007, S. 49 ff.; Heiss, 2009, S. 103; Kaiser, 2004, S. 4; Spiegel, \& Chytka, 2007, S. 574). Uta Spiegel und Hanna Chytka begründen die Vorrangstellung quantitativer Methoden in der Marktforschung folgendermaßen:

\begin{abstract}
Aufgrund des extremen Erfolgsdrucks und der immensen Folgekosten von Fehlentscheidungen spielt die Belastbarkeit der Ergebnisse von Marktforschungsstudien eine entscheidende Rolle. Um diesen hohen Grad an Absicherung der Befunde zu gewährleisten, wird den Studien eine möglichst große, genau definierte Stichprobe zugrunde gelegt und eine Verallgemeinerbarkeit der Aussagen auf die Grundgesamtheit der Zielgruppe angestrebt. Hinzu kommt die aus der obligatorischen Forderung nach Schnelligkeit und internationaler Vergleichbarkeit resultierende Notwendigkeit einer voll standardisierten Erhebung (Spiegel, \& Chytka, 2007, S. 573 f.).
\end{abstract}

In Übereinstimmung damit erklärt auch Werner Kaiser die quantitative Orientierung, die die Marktforschung der Automobilindustrie aufweist. Marktforschung muss

[... ] Ergebnisse ja auch unternehmensintern verkaufen, sie als Grundlage für z. B. Entscheidungen zwischen zwei alternativen Packungsgestaltungen oder Anzeigen nutzen lassen. Quantitative Messgrößen wie Mittelwerte oder Prozentanteile mit signifikanten Unterschieden erleichtern die interne Nachvollziehbarkeit und damit Akzeptanz von Marktforschungsergebnissen in einem betriebswirtschaftlich orientierten Umfeld (Kaiser, 2004, S. 4). 
Entsprechend bemerkt Heiss, dass in der Unternehmenspraxis quantitativen Ergebnissen seit jeher ein höherer Stellenwert zukomme als qualitativen. Für Manager sei es leichter, Entscheidungen auf Grundlage von Häufigkeiten und signifikanten Unterschieden zu treffen und zu rechtfertigen. Zahlen und statistische Kennwerte genießen eine höhere Akzeptanz in Unternehmen als qualitative Erkenntnisse (Bausch, 1990, S. 7 ff.; Heiss, 2009, S. 103 f.; Herrmann, \& Moeller, 2006, S. 118).

Doch obwohl auch die Automobilhersteller noch immer vor allem quantitative Studien umsetzen, hat die qualitative Marktforschung inzwischen einen angestammten Platz in sämtlichen Phasen des Produktentwicklungsprozesses eingenommen:

Denn das sich aktuell wandelnde bzw. diversifizierende Konsumverhalten macht den
Einsatz qualitativer Methoden unentbehrlich, um einen Einblick in die sich verän-
dernden Motive und Bedürfnisse der Kunden zu erhalten und die Subjektivität des
Produkterlebnisses einzufangen. [.. . ] Für die Hersteller geht es darum, die Interpreta-
tion des Produktes im Kopf des Konsumenten zu antizipieren und dort Alleinstellung
zu erreichen. [. . . ] Nur über die subjektive Produktwelt in den Köpfen der Kun-
den lassen sich Märkte in ihrer Ganzheit erkunden und Trends für die nahe Zukunft
ableiten. Und genau an dieser Stelle kommt die qualitative Marktforschung wirksam
zum Einsatz. Sie dient in der Regel der Vorbereitung oder der Ergänzung quantitativer
Ergebnisse. Ihr kommt weniger die Rolle eines Kontrollinstruments zu, sondern die
der Exploration, der Optimierung und der zukunftsgerichteten Prognose (Spiegel, \&
Chytka, 2007, S. 573 f.).

Es steht jedoch fest, dass die Marktforschung ihre qualitativen Methoden noch lange nicht ausschöpft. Es scheint, als hätte sich die qualitative Marktforschung mit ihrem heute zwar anerkannten Dasein, aber noch immer nur begrenzten Anspruch arrangiert. Ihr offener und kritischer Forschungsansatz verkommt zu einer ,,bloßen unverbindlichen Deskription“; ihre eigentliche Stärke, die Exploration, wird nicht genutzt. Stagnation ist die Folge (Balzer, 2007, S. 51 ff.; Heiss, 2009, S. 102 ff.; Holzmüller, \& Buber, 2009, S. 5 ff.). ${ }^{69}$ Spiegel und Chytka bewerten die Situation in der Automobilindustrie so:

Die permanente Weiterentwicklung des Automobils wird in Zukunft vermehrt qualitative Forschung erfordern. Denn die Innovationen im Automobilmarkt bringen auch eine Veränderung der Psychologie des Autofahrens mit sich, die es zu beobachten und zu beschreiben gilt (Spiegel, \& Chytka, 2007, S. 580).

${ }^{69}$ Qualitative Marktforschung wird, auch in Abgrenzung zu quantitativer, umfassend beispielsweise von Kepper (1996) behandelt sowie in zahlreichen Beiträgen mit je unterschiedlichen Schwerpunktsetzungen in den Sammelbänden von Buber und Holzmüller (2009) oder auch Naderer und Balzer (2007) betrachtet. 
Seit geraumer Zeit sieht sich die Marktforschung also mit diversen Herausforderungen konfrontiert. Bereits 2003 hat Andreas Giger einen Zukunftsessay veröffentlicht und in diesem anhand von fünf Thesen eine Neuorientierung der Marktforschung gefordert. Da, abgesehen von manchen Formulierungen, die mitunter auf die zwischenzeitliche Entwicklung und Etablierung sozialer Medien zurückzuführen sind, Gigers Kritik und die gegenwärtigen Forderungen gegenüber der Marktforschung Parallelen aufweisen, wird mit dieser die Darstellung der Wissensgenese in der Automobilindustrie noch einmal zusammengefasst. Kritisiert hat Giger vier Aspekte: (1) Die Marktforschung ist fest etabliert und dadurch träge geworden; sie steckt fest in einer nicht ungefährlichen evolutionären Phase, was an der erloschenen Begeisterung der Marktforscher selbst ersichtlich wird sowie auch am Rückgang der elementaren Marktforschungsressource, der Teilnahmebereitschaft an Interviews. (2) Nach wie vor ist die Marktforschung zu „datenfixiert“ und konzentriert sich in erster Linie auf das Sammeln möglichst vieler Daten. Es herrscht die Hoffnung, dass aus vielen Daten irgendwann schon irgendwie Wissen wird. Ein Bewusstsein für die grundlegenden Unterschiede, die zwischen Daten, Informationen und Wissen bestehen, gibt es nicht. (3) Die Marktforschung bleibt der Vergangenheit verhaftet; anstatt vergangenes Verhalten abzufragen, gilt es aber Einschätzungen im Hinblick auf die Zukunft der Märkte zu gewinnen. (4) Noch immer sitzt die Marktforschung in der „RepräsentativitätsFalle“, obwohl die Zukunft für repräsentative Befragungen nur bedingt geeignet ist, und hält am „Gesetz der großen Zahl“ als eine Selbstverständlichkeit fest. Längst schon muss sich die Marktforschung von ihrer Fixierung auf große Zahlen und repräsentative Stichproben lösen. Für sie gilt es, das „Gesetz der kleinen Zahl“ zu entdecken; in dessen Rahmen sind deutlich weniger Interviews vonnöten und bieten zudem erheblich mehr Optionen, in die Tiefe zu gehen und zum Kern vorzudringen. Damit ist der Bogen zu Gigers abschließender These gespannt: (5) Marktforschung muss sich zu einem „moderierten Dialog zwischen Marktpartnern" wandeln. Die Befragten sind nicht als Forschungsobjekte, sondern als Dialogpartner zu begreifen; es gilt ihnen mit anregenden Fragen zu begegnen und die Möglichkeit zu geben, zur Gestaltung der Zukunft beizutragen, indem ihre Stimme bei Entscheidungsträgern hörbar gemacht wird. „Der Wandel beginnt im Kopf", bemerkt Giger und meint die Köpfe der Marktforscher. Erst nach dem mentalen Wandel kann sich auch die Marktforschung verändern. Eine Nutzung der Optionen des Internets ist für Giger unabdingbar: ${ }^{70}$

\footnotetext{
${ }^{70}$ Einen mentalen Wandel fordern auch Herrmann und Moeller (2006, S. 113 ff.) von Marktforschung und auch Management.
} 
Wenn die Marktforschung eine Zukunft haben will, wird eine Fähigkeit unabdingbar sein [... ]: den Wandel lieben lernen! (Giger, 2003, S. 15).

Gigers Thesen, anhand derer er die gegenwärtige Marktforschung kritisiert und Impulse für ihre Zukunft zeigt, decken sich mit den zuvor dargestellten Befunden von Balzer, Spiegl und Chytka sowie von Kritzmöller. Unter Bezugnahme auf die eben angeführten Autoren resümiert Heiss das Dilemma der Automobilmarktforschung so:

Unternehmen bzw. Manager verlangen verstärkt nach belastbaren Daten, auf denen sie ihre Entscheidung begründen können. Doch diese Daten sind vergangenheitsbezogen und liefern keine Impulse für Innovationen (Heiss, 2009, S. 114).

Christoph Herrmann und Günter Moeller (2006) reflektieren diese Gegebenheit kritisch und erkennen „Schattenseiten des Wissensbooms“:

Wie in vielen anderen Unternehmensbereichen, so ist auch im Hinblick auf das Wissensmanagement inzwischen eine deutlich übertriebene Kennzahlenorientierung festzustellen. Dabei scheint die Quantität der gewonnenen Daten wichtiger zu sein als ihre Qualität. Überhaupt tendieren heute viele Manager dazu, so gut wie jede Entscheidung marktforscherisch absichern zu lassen, statt sich auch ein wenig auf die eigene Intuition zu verlassen. Das hängt vor allem damit zusammen, dass Unternehmen in vielerlei Hinsicht heute zu „Legitimationsmaschinen“ geworden sind. Jede Entscheidung will abgesichert sein, für jede noch so falsche Strategie gibt es eine Begründung. Diese Entwicklung hat zu einer kaum noch nachvollziehbaren Dominanz der Marktforschung im Innovationsprozess geführt (Hermann, \& Moeller, 2006, S. 118).

Heiss kommt zu dem Schluss, dass ein Wandel in der Marktforschung nur über zwei Wege erfolgen kann: Entweder durch eine Veränderung der Haltung in Unternehmen oder aufgrund eines Wandels in der Marktforschung dahingehend,

[. . . ] dass Manager wieder aufgrund ihrer Erfahrung, Intuition und nicht anhand vollständig abgesicherter Daten Entscheidungen treffen werden müssen (Heiss, 2009, S. 114).

Bereits im Jahr 2009 befand Heiss, dass das Internet auf Unternehmen und deren Kunden enormen Einfluss ausüben wird; ähnlich prognostizierte dies Giger schon 2003. Das heißt, dass bereits im Jahr 2003 ein Wandel der organisationalen Wissensgenese, auch in der Automobilindustrie, zu erkennen war; als entscheidender Faktor wurde das Internet benannt. Somit war schon lange bevor die Forschung aufgenommen wurde, auf die die hier vorliegende Arbeit gründet, absehbar, dass die 
Marktforschung flexibler und offener in Bezug auf ihr Methodenportfolio und die von ihr erkundeten Inhalte werden muss und sich den mit dem Internet einhergehenden Entwicklungen keinesfalls verschließen darf (Giger, 2003; Heiss, 2009, S. 114 ff.).

\subsubsection{Exkurs: Wissensmanagement}

Geht es im ökonomischen Kontext um Wissen, dessen Genese und Verwendung, so geschieht dies heute kaum unter einem anderen Titel als ,Wissensmanagement“. Die hier vorliegende Studie ist eine soziologische. Wie bereits gezeigt, ist die Soziologie als Wissenschaft dazu imstande sich mit dem Phänomen ,Wissen“ auch unter Bezugnahme auf Organisationen zu beschäftigen ohne dieses erst um ein Beiwort wie „Management“ anreichern beziehungsweise durch eine solche Ergänzung überhaupt greifbar machen zu müssen. Trotzdem handelt es sich bei Wissensmanagement um ein ,Konstrukt', dem auch die Soziologie sowohl in ihrer theoretischen wie empirischen Auseinandersetzung mit Wissen in Organisationen wiederholt begegnet. Daher wird das erste Theoriekapitel dieser Forschungsarbeit mit einem Exkurs: Wissensmanagement geschlossen. Zum einen schenkt dieser dem Wissensmanagement als wesentlichem Gegenstand von Organisationen in deren Beschäftigung mit Wissen Beachtung; zum anderen endet die Betrachtung der wissenssoziologischen Organisationsforschung dadurch mit einem Thema, welches sowohl die Wissenssoziologie als auch die Organisationssoziologie berührt und das ferner von zahlreichen weiteren Disziplinen, allen voran den Wirtschaftswissenschaften, tangiert wird. Ein Exkurs über Wissensmanagement zeigt die potentielle Weite des soziologischen Blicks und stellt außerdem die soziologische Perspektive, die in dieser Arbeit durchweg wissenschaftlich ist, zugleich als praktische Betrachtungsweise des Zusammenhangs von Wissen und Organisationen vor. In Bezug auf das Verhältnis von Wissen beziehungsweise Wissenschaft zu Management erkannte bereits Helmut Willke: 7172

\footnotetext{
${ }^{71}$ In den letzten Jahren ist auch eine vermehrte Beschäftigung mit Innovationsmanagement in der Praxis wie Literatur zu verzeichnen; die Nähe zum Wissensmanagement ist unverkennbar. Da diese Studie aber aus forschungsökonomischen und -strategischen Gründen Innovationsmanagement weder allgemein noch in Abgrenzung zum Wissensmanagement behandelt, empfiehlt sich ein Blick in soziologische Beiträge, zum Beispiel von Howaldt, Kopp und Beerheide (2011) oder Howaldt und Beerheide (2010) oder mit einem Bezug zur systemischen Perspektive von Meissner (2011); auch verorten Herrmann und Moeller (2006) Marktforschung zwischen Wissensmanagement und Innovationspolitik.

${ }^{72}$ Dieser Exkurs kann einen nur begrenzten Umfang aufweisen; daher kann nicht sämtliche Literatur zum Wissensmanagement, die mittlerweile in immensem Umfang vorhanden ist, gewürdigt werden. So finden beispielsweise auch die soziologischen Beiträge von Howaldt
} 
Wissen und Management, so bilden sich Manager und Wissenschaftler ein, passen nicht besonders gut zusammen. Mit den Details der wechselseitigen Vorurteile könnte man Romane füllen. Im Extremfall betrachten Manager Wissenschaftler als entscheidungsunfähige Grübler und umgekehrt Wissenschaftler Manager als besinnungslose Macher. Konzeption und Praxis des Wissensmanagements bieten gegenwärtig den seltenen Anschauungsunterricht dafür, wie zwei komplementäre Pakete von Vorurteilen von tiefgreifenden gesellschaftlichen und organisationalen Veränderungen gnadenlos bloßgestellt und obsolet gemacht werden (Willke, 1998, S. 1).

Wissensmanagement ist ursprünglich aus dem ökonomischen Diskurs hervorgegangen. Es handelt sich um einen Managementansatz, der sich seit den 1970er Jahren entfaltet und in den vergangenen Jahren einen rasanten Aufstieg erlebt. Im Zusammenhang damit werden aber nicht nur wirtschaftswissenschaftliche Fragestellungen, sondern ebenso zahlreiche von soziologischer Relevanz behandelt. Historisch ist Wissensmanagement in der Nähe von Knowledge Engineering zu verorten. Dieses Konzept besagt, dass die Validierung, Schaffung und Nutzung von Wissen in der Wirtschaft zunehmend an Bedeutung gewinnt. Olaf Katenkamp (2011) begreift Wissensmanagement gar als Weiterentwicklung des Knowledge Engineering und betont die Relevanz, die ihm heute in Organisationen zukommt, sowie die inzwischen entscheidende Rolle soziologischer Erkenntnisse (Katenkamp, 2011, S. 15; Knoblauch, 2014, S. 224, S. 334).

Nachdem die Anfänge des Wissensmanagements gemacht sind, entsteht mit der Zeit ein Bewusstsein dafür, dass die Entwicklung von Software weder im „luftleeren Raum“ von Organisationen stattfindet noch für isolierte Mitarbeiter

(2004), Howaldt, Klatt und Kopp (2004) oder Hislop (2005) keinen Eingang. Da sich diese Forschungsarbeit der Soziologie anschließt, wird außerdem der Blick anderer Disziplinen auf das Wissensmanagement, allen voran der der Wirtschaftswissenschaften und der Informatik, nicht näher thematisiert. Doch sie gibt Hinweise für die weitere Lektüre und den Blick in andere Fachrichtungen. Einen Überblick über diverse Ansätze und auch Einblick in sie, auch wirtschaftswissenschaftliche, bietet Katenkamp (2011). Al-Laham (2003) behandelt organisationales Wissensmanagement an der Schnittstelle von Organisationstheorie und strategischem Management. Für eine wirtschaftswissenschaftliche Sicht sind ferner Behrends, Bloemen, Mokwinski und Schroeder (2010) oder auch Krogh und Grand (2004) zu nennen. Beiträge der Managementforschung stammen von Schreyögg und Koch (2015), Schreyögg und Geiger (2002, 2003) sowie Schreyögg und Conrad (1996). Praxisorientiert mit Bezug zur Informatik oder auch mit Einbezug sozialer Medien betrachten das Wissensmanagement: Bächle, 2016; Bitzer, 2011; Gronau, \& Grum, 2016; Arns, Bentele, Niemeier, Schütt, \& Weber, 2014; Back, Gronau, \& Tochtermann, 2012; Bentele, Gronau, Schütt, \& Weber, 2012; Pircher, 2010; Razmerita, Phillips-Wren, \& Jain, 2016. Wissensmanagement ist ebenso Gegenstand der Betarchtung bei Heiss (2009), die es neben CRM und CKM positioniert. Neben der angeführten Literatur gibt es unzählige weitere Beiträge, die Wissensmanagement mit unterschiedlicher Schwerpunktsetzung behandeln. 
von Unternehmen erfolgt, sondern dass sie in den bereits bestehenden „sozialen Handlungszusammenhängen von Menschen" angewendet wird und es daher auch deren Wissen zu berücksichtigen gilt. In den 1990er Jahren erlebt das Wissensmanagement eine regelrechte Konjunktur; kaum ein Unternehmen beginnt nicht damit, „Wissen zu managen“. Dieser Erfolg hängt auch mit dem Diskurs um die Wissensgesellschaft oder Informationsgesellschaft zusammen, der die Bedeutung von Wissen für die Wirtschaft herausgestellt hat (Katenkamp, 2011, S. 15; Knoblauch, 2014, S. 334; Jäger, 2007b, S. 639 f.).

Immer wieder wird die Michael Polanyi (1891-1976) zurückgehende Unterscheidung zwischen implizitem und explizitem Wissen als Ursprung des Wissensmanagements angeführt (Katenkamp, 2011; Knoblauch, 2014, S. 335 f.). Im Kern geht es dabei um das Thema „unausgesprochenes Wissen“ beziehungsweise um Polanyis Entdeckung,

[. . . ] daß wir mehr wissen, als wir zu sagen wissen (Polanyi, 1985/2016, S. 14). ${ }^{73}$

Hubert Knoblauch (2014) merkt an, dass Polanyis Differenzierung zwischen den beiden Wissensformen für die Wirtschaftswissenschaften ebenso ungewohnt zu sein scheint, wie sie für die Soziologie bekannt ist. Die Literatur diskutiert verschiedene Konzepte von Wissensmanagement; zentrale Bedeutung für die Integration der Gedanken Polanyis in die Wirtschaftswissenschaften wird gemeinhin der Arbeit von Ikujiro Nonaka und Hirotaka Takeuchi (1997) zugesprochen (Jäger, 2007b, S. 643 ff.; Katenkamp, 2011; Knoblauch, 2014, S. 336 f.; Willke, 1998, S. 12 ff., S. 79).

In ökonomischer Hinsicht besteht die Funktion von implizitem Wissen darin, dass Unternehmen die Fähigkeiten, Expertise und Innovationskompetenz ihrer Mitglieder einsetzen und nutzen können. Implizites Wissen gilt auch als der „Klebstoff“" in einem Unternehmen, als dessen zentrale Ressource, als ,Logik' hinter seiner Praxis sowie als Verankerung des Sozialen und als Urquelle von Kreativität. Entweder tritt es als ein „Produkt“, das auf dem Markt angeboten wird, in Erscheinung oder wird als „Faktor der Wertschöpfung“ begriffen; mitunter gilt es auch als nicht oder aber kaum aufdeckbar. In Unternehmen nimmt Wissen häufiger die zweitgenannte möglich Rolle ein, die des Faktors der Wertschöpfung (Katenkamp, 2011, S. 28; Knoblauch, 2014, S. 337). ${ }^{74}$

\footnotetext{
${ }^{73}$ Die Bedeutung von Polanyi (1985/2016) für die Entwicklung des Wissensmanagements vertieft diese Arbeit nicht. Siehe dazu: Katenkamp, 2011; Knoblauch, 2015, S. 335 f..

${ }^{74}$ Mit implizitem Wissen in Organisationen und deren Wissensmanagement setzt sich Katenkamp (2011) auseinander und behandelt dabei auch detailliert die Konzeption von Polanyi
} 
Systemisches Wissensmanagement, wie es insbesondere Willke beschrieben hat, versteht eine Organisation als ,kollektive Ordnung des Wissens“. In seinem systemtheoretischen Ansatz charakterisiert Wilke Wissensmanagement als „Hybrid aus Praxiserfahrung und Theorieentwicklung"; es handle sich dabei um eine strategische Managementaufgabe, deren Ziel nicht in einer detaillierten empirischen Analyse von Wissen besteht, sondern in der effizienten Nutzung und Planung von Wissen als Ressource (Katenkamp, 2011, S. 22 ff.; Knoblauch, 2014, S. 337; Willke, 2002, S. 118): $:^{75} 76$

In eine kurze Formel gepresst, lässt sich Wissensmanagement als die strategische Managementaufgabe verstehen, die kritische und knappe Ressource Wissen genauso sorgfältig zu bewirtschaften wie andere kritische Ressourcen der Organisation. Besondere Bedeutung kommt dieser Aufgabe zu, weil im Kontext der Wissensökonomie und der Wissensgesellschaft Kompetenzen und Expertise zum dominanten Produktivfaktor avancieren und damit die Generierung und Nutzung von relevantem Wissen zu einem zentralen Projekt der ,intelligenten Firma“ wird (Willke, 2002, S. 116).

Somit kommt der „Intention“ eines Unternehmens, dessen Strategie und Visionen, im Kontext von Wissensmanagement eher eine praktische als eine analytische Rolle zu (Knoblauch, 2014, S. 337). Wissensmanagement ist laut Willke

[. . . ] die Gesamtheit organisationaler Strategien zur Schaffung einer ,intelligenten" Organisation. Mit Blick auf Personen geht es um das organisationsweite Niveau der Kompetenzen, Ausbildung und Lernfähigkeit der Mitglieder; bezüglich der Organisation als System steht die Schaffung, Nutzung und Entwicklung der kollektiven Intelligenz und des ,collective mind“ in Frage; und hinsichtlich der technologischen Infrastruktur geht es vor allem darum, ob, wie und wie effizient die Organisation eine zu ihrer Operationsweise kongeniale Kommunikations- und Informationsstruktur nutzt (Willke, 1998, S. 39).

(1985/2016) sowie deren Integration in die Wirtschaftswissenschaften durch Nonaka und Takeuchi (1997). Ebenso hat Knoblauch (2014, S. 336 f.) den Kerngehalt deren Arbeit prägnant zusammengefasst und außerdem explizit auf die Wissenssoziologie bezogen. Diese Arbeit geht aus nicht näher darauf ein.

${ }^{75}$ Willke hat seine Konzeption des systemischen Wissensmanagements theoretisch und praktisch anhand zahlreicher Fallstudien herausgearbeitet. Siehe hierzu: Willke (1998, 2011); Drepper (2007, S. 607 f.); Katenkamp (2011).

${ }^{76}$ Katenkamp (2011) betont die Eignung von Weicks Sensemaking zur Analyse und Konzeptionierung impliziten Wissens im Wissensmanagement. Mit dem Ansatz von Weick hat sich im Zusammenhang mit Wissensmanagement auch Willke (1998) beschäftigt. Im Hinblick auf Weicks Konzeption muss an dieser Stelle ein Verweis auf die in der vorliegenden Forschungsarbeit enthaltene Darstellung der kognitions- und wissenssoziologischen Perspektive auf die organisationale Wissensgenese (2.2.3.2) genügen. Für eine Diskussion im Kontext von Wissensmanagement siehe: Katenkamp, 2011, S. 24 f., S. 132 ff.; Willke, 1998, S. 41 ff.. 
Für Willke ist Wissen damit eine ,soziale Größe“, die von „lernenden“ Organisationen getragen werden kann (Knoblauch, 2014, S. 337; Willke, 1998, S. 41 ff.). Mehrere Jahre nach Willke, aber in Anlehnung an ihn legt auch Katenkamp das Wissensmanagement als ,transsubjektiven und sozialen Prozess des organisationalen Lernens" dar:

Wissensmanagement zielt auf eine neue intelligente Organisation der Unternehmen, auf Netzwerkstrukturen und neue Formen des organisationalen Lernens ab. [. . . ] Das Management von Wissen, Lernen und Wissensarbeit agiert im Dreieck einer informationellen Infrastruktur, der Vermittlung von kognitiven Repräsentationen und der organisationalen Einbettung von Wissen in Verhaltensweisen, die [. . ] nicht entlang der alten Arbeitsteilung, sondern einer neuen ,division of knowledge“ funktioniert, die vor allem aus den ,implicit shared practices“ [ . . ] erwächst (Katenkamp, 2011, S. 16).

Weiter konkretisiert Katenkamp ein ,Wissensmanagementsystem“ als ein „dynamisches Anwendungssystem“. Dieses enthalte Tools zur Identifikation von Wissen, unterstütze die aktive Suche sowie Weitergabe von Wissen und treibe sowohl die Verteilung und Nutzung sowie auch die Neuentwicklung von Wissen voran. Semantische und vernetzte Wissensquellen mit „universellen Softwareagenten“, wie beispielsweise Data Mining, gewinnen laut Katenkamp an Bedeutung. In der Praxis des Wissensmanagements zur Anwendung gebrachte Tools seien aber in erster Linie auf explizites Wissen ausgelegt:

Societales Wissensmanagement setzt dagegen auf das implizite Wissen und eine behutsame Strategie des Ausbaus der Wissensbasis einer Organisation. Statt einer reinen IT-Lösung präferiert es eine (Wissens-)Kulturveränderung, eine Stärkung der Wissensbasis mit U-Boot-Projekten, d. h. auf Pilotprojekte, die langfristig angelegt und nicht Top-down organisiert sind sowie auf die Entwicklung generischer (verbindender) Instrumente [. . . ]. Viele Instrumente im Wissensmanagement sind generell blind auf dem ,impliziten Auge“: Ein Großteil der Werkzeuge zielt auf das explizite Wissen und verortet das implizite Wissen im persönlichen Wissen als unsteuerbare Größe im Transfer. Was dazu führt, dass aus der Sicht der Organisation implizites Wissen strategisch als unberechenbarer, nicht steuerbarer Faktor angesehen wird [. . . ] (Katenkamp, 2011, S. 17 f.). 
In diesem Sinne beschreibt auch Willke organisationales Wissen als ein

[. . . ] Wissen, das nicht in den Köpfen von Menschen gespeichert ist, sondern in den Operationsformen, Artefakten und sonstigen Verkörperungen von Problemlösungskompetenz eines sozialen Systems. Organisationales oder institutionelles Wissen steckt in den personenunabhängigen, anonymisierten Regelsystemen, welche die spezifische Operationsweise, die Intelligenz, die Expertise und die Problemlösungskompetenz eines Sozialsystems definieren. Vor allem sind dies Standardverfahren [... ], Leitlinien, Kodifizierungen, Arbeitsprozess-Beschreibungen, etabliertes Rezeptwissen für bestimmte Situationen, Routinen, Traditionen, etablierte Regeln, spezialisierte Datenbanken und strukturierte Informationsspeicher, expliziertes und kodiertes Produktions- und Projektwissen, Fallsammlungen, Mythen, „war stories“ und Praxisgeschichten sowie die transpersonalen Merkmale der spezifischen Kultur einer Organisation (Willke, 2002, S. 130).

Letztlich betont jedoch auch Willke, dass das ,intellektuelle Kapital einer Organisation“ sowohl auf dem Humankapital einzelner Personen als auch auf dem „organisationalen Wissenskapital des Sozialsystems selbst“ beruhe. Sein Potential als eine an der Zukunft orientierte sowie auf Innovationen gerichtete Transformation von Organisationen kann Wissensmanagement laut Willke erst dann entfalten, wenn die herkömmlichen Instrumente der Messung von Leistung und Qualität der Organisation grundlegend überarbeitet werden. Dafür sei die Reflexionsfähigkeit einer Organisation unabdingbar. Obwohl Willkes Zusammenfassung der drei Faktoren des Wissensmanagements aus dem Jahr 1998 stammt, erscheint dieser Befund auch heute noch zutreffend. Zwar haben sich, nicht zuletzt durch das Aufkommen und die Etablierung sozialer Medien, die Möglichkeiten, derer sich eine Organisation im Hinblick auf ihre Kommunikations- und Informationsstruktur bedienen kann, enorm weiterentwickelt, doch ist dieser Aspekt neben dem Humankapital und organisationalen Wissen nach wie vor nur einer von insgesamt drei Faktoren, die es für ein erfolgreiches Wissensmanagement zu bedenken gilt (Willke, 2002, S. 132; Willke, 1998, S. 39, S. 86 ff.). ${ }^{77}$

\footnotetext{
77 Willkes Plädoyer für die Revidierung der Analyse von Leistung und Qualität der Organisationen durch Einbezug qualitativer Faktoren und entsprechender Verfahren zu deren Untersuchung kann im Rahmen dieser Forschungsarbeit nicht vertieft werden; siehe hierzu: Willke, 1998, S. $86 \mathrm{ff}$. .
} 
Open Access Dieses Kapitel wird unter der Creative Commons Namensnennung 4.0 International Lizenz (http://creativecommons.org/licenses/by/4.0/deed.de) veröffentlicht, welche die Nutzung, Vervielfältigung, Bearbeitung, Verbreitung und Wiedergabe in jeglichem Medium und Format erlaubt, sofern Sie den/die ursprünglichen Autor(en) und die Quelle ordnungsgemäß nennen, einen Link zur Creative Commons Lizenz beifügen und angeben, ob Änderungen vorgenommen wurden.

Die in diesem Kapitel enthaltenen Bilder und sonstiges Drittmaterial unterliegen ebenfalls der genannten Creative Commons Lizenz, sofern sich aus der Abbildungslegende nichts anderes ergibt. Sofern das betreffende Material nicht unter der genannten Creative Commons Lizenz steht und die betreffende Handlung nicht nach gesetzlichen Vorschriften erlaubt ist, ist für die oben aufgeführten Weiterverwendungen des Materials die Einwilligung des jeweiligen Rechteinhabers einzuholen. 